\title{
Pacific Arts
}

Journal of the Pacific Arts Association

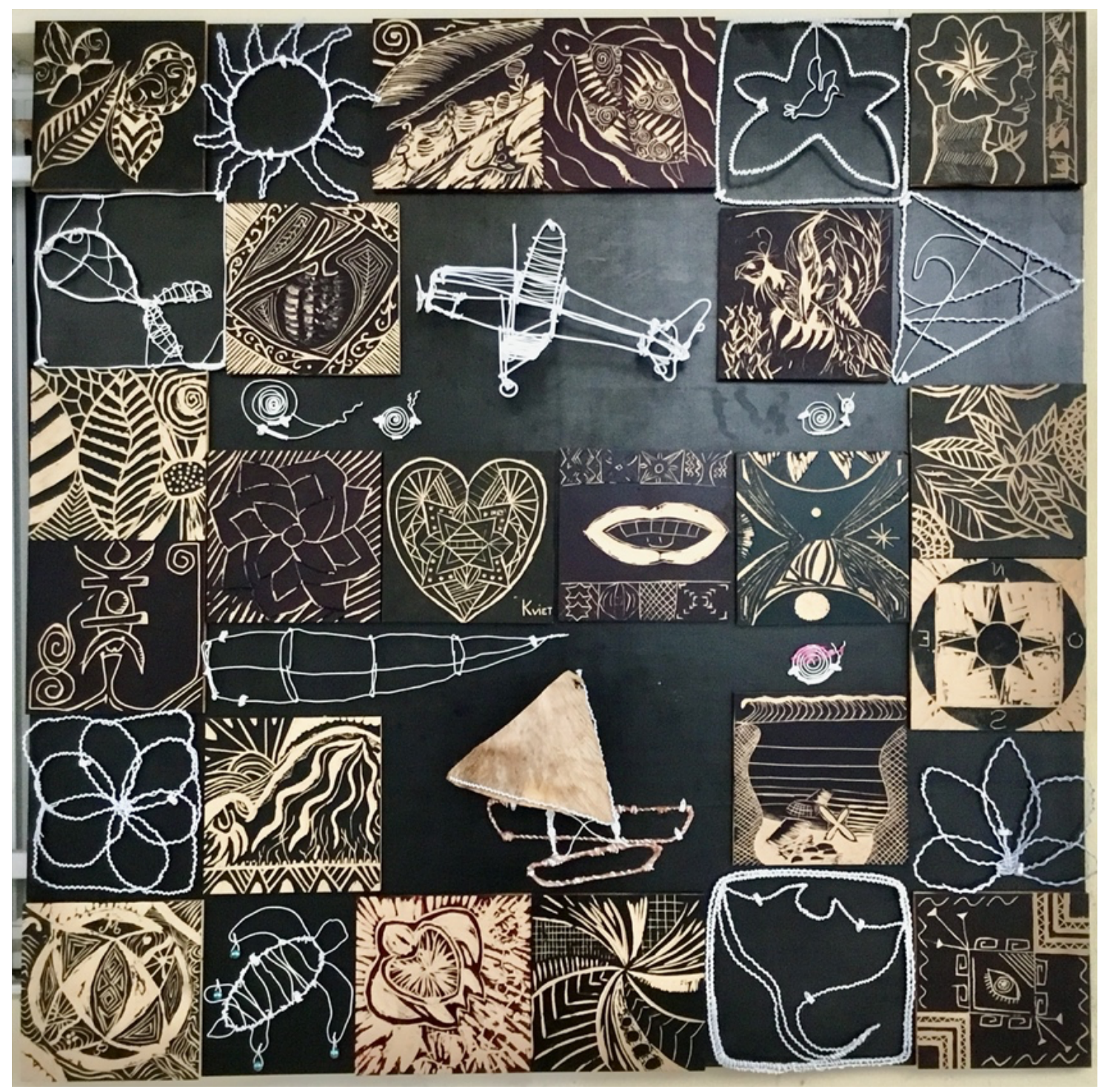

N.S. Vol. 21 No. 1 


\section{Pacific Arts}

N.S. Vol. 21, no. 1, guest edited by Anne E. Guernsey Allen

ISSN: 2769-108X (online), 1018-4252 (print), @2021

eScholarship

California Digital Library (CDL)

University of California-Office of the President

1111 Franklin Street

Oakland, CA 94607 USA

Executive Editors: Stacy L. Kamehiro and Maggie Wander

Editorial Assistant: Joslyn Chu

Copy Editor: Emily Bowles

\section{Editorial Board}

Anne E. Guernsey Allen

Carol S. Ivory

Lindy Joubert

Carol Mayer

Karen Stevenson

Nina Tonga

Caroline Vercoe

Wonu Veys

Edward P. Wolfers

\section{Back Issues (1990-2017/2019): https://www.jstor.org/journal/pacificarts}

Pacific Arts is the journal of the Pacific Arts Association, an international organization devoted to the study of the arts of Oceania (Aboriginal Australia and the Pacific Islands). The journal was established in 1990 and is currently issued as an annual volume in a new series that began in 2006. In 2020, the journal moved to eScholarship, the open access scholarly publishing program of the University of California/California Digital Library. For information on upcoming calls and submission guidelines, please email us or visit our website.

\section{Contact \& Website:}

\section{PacificArts@ucsc.edu}

https://escholarship.org/uc/pacificarts

The journal receives support from the Pacific Art \& Visual Studies Fund, established through the University of California-Santa Cruz Foundation, which also supports Oceanic arts research and teaching. For more information or to make a contribution, please visit this page.

Cover Image: Navigation, 2019. Collaborative student work using wire, plastic raffia, pearls, feathers, coconut tree bark, ink, and machine- and hand-pressed woodblock prints, $122 \times 61 \mathrm{~cm}$. Created in a contemporary 3D tapa art composition workshop led by Ela To'omaga and Patrice Kaikilekofe, University of New CaledoniaHigher School of Teaching and Education (École Supérieure du Professorat et de l'Éducation) site. Courtesy of Siapo Art Centre 


\section{Pacific Arts \\ Journal of the Pacific Arts Association}

NS Vol. 21 No. 1, 2021

\section{Guest Editor: Anne E. Guernsey Allen}

$1 \quad$ A Message from the Editors

Stacy L. Kamehiro and Maggie Wander

\section{Discussion Forum: Art Education in Oceania}

2 Introduction: Teaching the Future of Pacific Art

Anne E. Guernsey Allen

5 An Evolution of Teaching Art in Sāmoa: A Personal Journal-The History, Insights, Challenges, and Successes of Teaching Visual Art at the Tertiary Level Leua Latai

24 Singing in Harmony: Reflections on Forty Years of Teaching Art in New Zealand Schools

Laura Sunderland

32 Learning to Surf (Se'e) on a Wave, from Island to Urbanesia

Ela To'omaga Kaikilekofe

44 Who Speaks for Sāmoa? Some Reflections by a Pālagi Teacher of Pacific Art and Culture in the American Midwest

Anne E. Guernsey Allen

\section{Articles}

$51 \quad$ Angels in West Papua. In Memoriam Donatus Moiwend Michael Cookson, Stuart Kirsch, and Jason MacLeod

60 "Fijian Islanders preparing for a feast" (1959): The Influence of Photography on Popular Opinions of the Pacific Max Quanchi 
76 Canoe Carvings from Western Solomon Islands: The Operative Efficacy of Simultaneous Visual Presences

Deborah Waite

\section{Research Notes}

107 ARTventures: Art and Life in the Contemporary Pacific Susan Cochrane

News and Events

112 Announcements 


\section{STACY L. KAMEHIRO AND MAGGIE WANDER A Message from the Editors}

This issue of Pacific Arts, which includes five contributions to a discussion roundtable, three articles, and one research note, is guest-edited by Anne E. Guernsey Allen. The discussion forum on "Art Education in Oceania" reflects Anne's passion for, and dedication to, education. She has received numerous awards for teaching, including a Distinguished Teaching Award and five Trustees Teaching Awards from Indiana University Southeast (IUS), and was selected as a member of Indiana University's Faculty Colloquium on Excellence in Teaching. Anne regularly sponsors trips for her students to major cities such as Chicago, New York, and Washington, to broaden and enrich their experience of art and culture. She also takes groups of her IUS students to Sāmoa for month-long, intensive field-study programs.

We take this opportunity to thank Anne for her many years of excellent leadership and service as the executive editor of Pacific Arts, beginning with a special issue on Oceanic architecture in 2007 and then co-editing the 2008 volume with Carol Ivory (Professor Emerita, Washington State University) and Virginia-Lee Webb (art historian and independent curator). From 2008 to 2019, Anne, with the support of Mark D. Stansbury-O'Donnell (Interim Dean for the College of Arts and Sciences, University of St. Thomas) and the editing and design work of Molly Huber (Minnesota Digital Library, University of Minnesota), produced journal issues that addressed a diverse array of Oceanic art, visual culture, artists, and topics. On behalf of the Pacific Arts Association, we offer our sincere gratitude and appreciation. Thank you, Anne!

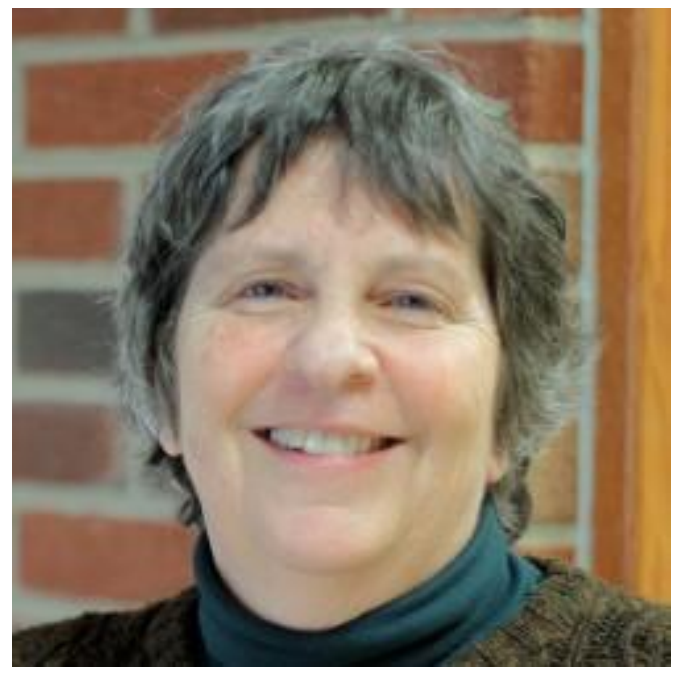

Anne E. Guernsey Allen, PhD, Professor of Fine Arts-Art History and Co-director of Study Abroad and Global Awareness, Indiana University Southeast 


\title{
ANNE E. GUERNSEY ALLEN Teaching the Future of Pacific Art
}

\begin{abstract}
Although a few scholars have examined the training of Indigenous Pacific artists during the period of early contact with Europeans and Americans, as well as the education of Indigenous artists who practice heritage arts in the Pacific today, almost nothing has been written on the instruction of art in modern classroom and workshop settings with regard to Pacific Islanders and Aboriginal Australians. The four Discussion Roundtable articles in this volume focus on teaching art in Oceania - three address art education for Pacific Island students in a variety of settings, while the fourth is concerned with the presentation of Pacific arts and artists to an outside audience made up of American college students. As a departure from the academic articles usually found in these pages, and in contrast to the other contributions to this volume, these four pieces are narratives of personal journeys of discovery.
\end{abstract}

Keywords: art, education, Oceania

For decades, art historians, anthropologists, and a wide range of academics have investigated the Oceanic arts of the past and the continuing creativity of artists from this region. Although the training of Indigenous Pacific artists during the period of early contact with Europeans and Americans has been examined by some scholars, and the education of Indigenous artists who still practice heritage arts has been discussed by a few others, almost nothing has been written on art instruction in modern classroom and workshop settings in regard to Pacific Islanders and Aboriginal Australians. Since its inception in 1990, Pacific Arts: The Journal of the Pacific Arts Association has published on myriad aspects of the creativity of the cultures and individuals that come from or identify with moana. However, the topic of art education in secondary schools, colleges, universities, and community workshops, has not been investigated. Of the four Discussion Roundtable articles in this volume, all of which focus on teaching art, three address art education for Pacific Island students in a variety of settings, while the fourth is concerned with the presentation of Pacific arts and artists to an outside audience consisting of American college students.

As a departure from the academic articles usually found in Pacific Arts, and in contrast to the other two papers presented in this volume, these four pieces are narratives of personal journeys of discovery. Laura Sunderland speaks of her many years as an art teacher in Aotearoa New Zealand-her joys and frustrations, as well as those of her high school students. Leua 


\section{Allen | Teaching Pacific Art}

Latai presents the history of art education in the nation of Sāmoa and the challenges for both teachers and students as they try to make their way as active creatives. In contrast to these school-based accounts, Ela To'omaga recounts efforts to integrate art production and cultural self-awareness into a community arts program, with a particular focus on a siapo workshop that bridges past and present in the making of tapa by using contemporary materials. Finally, the focus of my paper provides the flip side to these narratives: I write not about the training of future artists, but about the presentation of historic and contemporary Pacific art to American college students from Indiana in the United States.

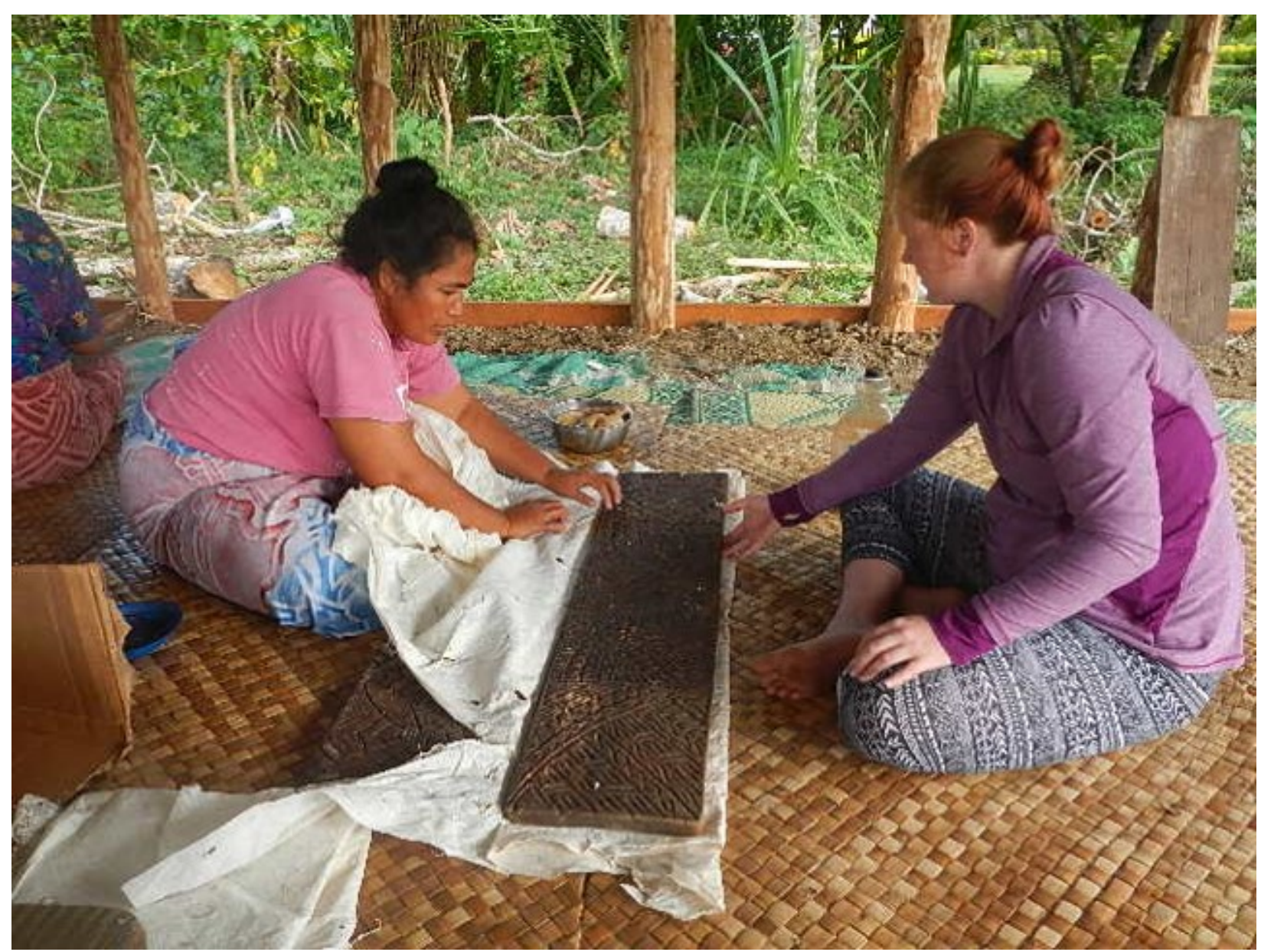

Fig 1. Siapo maker Makulata Fa'atoafi working with Indiana University Southeast student Rachel Mulvey. Siutu Sala'ilua, Sāmoa, 2014. Photograph by Cassandra Guernsey. Courtesy of the author

It is my hope that in each article the reader catches a glimpse of the continuing creativity of Pacific Islanders and, perhaps, sees promise for the future. It is today's young people, truly the focal point of these articles, who will have to contend with the challenges of climate change, the inequities of capitalism, and a world divided in the future. "Art is not a mirror held 


\section{Allen | Teaching Pacific Art}

up to reality, but a hammer with which to shape it." "If the arts are a tool with which reality can be shaped, it is art education that helps the next generation fashion and use those tools. This is my hope. It is why I take students to Sāmoa every couple of years. It is why the authors featured in this volume decided to dedicate themselves to teaching.

\section{Notes}

${ }^{1}$ This quote is variously attributed to Bertolt Brecht, Leon Trotsky, and Vladimir Mayakovsky. See, for instance, respectively, Peter McLaren and Peter Leonard, Paulo Freire: A Critical Encounter (NY: Routledge, 1993), 80; Leon Trotsky, Literature and Revolution, edited by William Keach, translated by Rose Strunsky (Chicago: Haymarket Books, 2005), 120; Rjurik Davidson, “Under the Hammer," Overland, Nov. 11, 2011, https://overland.org.au/2011/11/under-the-hammer/; and Andrew Samuels, The Political Psyche (NY: Routledge, 1993 ), 9. 


\title{
LEUA LATAI
}

\section{An Evolution of Teaching Art in Sāmoa: A Personal Journey-The History, Insights, Challenges, and Successes of Teaching Visual Art at the Tertiary Level}

\begin{abstract}
This article traces the history and evolution of art education in independent Sammoa from the perspective of personal experience, while also considering numerical data. It discusses art as a discipline taught in Sämoan secondary schools and focuses on the development of the creative arts at the tertiary level. The essay reflects on the history and challenges of teaching visual art in Sāmoa, including successes and setbacks. Also considered are the struggles for students pursuing visual art as a career interest in Sämoa. Examples of works of art created at the Leulumoega Fou School of Fine Arts are included, as are pieces by current National University of Sāmoa art students.
\end{abstract}

Keywords: Sāmoa, art, education

This article reviews the history and evolution of art education in Sāmoa from personal experience. It discusses art as a discipline taught in Sāmoan secondary schools and emphasizes the creative arts at the tertiary level. It reflects on the history, insights, and challenges of teaching visual art in Sāmoa from an individual perspective as both a student and teacher.

\section{Early Years and Influences}

I lived my early years in Papua New Guinea, where my Sāmoan parents were missionaries. I was home-schooled by my mother through the Australian International Correspondence School. She had trained as a teacher at the Western Sāmoa Teachers Training College (WSTC) in Malifa in the early 1950 s and conducted lessons for my brother and me until our family returned to Sāmoa in 1973. I entered public school for the first time when my parents enrolled me at Apia Primary School at Standard 3. Being in class with other Sāmoan children was quite a culture shock for me because it contrasted with my sheltered life growing up in the highlands of Papua New Guinea. 


\section{Latai | Teaching Art in Sāmoa}

I was introduced to art at the age of eleven through the influence of my older brother, who was talented in drawing and painting. As the younger sibling, I admired his ability to capture the natural environment and thus wanted to emulate his work. The Sāmoan female figure and the flora and fauna around our home were images that I enjoyed drawing while growing up. I drew stick figures of the Sāmoan taupou (daughters of a high chief), and I was especially interested in the tuiga, the ceremonial headdresses worn by the taupou. Performing the taualuga (a ceremonial dance) was a cultural activity I participated in as the daughter of a church minister, and I loved the intricate patterns of the traditional costumes I wore to perform at our church functions and events.

\section{Encounters with an Italian Maestro, Ernesto Coter}

As a school project when I was ten years old, we were asked to come up with a topic of personal interest to present to our fellow students. At the time, my uncle, the late Reverend Oka Fauolo, was the Secretary of the Congregational Christian Church of Sāmoa (CCCS). He and his wife, my aunt So'oletaua, hosted many church guests from all over the world. One of my uncle's guests then was the Italian artist Ernesto Coter, who later went on to successfully develop and teach the art curriculum at Leulumoega Fou College. With encouragement from both my parents, I wrote up interview questions for Mr. Coter and his wife, Maria, and headed off to Leulumoega Fou, where they lived on campus. I distinctly remember being nervous as I walked up the hill and knocked on their old glass door. A short man in his late thirties greeted me. He had a beard and a warm friendly face, and he smiled as I explained why I had come. He became excitedly animated and he invited me into his home, tickled with the idea that a tenyear-old wanted to interview him as an artist. I received an $\mathrm{A}++$ for my project. At the time, art was not a subject taught at primary schools or high schools in Sāmoa, even though it had been part of the curriculum at the WSTC since the early 1950 s.

I met Coter again in 1982 upon my return to Sāmoa from New Zealand, where I had been attending Christchurch Girls High School. I had enjoyed taking art in Form 5, and had done well on the New Zealand School Certificate. However, because I was homesick, I wanted to continue studying in Sāmoa and refused to return to New Zealand to complete my senior year. Unfortunately, none of the secondary schools in Sāmoa offered art as a subject except for Leulumoega Fou College under the successful direction of Coter. I wanted to pursue visual art as a university entrance-exam subject and met with Reverend Lale leremia, the principal of the college. He reintroduced me to Coter, who took me in as his first student studying visual art for the 1982 New Zealand university entrance exam.

After successfully completing Form 6, I was accepted into the WSTC in 1983. Maria Coter had briefly taught the art program for secondary teachers, but I unfortunately had 


\section{Latai | Teaching Art in Sāmoa}

missed out on that opportunity. In 1986, after graduating, I taught for a year at Papauta Girls College under the leadership of the late principal Salamasina Malietoa. Arts and handicrafts were taught at Papauta, with an afternoon curriculum of making traditional baskets, mats, and the siapo and elei (printed fabrics). There I met Coter again; he was teaching evening classes in drawing and painting for those interested in pursuing art as a hobby and was experimenting with Sāmoan clay pottery. Whilst I was assisting with his clay projects and learning ceramics from him, Coter persuaded me to join him in developing the Leulumoega Fou School of Fine Arts. I requested to be transferred there and taught English and art history from 1987 to 1994. Our faculty consisted of Ernesto Coter, Emani Epati, Alapati Avealalo, Lealofi Siaopo, and me. Our first students were Penehuro Papalii, Panapa Lafoai, Misikopa Misikopa, Tafa Iuta, Lulu Tiatia, Mose Tia, Atoa Setu, Fa'amatala Fa'amatala, Risati Ete, Donna Kamu, and Pauline Kohlhase, among others.

\section{Leulumoega Fou School of Fine Arts, 1986-2021}

A school of fine arts for those interested in pursuing a career as an artist was first proposed by Coter and began under the CCCS. The school also served as an alternative education venue for young people who were unable to complete their secondary school education. With the success rate of its students passing the New Zealand school certificate and university entrance exam in fine arts, as well as the growing interest of students in arts disciplines, the Leulumoega Fou School of Fine Arts (LFSFA) was established as a separate entity in 1986. The school offered specialized courses in fine arts, delivering a certificate and diploma developed by Coter and the Education Committee of the CCCS.

After thirty years, in 2016 the CCCS changed the name of Leulumoega Fou School of Fine Arts to the Congregational Christian Church of Sāmoa School of Fine Arts and Museum (CCCSSFAM). The school currently operates under the governance and management of the Church. Its vision is to "provide equitable education for all...[and] to produce and maintain quality recognition and relevant Fine Arts education and Museum service..."1

The LFSFA was modelled on the creative energy, scholarship, and mentorship of the Italian Renaissance bottega workshops and studios of fifteenth-century Florence. Within these Italian co-working spaces there were master artists who were committed to teaching new artists, whereby "talents were nurtured, new techniques were at work, and new artistic forms came to light with artists competing among themselves but working together." 2 The

Renaissance artists valued knowledge as a fundamental part of the creative process. ${ }^{3}$ This creative energy, scholarship, and mentorship were key elements on which LFSFA is modelled. During the Renaissance, teaching took place in the studios and knowledge was passed on and shared amongst talented artists, whether painters, sculptors, carvers, cartoonists, illustrators, 
architects, or anatomists. "All of them gave form and life to Renaissance communities, generating aesthetic and expressive as well as social and economic values. The result was the entrepreneurship that conceived revolutionary ways of working, of designing and delivering products and services, and even of seeing the world." ${ }^{4}$ The art studios of Florence were

communities of creativity and innovation where dreams, passions, and projects could intertwine. The apprentices, workers, artisans, engineers, budding artists, and guest artists were interdependent yet independent, and their disparate efforts loosely coordinated by a renowned artist at the centre-the "Master." But while he might help spot new talents, broker connections, and mentor younger artists, the Master did not define others' work. ${ }^{5}$
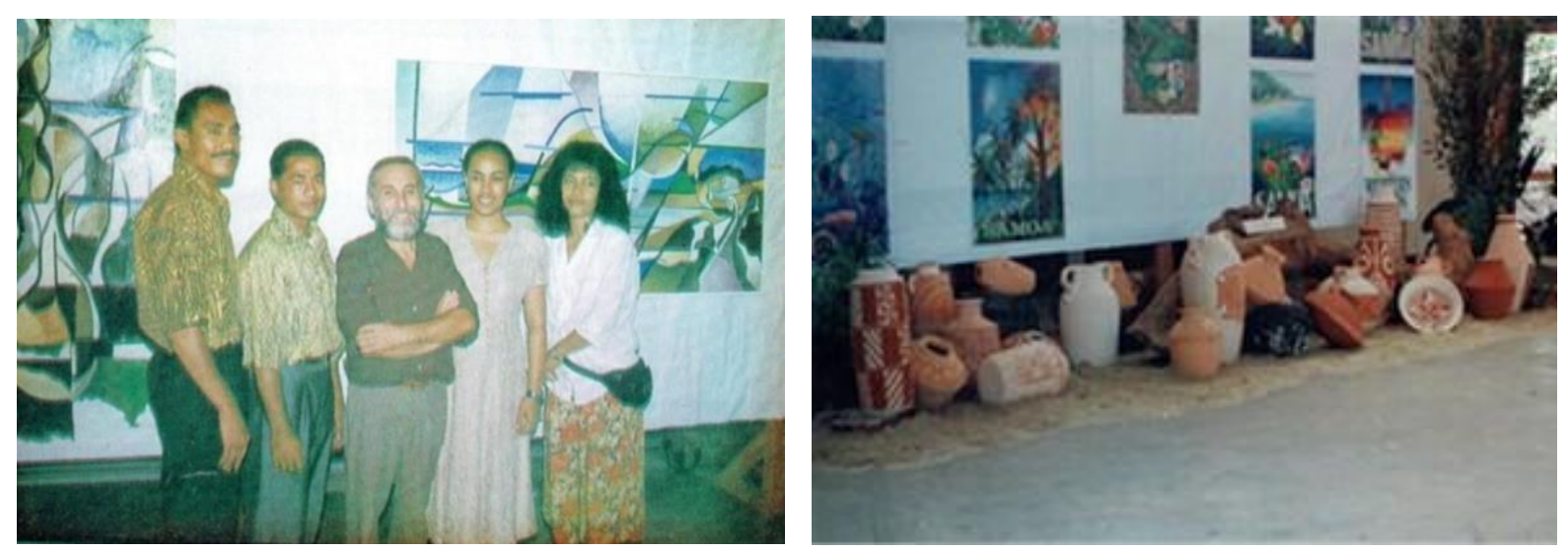

Figure 1 (left). Emerging young Sāmoan artists with teacher Ernesto Coter at the launching of the Rebirth of the Past exhibition: (left to right) Lulu Tiatia, Penehuro Papalii, Coter, the author, and Lealofi Siaopo, 1994. Courtesy of the author

Figure 2 (right). Handmade pottery made by the author using imported and local clay, 1994. Courtesy of the author

This sense of shared endeavour is at the heart of LFSFA and its successor school. An exhibition that epitomized this idea was the school's first graduation exhibition, Rebirth of the Past, curated by Ernesto and Maria Coter in 1994. With this show, a new group of young Sāmoan artists was catapulted into the public eye under the mentorship of Coter. Artists such as Lulu Tiatia, Mose Tiata, Leua Latai, Penehuro Papalii, Lealofi Siaopo, and others, were able to create works that expressed a revisitation and rebirth of the past as had never been seen in Sămoa. The exhibition included sculptures, ceramics, posters, paintings, and carvings, all expressing Sāmoan thought and ethos. The show reflected the natural environment, Sāmoan culture, legends, and traditional life, emphasizing the natural beauty of Sāmoa whilst promoting the importance of climate change and Sāmoan-ness. A recent painting by LFSFA graduate Lealofi Siaopo (Fig. 3) takes the Sāmoan legend of Sina and the Tuifiti as its subject. 
Inspired by Sāmoan mythology and legends taught at the school, Siaopo's painting also emphasises the importance of myths in Sāmoan culture and customs.

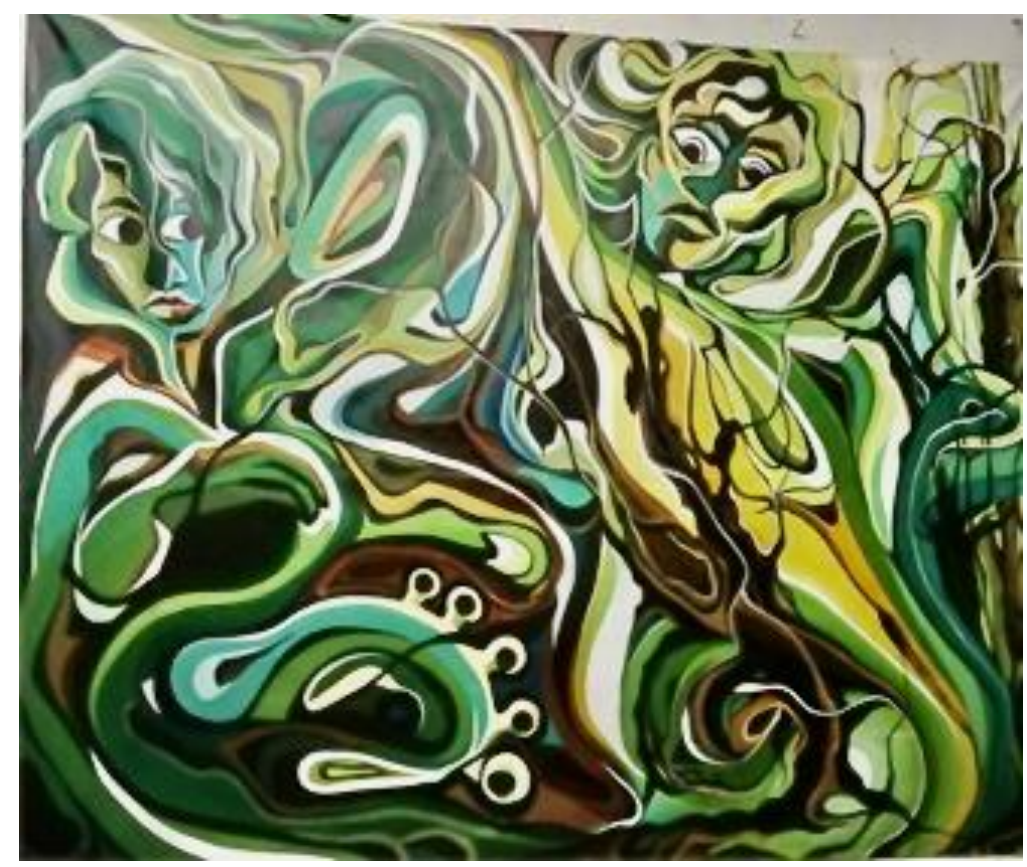

Figure 3. Lealofi Siaopo, Sina and the Tuifiti. Acrylic on canvas, 8" X 6", 2020. Photograph courtesy of the artist

In addition to the importance of both Renaissance ideals and Sāmoan traditions, culture, and heritage, Coter's vision and philosophy for LFSFA encompassed Greek aesthetics and notions of beauty. Curricular emphasis was also placed on the preservation and promotion of Sāmoa's natural environment. The school's first graduation and art exhibition in 1994 set the standards of the school locally, regionally, and internationally, and has never been surpassed. It reflected the importance of experienced and appropriate mentorship guided by talent, skill, ingenuity, intelligence, and knowledge.

\section{Congregational Christian Church of Sāmoa School of Fine Arts \& Museum, 2016-21}

Despite the success of the CCCSSFAM, there is still a great need for qualified, experienced staff in maintaining the quality and development of the school. The departure of Ernesto Coter from LFSFA in 1998 left a huge void that was difficult to fill. From 1999 to the present, graduates of LFSFA and CCCSSFAM have run the school through their committed efforts to sustain its teachings and vision. The CCCS continues to fund and support the school and efforts are being made to replicate its successes of the early 1990s. Although there is 


\section{Latai Teaching Art in Sāmoa}

commitment, circumstances have resulted in an inability to provide suitable career pathways for the students. For instance, as discussed in the school's Quality Management System report, when interviewed, current students revealed that their aspirations for future career opportunities lay in the elei-printing business. Some expressed their dreams to continue further studies overseas and at the National University of Sāmoa (NUS). ${ }^{6}$

Eighty percent of CCCSSFAM graduates work in local commercial printing businesses, teach at the local secondary schools, have their own business, or have moved overseas to pursue art careers. ${ }^{7}$ Today, thirty-three years after its founding, the school still needs financial resources, as well as skilled and experienced staff. The CCCS has to recognise the current requirements and demands placed on young people by Sāmoa's creative industries in order to support its clients. Creating and producing "art for art's sake" is not sufficient in today's fast-changing world. With Sāmoa's youth unemployment rate over eighteen percent and rising, ${ }^{8}$ there is need for the CCCSSFAM to upgrade its programs by providing classes that teach computing skills and IT knowledge to support more sustainable career pathways for its students.

In 2018, the Sāmoa Qualifications Authority (SQA) reviewed the CCCSSFAM and its programs as part of the accreditation process. ${ }^{9}$ In its report, the review panel indicated concerns about the school's delivery of its curriculum program. Noted were the neglect of the school's historical collection by faculty; the need for professional development among the staff; inadequate physical learning resources such as a library, online resources, and a computer lab; and inconsistencies in financial resources. In spite of the problems noted across the layout of its program, the SQA review panel commended the school's enrolment policy, which unlocks pathways both for those who are unsuccessful in mainstream subjects and those of mature age wishing to pursue a career in the fine arts. ${ }^{10}$ Most noteworthy is the continued support of the CCCSSFAM and the CCCS's commitment to the recommendations provided by the SQA in the vigorous monitoring of the school and its program.

Between 2008 and 2019, sixteen percent of the graduates of NUS and LFSFA obtained a diploma in fine arts, eighteen percent graduated with a diploma in education specializing in visual arts from NUS, and fifteen percent of graduates successfully gained a diploma in fine arts and education (Graph 1). Since 2008, graduates of the former LFSFA have moved on to successful careers teaching art as a subject in Sämoan secondary schools, as well as at private and overseas institutions; a recent survey of secondary art teachers teaching on the islands of Upolu and Savai'i indicated that the majority of art teachers in the field were trained at either CCCSSFAM or NUS. Other graduates work as curriculum developers at the Ministry of Education, Sports and Culture, and some teach at the tertiary level at NUS. Still others have opened up their own art studios and galleries in Sāmoa such as Beautiful Expressions of 


\section{Latai | Teaching Art in Sāmoa}

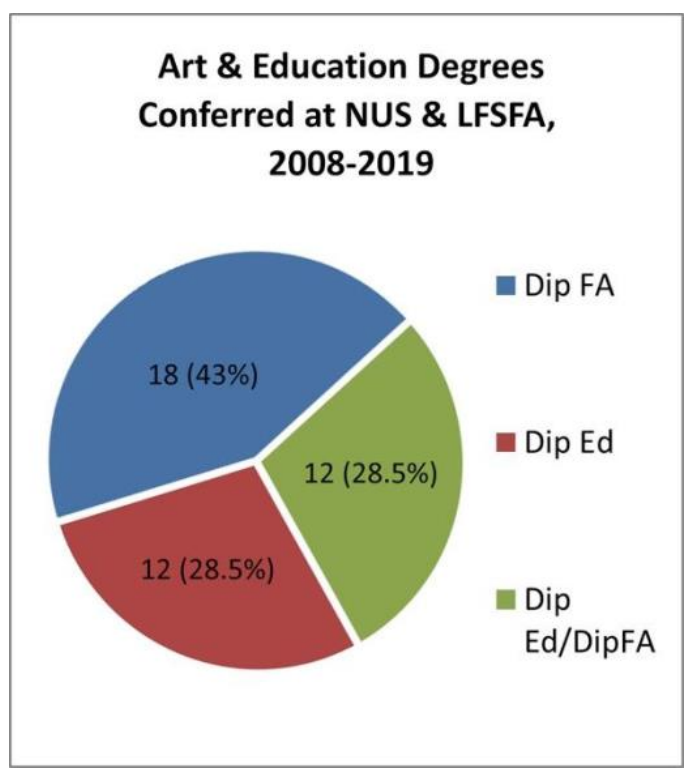

Graph 1. Art and Education degrees conferred at the National University of Sāmoa (NUS) and the Leulumoega Fou School of Fine Arts (LFSFA), 2008-2019. Graph created by the author

Nature (B.E.N.), run by Penehuro Papalii, and the Manamea Art Gallery, owned by Lalovai Peseta. A few graduates run their own elei-printing businesses and others have moved overseas to pursue further education or careers in the arts. One LFSFA graduate was the first Sāmoan to have graduated from the prestigious School of the Art Institute of Chicago in the United States.

According to the Ministry of Education Sports and Culture's (MESC) School Operations Department 2019 report, a survey conducted in 2019 determined that twenty-three of the twenty-seven government secondary schools in Sāmoa offer visual art as a subject (Table 1). ${ }^{11}$ The remaining four do not offer art due to a shortage of trained art teachers. In addition, there are eight private schools and thirteen church-run secondary schools in Sāmoa offering art, bringing the total of secondary schools that offer art in Sāmoa to forty-four.

\begin{tabular}{|l|c|c|c|}
\hline $\begin{array}{l}\text { Secondary Schools } \\
\text { by Type }\end{array}$ & Upolu & Savai i & Total \\
\hline Government Colleges & 18 & 5 & 23 \\
\hline CCCSS Colleges & 5 & 2 & 7 \\
\hline Catholic Colleges & 4 & 2 & 6 \\
\hline Other/ Private Colleges & 6 & 2 & 8 \\
\hline Total & 33 & 11 & 44 \\
\hline
\end{tabular}

Table 1. Secondary education institutions in Sāmoa offering art instruction, 2019 


\section{Latai Teaching Art in Sāmoa}

At these secondary schools (private, church, and government), a total of forty-three art instructors are currently teaching at the secondary level. Twelve were trained at the CCCSSFAM and have pursued further training at the National University of Sāmoa, graduating with a second diploma and a bachelor of education-secondary degree majoring in visual art. Thirty-four art teachers were trained from other institutions and the National University of Sāmoa.

When I first joined the Faculty of Education at NUS in 2008, the highest qualification attained with visual art as a subject was a diploma in education for secondary teaching. In 2010, a bachelor of education at the secondary level was offered, thus students pursuing a goal of teaching could enrol in a major specializing in visual art. In the academic year 2016-17, eight secondary teachers majoring in visual art graduated with a bachelor's degree in secondary education from NUS.

\section{Development of a Visual Arts Curriculum for the Secondary and Primary Levels}

In the early 2000s, the secondary school curriculum for visual arts for teaching visual art at the secondary level was developed by the Sāmoa Ministry of Education, Sports and Culture. The curriculum was developed by Maria Coter, Momoe Malietoa Von Reiche, Dr. Vanya Taulealo, myself, and others. It allowed visual art to be taught from Years 9 through 13, with the discipline now part of the School Certificate (SC) and Secondary School Leaving Certificate (SSLC) national examinations. In 2004, visual art was implemented in all government schools as an examinable subject for the SC and SSLC national examinations. Naturally, trained secondary teachers were needed to implement the curriculum. Those who were interested in teaching visual art at secondary schools enrolled in the bachelor of education-secondary program, majoring in visual art and another specialized subject of interest. In 2009-10, the diploma in education was phased out and replaced by the bachelor of education in secondary teaching. In 2015, a restructuring of the education programs at NUS led to more changes. The visual art major and other disciplines including music, performing arts, physical health and education, food textiles, and technology were put on hold.

Currently, NUS offers only a minor in visual art for those interested in pursuing a career in the arts and teaching at the lower secondary level (Years 9-11). The Expressive and Practical Arts Department at NUS was dismantled and merged under the Teacher Education Department. The visual art courses offered are designed to train teachers for primary and the lower secondary level grades (Years 9-11). The two remaining departments under the Faculty of Education are the Education and Teacher Education Departments. The bachelor of education degree in secondary teaching no longer exists, and all the expressive arts disciplines 
are offered only as minors. In the academic year 2020-21, a proposal was put through to revive the visual arts major to be offered under the Faculty of Art programs.

Vigorous discussions-with strong opposition to the reoffering and existence of the art major-are ongoing, despite the curriculum being taught and implemented as an examinable subject in secondary schools for the SSC and SSLC national exams. With the bachelor of education in secondary teaching being phased out, students interested in pursuing a career in the arts and teaching in secondary schools have to pursue a bachelor of arts degree. The visual art courses currently sit under the Faculty of Education whilst there is still ongoing conversation on their relevance. Recently, there has been a drive to reinstate offering a bachelor of education degree in secondary teaching in visual art under the Faculty of Education. There is much debate on the existence of the arts at NUS due to resource constraints, ignorance, relevance, and poor attitudes towards its significance in education. Sadly, the university fails to see either the lucrativeness of the arts or the arts as a worthwhile career pathway for our young people, even with the youth unemployment rate in Sămoa at over eighteen percent and rising. ${ }^{12}$

\section{Teaching Art at the Tertiary Level, 2008-21: Challenges and Success Stories}

It has been fourteen years since I came to NUS to teach visual art and education to primaryand secondary-teacher trainees. The success of the visual art courses taught at NUS is reflected in the interest and commitment of the students pursuing a career in the arts and the faculty and staff involved. Most students enrolled in the visual arts courses comment on having been inspired and motivated by their own primary and secondary art teachers, highlighting the importance of mentoring by those teaching in the field. The flow of students into NUS's visual arts program has been attributed to the NUS art teachers who have a reputation for being passionate and inspiring. Another contributing factor is the continuing upgrade of qualifications offered for secondary art teachers at the tertiary level, despite the challenges in acknowledging the importance of arts education as a viable career pathway.

Most remarkable, however, are the efforts of graduates from LFSFA who are seeking higher degrees in the arts and teaching certifications in pursuit of their art careers. Within the last fourteen years, many secondary art teachers in Sāmoa have upgraded from a diploma to a degree qualification. Between 2015 and 2018, thirteen students successfully completed a degree in secondary level education with a major in visual art and are now teaching in the field. ${ }^{13}$ In 2021, it is predicted that fourteen students will graduate with a minor and hopefully a major in visual arts by 2022-23. In 2019, the MESC School Operations Division recorded 1,459 students enrolled in visual arts for Years 12 and 13 across all secondary schools in Sāmoa. ${ }^{14}$ 


\section{Latai | Teaching Art in Sāmoa}

These numbers anticipate an influx of students coming into the visual art programme at the National University of Sāmoa.

\section{Collaborations and Partnerships, 2008-21}

Much of the success of the visual art courses offered at NUS over the years has been due to staff involvement in teaching and learning, and, in particular, the keen interest that students bring to the art program. In order to implement the visual art courses, art instructors, together with the support of students, must put a great deal of effort into acquiring the necessary supplies and equipment, as the departmental budget does not cover all needs. This includes applying for grants and funding. In 2016, the student organization Art Agency NUS received the Civil Society Organization Public Joint Forum Grant for Innovative Learning and Capacity Building, in recognition of its work on educational and professional arts development in vulnerable communities and advocating for the voice of the voiceless through innovative and well-managed projects. The grant was funded by the Australian government and the European Union through the Civil Society Support Programme. It funded the Art Agency Visual Literacy Project, which supports graphic design, illustration, and print media. The students' project involved the production and illustration of children's books in the Sāmoan language, with a focus on local author Fiapopo Taulogo (Figs. 4-5). ${ }^{15}$
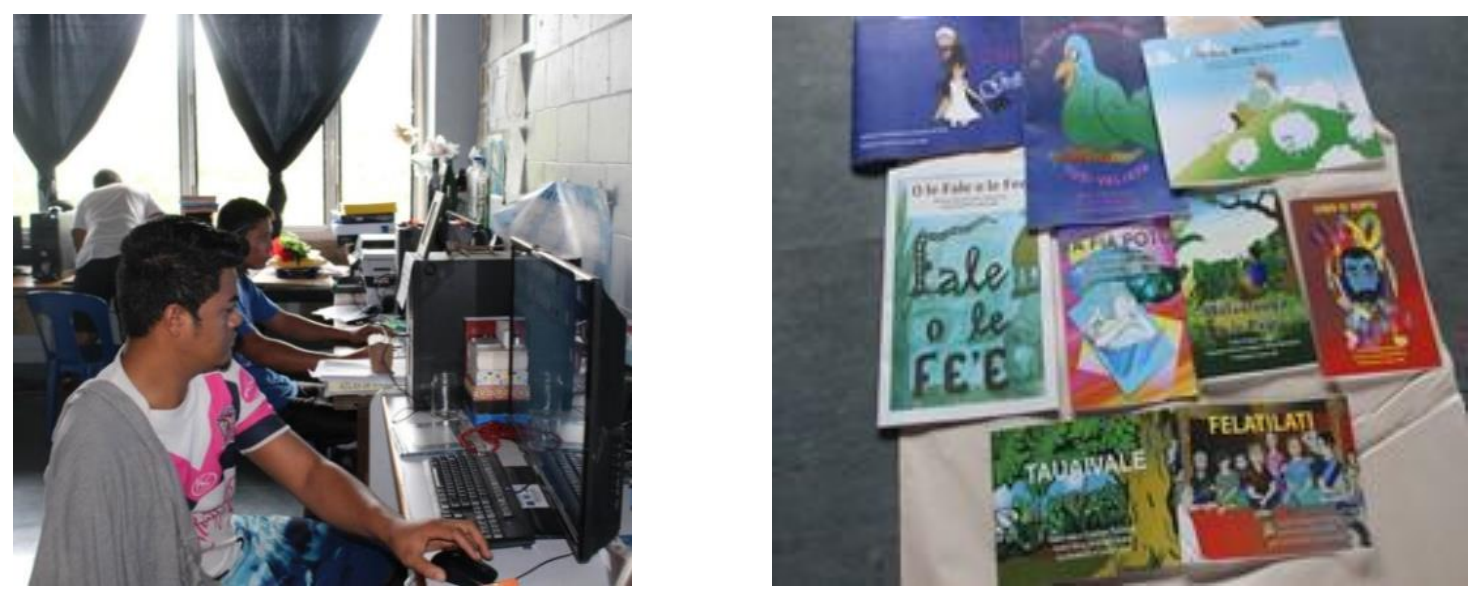

Figure 4 (left). NUS students leremia Tu'upo and Leala Mose working on the Art Agency Visual Literacy Project, 2016. Courtesy of the author

Figure 5 (right). Children's books with illustrations by National University of Sāmoa art students, 2016. Courtesy of the author 


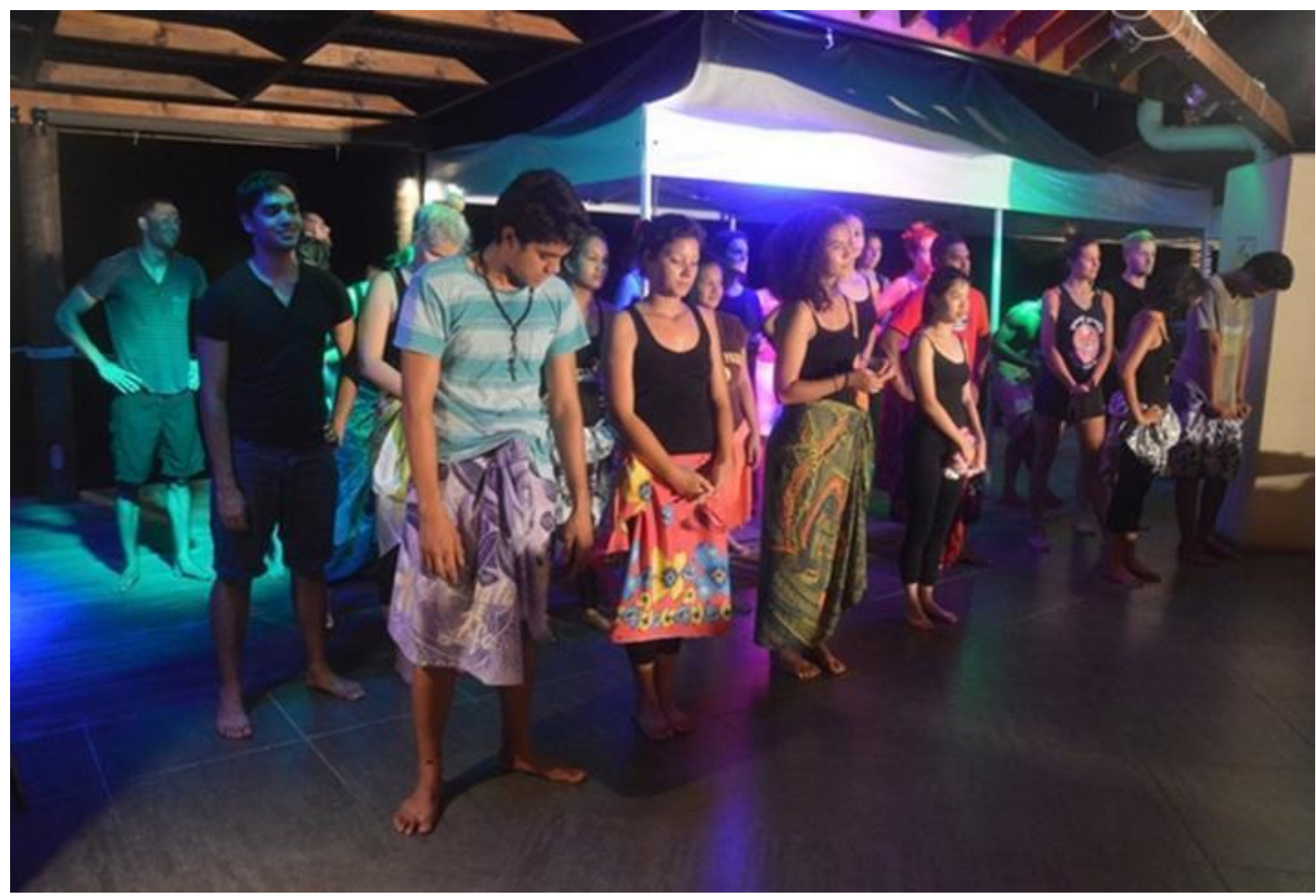

Figure 6. Students from the Australian National University, the National University of Sāmoa, and the University of the South Pacific rehearsing a performance at the Sinalei Resort, Sāmoa, 2013. Courtesy of the author

Collaborations and partnerships with international, regional, and local institutions have been key to sustaining the visual art courses at NUS over the last fourteen years, as these organizations recognize the importance and value of a tertiary arts education. Partnerships with other universities have been established, such as with Professor Christine Yeh at the School of Education at the University of San Francisco, and continued friendships with staff and students at Indiana University Southeast through Professor Anne Allen. Professor Carol Mutch at the University of Auckland has supported student work through publications such as the poetry book Talanoa Fogafala, which was edited by Professor Mutch and myself. The book consists of original poems written by Auckland University and NUS staff and was published in 2019 with illustrations by NUS visual art students. Other partnerships include conducting research with Dr. Lex Mc Donald at Victoria University, focused on the Moving On Art Therapy Program for children affected by the 2009 Sāmoa tsunami. Professor Katerina Teaiwa (Australian National University) and the late Seiuli Allan Alo (University of the South Pacific and president of the Sāmoa Arts Council) brought together young people from Australia, Sāmoa, and the Pacific to engage in cultural community projects that enriched student experiences (Figs. 6-7). Partnerships with the New Zealand, British, American, and 


\section{Latai | Teaching Art in Sāmoa}

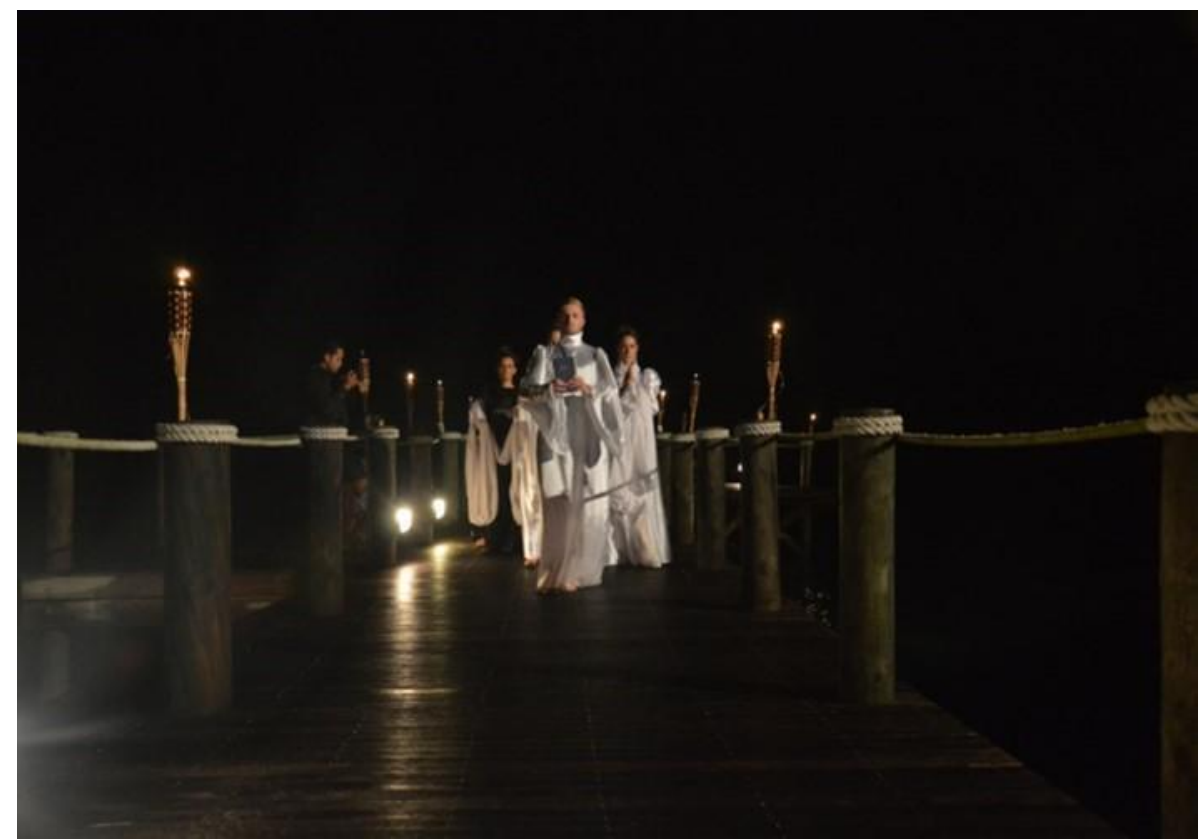

Figure 7. Australian National University students performing the arrival of missionaries to Sāmoa. Sinalei Resort, Sāmoa, 2013. Courtesy of the author

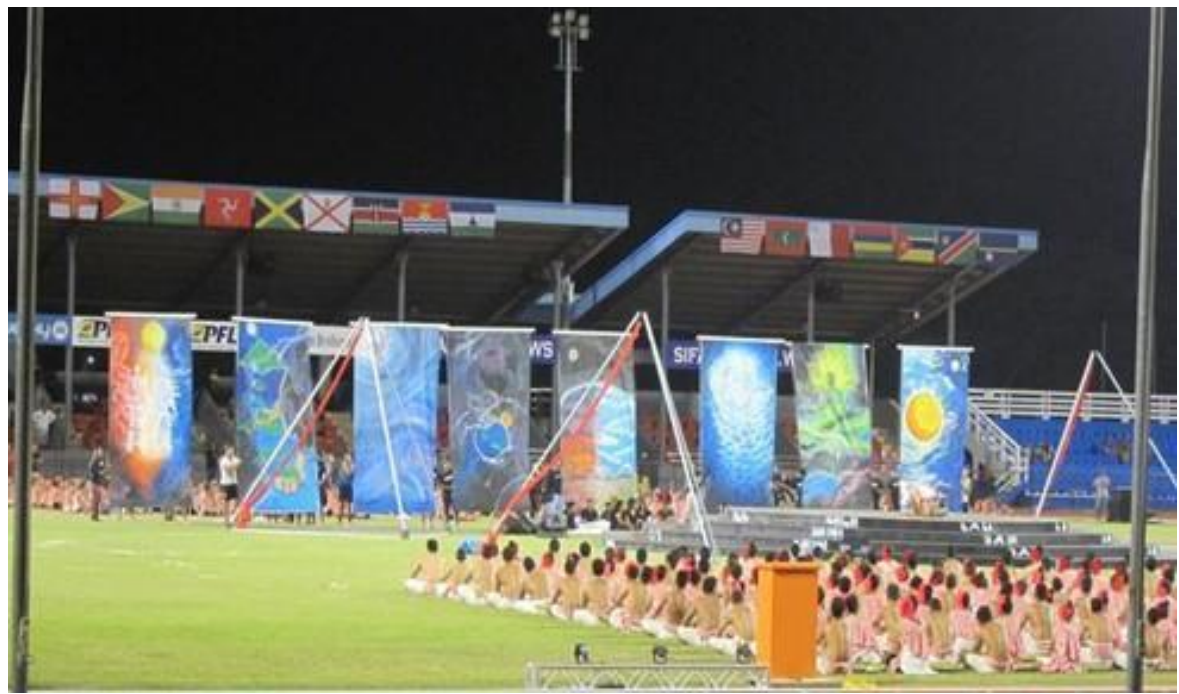

Figure 8. National University of Sāmoa art students, Banners of the Sämoan Creation Story. Commonwealth Youth Games Opening Ceremony, Sāmoa, 2016. Courtesy of the author

Australian embassies have provided financial resources in support of student art exhibitions, publications, and students' promotion and marketing their own art work. The revenues from the students' art sales are divided between the students and NUS, which has assisted in funding resources for the visual art courses from time to time.

Invitations from the United Nations, World Health Organization, Food and Agriculture Organization, United Nations Development Program, and Small Island Developing States—as 
well as the 2018 Pacific Arts Association conference and the 2016 Commonwealth Youth Games, both held in Sāmoa-have provided fine arts students with opportunities to participate with other young people in initiatives supporting and enriching their experiences as students and artists. In 2010, the Aleipata school district's Moving on Art Therapy program was invited to exhibit drawings and paintings and share their research findings at the New Zealand Parliament Building in Wellington. The public response from the local and international communities, through the provision of art materials and resources to NUS's visual art program, was overwhelmingly supportive. In 2016, NUS art students designed banners and participated in the opening ceremony of the Commonwealth Youth Games (Fig. 8).

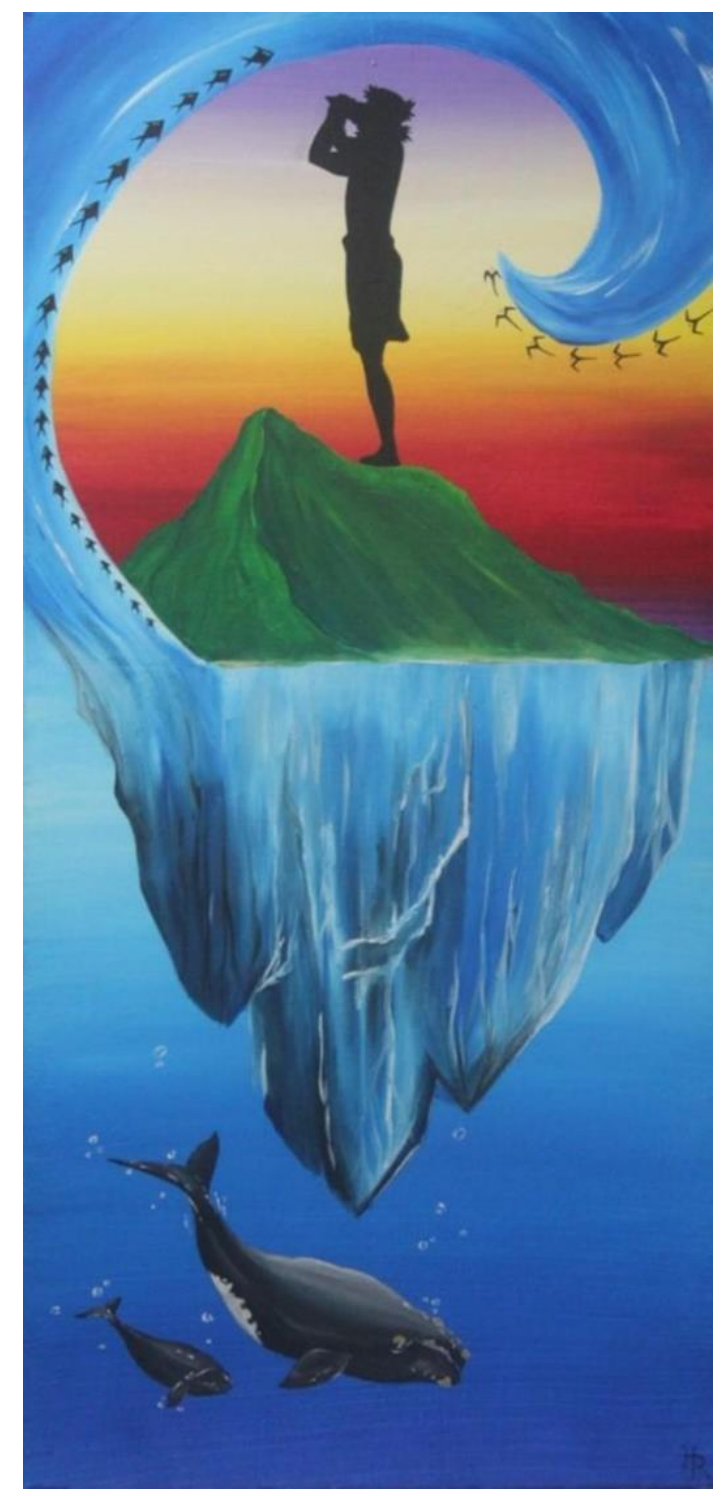

Figure 9. Hailey Rasmussen, Tidal Wave. Acrylic on canvas, 12" x 24", 2021. National University of Samoa. Photograph by the author. Courtesy of the artist 


\section{Latai | Teaching Art in Sāmoa}

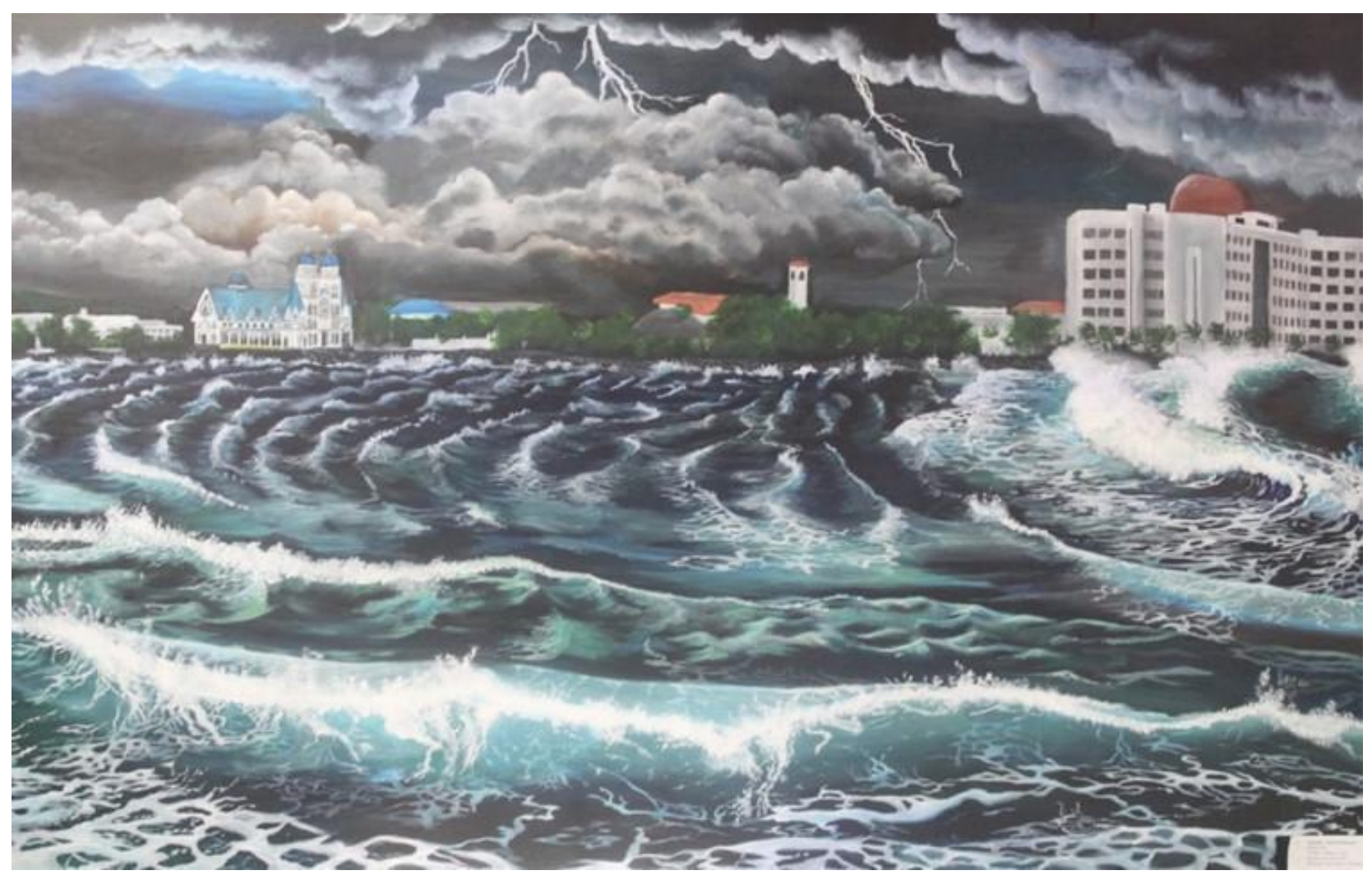

Figure 10. Talalelei Solomona, Eleéele Fou (Reclaimed Area). Acrylic on plywood, 8" x 4", 2021. National University of Sāmoa. Photograph by the author. Courtesy of the artist

In 2018, an international juried exhibition involving art faculty and students from NUS and Indiana University Southeast (IUS) in the United States was co-facilitated at the Niuleá Exhibition Space at NUS and Ronald Barr Art Gallery at IUS. The exhibition provided students with experience exhibiting their artworks both locally and internationally. In 2021, the British High Commissioner to Sāmoa collaborated with NUS in a regional photography competition and exhibition highlighting the impacts and effects of climate change. Visual art students were invited to create paintings that illustrated their take on climate change (Figs. 9-11) and to be involved in curating the exhibition. The exhibition provided an avenue for students to extend their arts experiences beyond the classroom and engage in community initiatives that were beneficial for all (Figs. 12-13). 


\section{Latai | Teaching Art in Sāmoa}

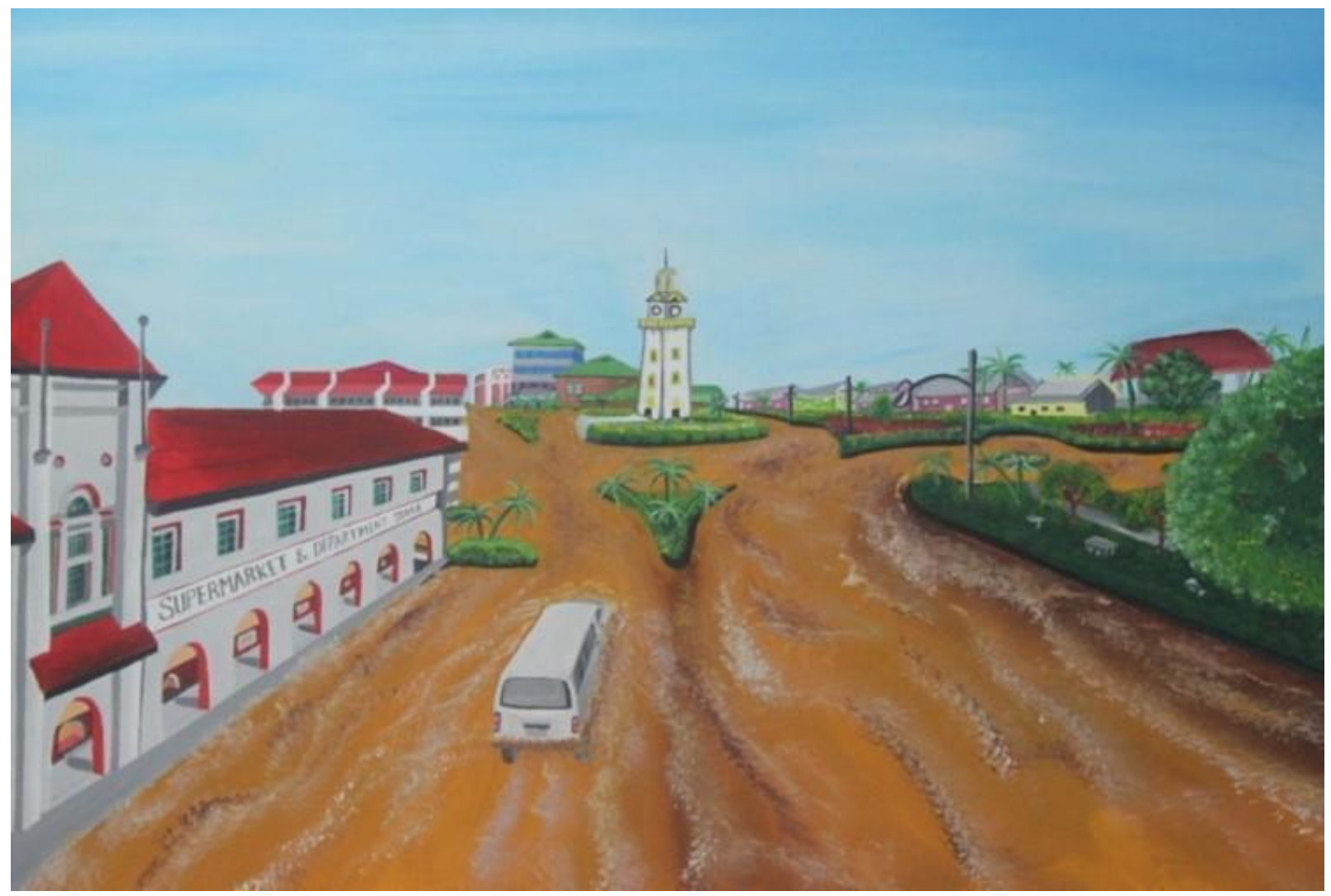

Figure 11. Sofara Sofara, Effects of Climate Change in Apia. Acrylic on canvas, 4" X 6", 2020. National University of Sãmoa. Photograph by the author. Courtesy of the artist

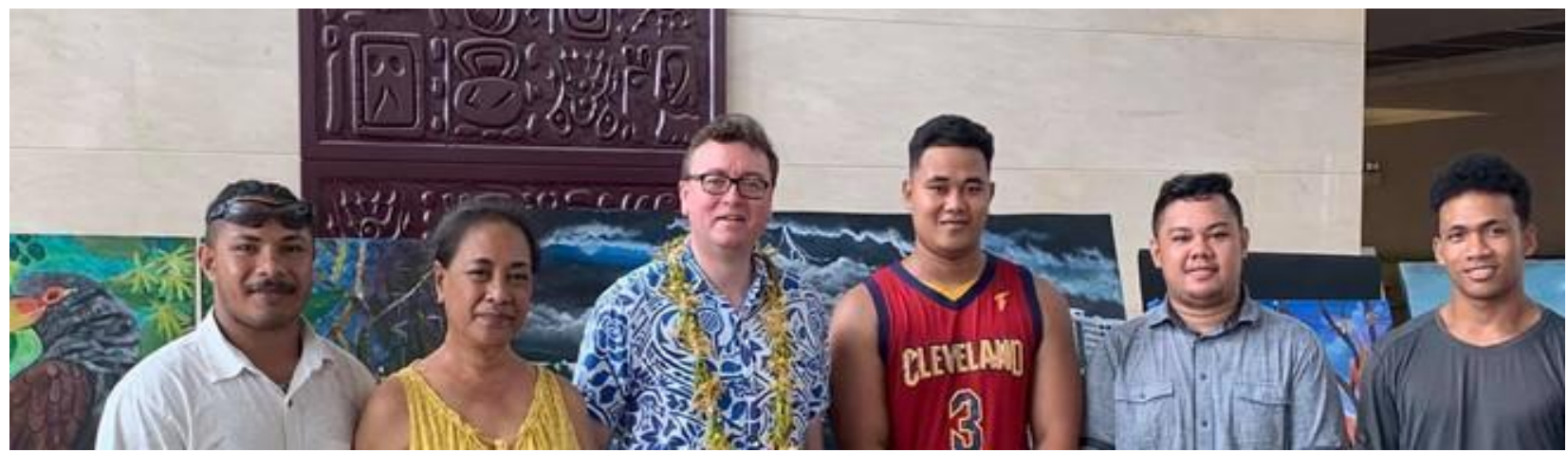

Figure 12. The author (second from left) with His Excellency David Ward, British High Commissioner to Sāmoa (third from left), and National University of Sāmoa art students (left to right) Gert-Jan Jakobus, Sofara Sofara, Ierenimo Pio, and Faitogafiti Mika. UK Climate Change Photography Competition and Art Exhibition, Tatte Building, Apia, Sāmoa, 2021. Courtesy of author 


\section{Latai | Teaching Art in Sāmoa}

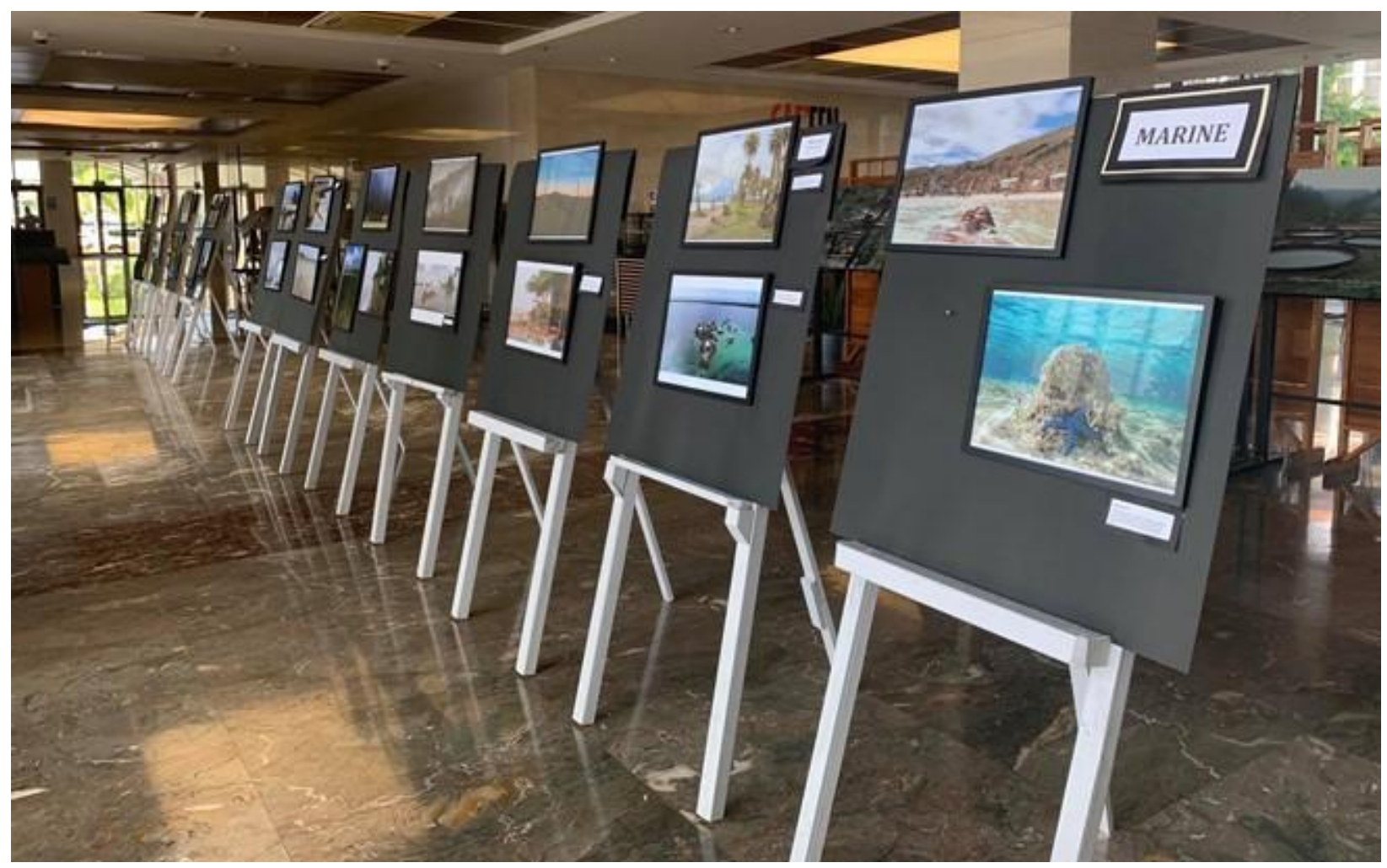

Figure 13. View of UK Climate Change Photography Competition and Art Exhibition, curated by National University of Sāmoa art students Gert-Jan Jakobus, Sofara Sofara, lerenimo Pio, Faitogafiti Mika, Maumalo Natia, Miracle Poutoa and Leua Latai. Tatte Building, Apia, Sāmoa, 2021. Courtesy of the author

Partnerships with local, regional, and international institutions have been both successful and very popular with Sāmoan students wishing to engage with young people from overseas universities and organizations. Friendships made through these programs continue among our students and alumnae. Art students have also successfully continued their studies abroad, pursuing careers in visual art, graphic design, illustration, and education in Indonesia, New Zealand, China, and Australia. Furthermore, in the last ten years, NUS's visual art program has trained more than twenty secondary visual-art teachers with a first degree in education with specialization in art. Data collected from a survey conducted in 2019 and the Operations Division of the MESC reported that twenty-three secondary art teachers were brought into the government secondary schools in Sāmoa (Graph 2). 


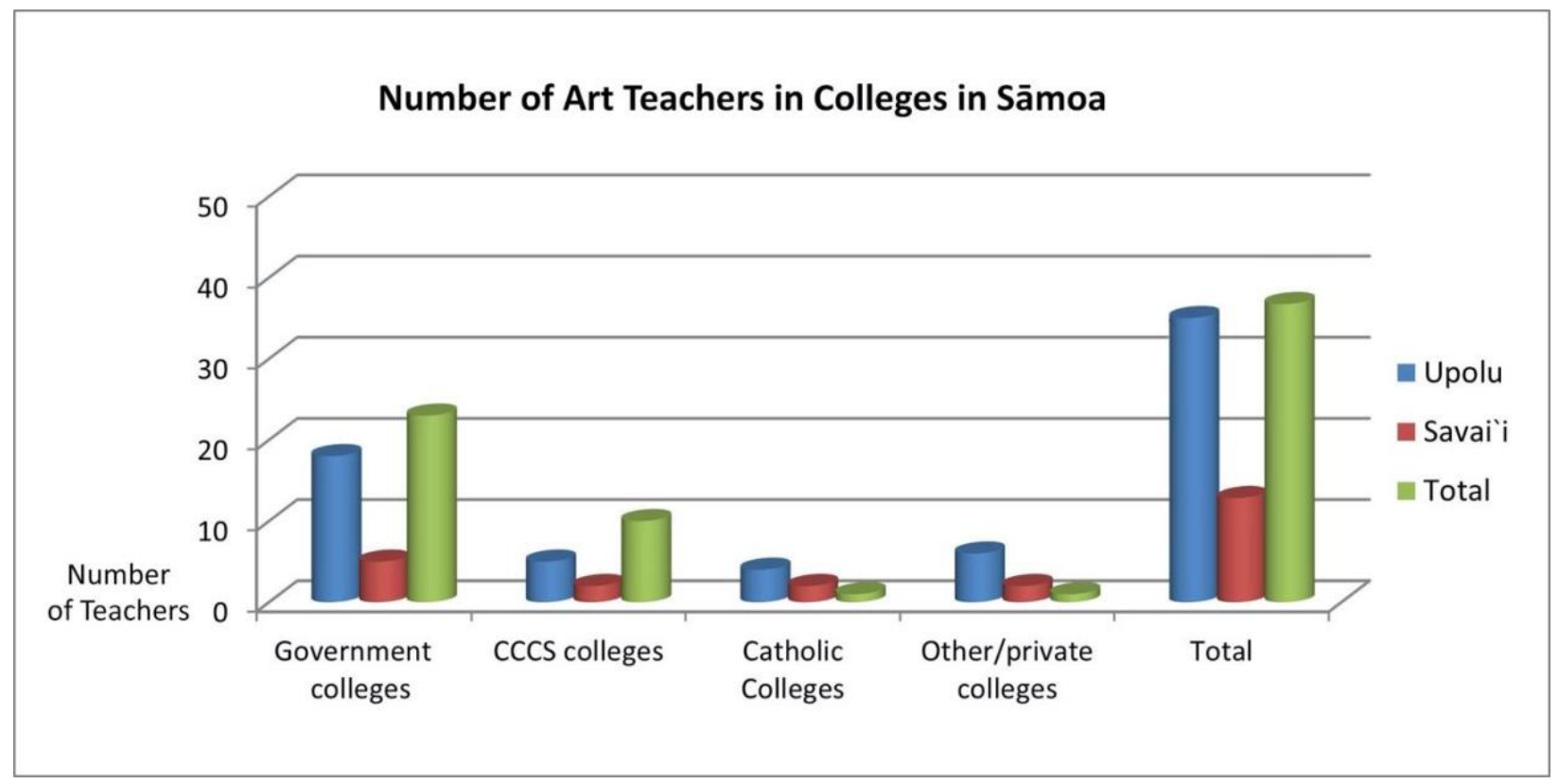

Graph 2. Number of art teachers in Sāmoa, 2019. Graph created by the author

\section{Reflection}

From the perspective of having been both an art student and instructor in the past fifty years, I have experienced and witnessed a robust development of the arts in Sāmoa. My country has come a long way; there is now a teaching curriculum for expressive arts and visual arts for the primary and secondary levels offered at the National University of Sāmoa. I, myself, am currently pursuing a PhD in creative practice at the Centre for Sāmoan Studies at NUS. In addition to other schools of fine art, such as the CCCSSFAM, we have the MADD (Motivational Art, Dance, and Drama) Gallery, owned and run by Momoe Malietoa Von Reiche; the Beau Rasmussen Carving Studio; the Vanya Taulealo Art Gallery; and the previously mentioned Beautiful Expressions of Nature and Manamea Art Gallery. Sāmoa has three art and culture museums and the Sāmoan government will be opening its new Sāmoa Culture Centre in 2021. In performing arts, we have S.P.A.C.E, a dance studio created by the late Seiuli Allan Alo. These art spaces have created economic prospects for those interested in the arts. These studios and galleries contribute to the economic development of Sāmoa and create an enriching environment that provides opportunities for our young people, especially those interested in pursuing careers in the field of art.

This expansion in the arts has generated more opportunities for NUS to develop areas such as museum studies, archival and art management courses, and programs that cater to Sāmoa's growing creative industries. Despite all these developments, the growth of the visual arts still remains relatively stagnant and the sustainability of the arts over the years has been held back due to lack of recognizing visual art's potential, true value, and significance to the 
economic growth and development of Sāmoa. There is much focus on the development of subjects including math and science to the detriment of the arts, despite NUS's vision to prioritise and safeguard Sāmoan cultural heritage of which the arts are an imperative part.

In some way or another, out of interest and commitment, I have been involved in the development of the arts in Sāmoa over the last fifty years. On a human level, it has been a discipline in which I have found consolation-the arts allow me to be myself and independently express my views, as well as share others' experiences, skills, knowledge, and development. For others, art provides solace, the freedom to express their creativity, and a voice to react to the ever-changing social, cultural, and political environments. Keith Haring, an American pop artist, once said, "Art should be something that liberates one, provokes the imagination and encourages people to go further."16 My journey as an artist, student, and instructor has taken me to places I never dreamed I would reach. I owe much to the generous people I have met along the way. My voyage has not ended and I look forward with great anticipation to the next phase of my artistic journey.

Leua Latai was born in Papua New Guinea to Sämoan missionary parents. She graduated from Western Sämoa Secondary Teacher Training College and taught at Papauta Girls College, as well as Leulumoega Fou College and the Leulumoega Fou School of Fine Arts, acting as curator and coordinator from 2006 to 2008. She married a Peace Corps volunteer and emigrated to the United States, earning a BA (University of Wisconsin) and MFA in art (School of the Art Institute of Chicago). She is currently a senior lecturer in visual art and education at the National University of Sāmoa and pursuing her doctorate in Sämoan studies at the Centre for Sämoan Studies.

\section{Notes}

1 Sāmoa Qualifications Authority Programme, SQA Accreditation Report: Congregational Christian Church of Sämoa, Congregational Christian Church of Sämoa School of Fine Arts, and Museum Certificate III in Fine Arts (Apia: Sāmoa Government Printing, 2018), 4.

2 Piero Formica, "The Innovative Working Spaces of 15th Century-Italy," Harvard Business Review, April 27, 2016, https://hbr.org/2016/04/the-innovative-coworking-spaces-of-15thcentury-italy.

${ }^{3}$ Ibid.

${ }^{4}$ Ibid.

${ }^{5}$ Ibid.

${ }^{6}$ Sāmoa Qualifications Authority Programme, SQA Accreditation Report, 13-14.

${ }^{7}$ Ibid.

${ }^{8}$ Aaron O'Neill, "Youth Unemployment Rate in Samoa," Statista: Economy \& Politic, July 15, 2021, https://www.statista.com/statistics/808904/unemployment-rate-in-samoa/.

${ }^{9}$ Sāmoa Qualifications Authority Programme, SQA Accreditation Report, 13-14. 


\section{Latai | Teaching Art in Sāmoa}

10 Ibid., $13-24$.

${ }^{11}$ Ministry of Education Sports and Culture, personal communication, email, Sept. 14, 2020.

12 O’Neill, "Youth Unemployment Rate in Samoa."

${ }^{13}$ Data gathered from author's student assessment records of graduates.

${ }^{14}$ Ministry of Education Sports and Culture, personal communication, email, Sept. 14, 2020.

${ }^{15}$ The Art Agency Visual Literacy Project provided art education students with illustration and graphic design skills to create children's books in order to promote literacy and numeracy skills. It also enabled secondary art teachers who were in training to create children's books in both the Sāmoan and English languages. Grant funding provided for computer hardware and software to support the book projects.

${ }^{16}$ Victoria Kennedy, "The 10 Best Keith Haring Quotes," Canvas: A Blog by Saatchi Art, May 4, 2017, https://canvas.saatchiart.com/art/art-news/the-10-best-keith-haring-quotes. 


\title{
LAURA SUNDERLAND
}

\section{Singing in Harmony: Reflections on Forty Years of Teaching Art in New Zealand Schools}

\begin{abstract}
This paper presents experiences and personal reflections on teaching art in multicultural secondary schools in New Zealand for over forty years. An educational construct that puts students' lived realities and cultural experiences at the forefront of their education-primarily through a process of respecting them and their communities-is presented by an art teacher whose career and practice have moved from a monocultural, Eurocentric system to a more equitable, diverse, student-based culture.
\end{abstract}

Keywords: art, education, student-based, Pacifica, Māori, inclusive

Let me begin by saying that this paper presents personal reflections on teaching art in New Zealand for over forty years - it is not intended to be an academic paper. It covers some of my thoughts and experiences as well as touches on some of the changes I have seen in multicultural secondary schools-changes to which I have, hopefully, contributed. The focus of my career and practice has been moving from a monocultural system that represents the dominant European culture to a more equitable, diverse, student-based culture-while always teaching art with the goal of giving students the best opportunities for personal growth and self-realization. Here I present an educational construct that puts students' lived realities and cultural experiences at the forefront of their education through a process of respecting them and their communities. I could support what I am writing with more citations and learned quotes, but I prefer to present what has worked for me and for my students through four decades of teaching art to Māori, Pacific Island, and other students in New Zealand. This is what they have taught me over those decades.

We are all aware of the continuing educational failures-according to Western ideas of education-of students from Indigenous, diasporic, and nondominant cultures. The statistics reflecting this calamity are found throughout the world. Explanations include socioeconomic factors and the privileging of the dominant culture's beliefs and value systems to create a hidden curriculum advantage that furthers assimilation as a solution. The lack of connection between nondominant students' visions of themselves and their environment and 


\section{Sunderland $\mid$ Singing in Harmony}

an educational system created by the dominant culture promotes an ideology with little or no relevance to marginalized people.

Assimilation has clearly not been a useful agenda; many young minds and lives have been left behind, left out, and let down as a result and New Zealand society itself has suffered the loss of what those students have to offer. We need to embrace and promote all of our students by treating them all equally. This is accomplished not by offering all of them the same programme, but by offering each and every student instruction that is suited to that child and their family. Educators need to see both the dominant and marginal cultures with equal value and to present them with equal opportunities.

Abraham Maslow's classic hierarchy of needs sets out a clear and concise vision of what we each need in order to succeed and to nurture the capability of higher thought. ${ }^{1}$ Once the basic needs of food, water, warmth, and rest are met, we move immediately to safety and security, and then belongingness and love. These are needs that, in the past, society has expected families and the community to meet, yet too many students are not given these basic conditions for success. As members of any society, we have a moral responsibility to do what we can to fill in these gaps; as educators, we have an even greater responsibility.

Culturally responsive teaching, as set out by John Dewey, is a system that recognizes the importance of including students' cultural references in all aspects of learning, and is the first step in providing safety and security. ${ }^{2}$ Having your culture, vision, and individuality acknowledged and valued by others is key to inclusiveness. In recent years, the increase in and greater diversity of immigrants in New Zealand has presented even greater challenges to student-centered learning. Childhood is a time of discovering oneself and one's own place on this earth. In many ways, this is the most important task we have as humans. How scary! How, as educators, can we tap into this diversity of life experience?

When I immigrated from the United States to New Zealand as a teacher in the mid1970s, I was put in the position that many young teachers face: I was given the classes that no one else wanted, with scant advice that included "Don't smile until Easter." In the small Bay of Plenty town where I taught, my classes included the Māori children who lived up in the valleys and out in the hills. These were the ones who often missed school because they were helping out at home, attending a tangi (a week-long ceremony associated with the death of a loved one), or were escaping for another reason, one being that school was not a safe or happy place for them.

Teaching such a class can easily knock the idealism out of you, and it was a learning experience for me. Coming from Berkeley, California, I had no experience or knowledge of New Zealand culture and even less about Māoritanga (Māori culture). I was finding my way as I went along in this new environment. My students were as resourceful as any others in their attempts to keep me from teaching my planned lessons; they gave excuses ("The pakeha [non-Māori of European descent] stole my book," "The horse ate my homework") and tried 


\section{Sunderland $\mid$ Singing in Harmony}

to cajole me into talking about something off-topic and more fun ("Please tell us about America," "Tell us about the famous people").

I cannot remember what precipitated the event, but one day two boys in my class started to have a bit of a push and shove. I stood between them. One boy let out a stream of expletives that would have made any of the local mill workers proud. In 1970s, small-town Aotearoa, this was far from acceptable and, as a teacher, I was obligated either to cane the boy myself or send him to the appropriate white man administrator. I decided to do it myself to expedite the process and avoid the notice of the older teachers and other busybodies in the staff room eager to give me unsolicited advice. I delivered the prescribed corporeal punishment for the boy's offense. The boy became sulky and subdued and the lesson continued until the bell rang, at which point a clutch of girls came up to me, shy but full of anticipation. "You caned the Tohunga's [traditional priest] son. He is gonna get his dad to put the makutu [spell] on you." I am not sure if they were telling me this with regret or excitement, but my Irish ancestry, the folklore of which features many spells and curses, quivered.

The next morning, I went to school seemingly suffering no ill effects from a curse. A large Mãori man met me at my classroom door. He was definitely not another teacher, as at the time they were all päkehā (Europeans), and this man was also wearing a bush shirt and steel-toed boots.

"Are you Miss Sunderland?"

Oh no, I thought, here comes the curse, right to my face. But what he said next was not what I expected.

"Thank you. Thank you for treating my tama, my boy, like all the other kids," he said.

What that father wanted was for his child to be treated with fairness and equality, both in praise and in punishment. For educators to have the same expectations of his son, behaviorally and educationally, as for any other child. He wanted for his child what we all want for our own children: a just system that serves us all with respect and fairness, and offers success to all. This incident, although I did not recognize it at the time, would presage my teaching practice. It was a harbinger of my understanding of what worked for parents, caregivers, students, and myself. No, not the caning, which seems barbaric judged by today's standards, but treating that student-and, implicitly, every student-equally. This was the parent's desire, that institutions expect the same standards of, and respond in the same way to, all learners. Teachers' low expectations of some students because of their race, ethnicity, or background are a soft bigotry that has been allowed to persist.

When I decided, after two years, to move from the Bay of Plenty to Northland, a different tribal area, my students were horrified, and insinuated that the Ngā Puhi, the dominant Northland hapū (subgroup) there, were still cannibals: "You can't go up there, Miss! The Māoris up there still sharpen their teeth!" In short, fellowship did not extend among the 


\section{Sunderland $\mid$ Singing in Harmony}

subgroups of what appeared to an outsider to be a single, homogenous group. I have had similar experiences with every group of people I have come into contact with in New Zealand: diverse Pacific peoples who each identify with first their kin group and then with their village, island, or home country. Similar examples abound worldwide - the Dutch do much the same, from Frisians in the north to Brabantians in the south-and can be broken into even smaller groups by religion, language, and social affiliation.

In New Zealand, our founding document, Te Tiriti o Waitangi (The Treaty of Waitangi), sets out the rights and responsibilities of Indigenous and colonizing peoples and is recognized by the department of education. ${ }^{3}$ Ka Hikitia, the policy document that sets out the government-approved strategy for Māori education, states that "school leadership will consider the principles of Te Tiriti o Waitangi by building a sense of identity, actively protecting and preserving the Māori language and connecting the culture of the community and whānau to what is valued in each school." 4 As an eventually naturalized New Zealander, I agree that the rights of the Indigenous culture must be recognized and protected. However, as an educator, I would argue that these rights and protections should be given to all cultures in our society and, by extension, to all students in our schools.

The recognition of my students as individuals with unique experiences and needs has been the intention of my teaching practice; it enables all my students to succeed-as Māori, Pacifica, Pākehā, Asians, and, simply, as humans. Like any practice, it has been built on pedagogy and my personal experience as both a parent and as a person. I believe each student should receive the best practice I can offer. This begins with safety, security, and belonging. Most of my career has been spent teaching art to teenagers-not the easiest group to admire. Who among us would be a teenager again? The hormones, the physical and personal growth, the weight of societal and family expectations... The challenge of teaching them deserves respect, as any epic task does. Try to begin with respect, honoring the process your students are embarking upon; we can only guess at their lived realities. Sometimes it is hard to like, much less admire, our students, but we can always respect their journey. Young people's emotional sensors are fine-tuned and you cannot fake it; you have to work at it. Some teenagers are a greater challenge than others, but I endeavor to see them as individuals and show them regard. Begin this regard by learning to pronounce your students' names correctly. Let them teach you, let them laugh at your mistakes, and try harder next time. To do this you have to listen; listening is the beginning. My last name, Sunderland, is often not heard or listened to, so sometimes I am called "Sutherland," the more common surname. It can be annoying. I also know that if I do not correct the speaker's mistake, it is either because I don't value the speaker or it is a relationship I do not want to foster. Conversely, I show my students respect by allowing them to teach me about themselves; I show them respect and start to gain their respect so that I can teach them. I like to think of this as analogous to 


\section{Sunderland $\mid$ Singing in Harmony}

learning harmony; I "sing" in harmony to my student's "music" and the result is explicit inclusion.

Of course, long before I even meet them, I tacitly acknowledge my students by making the physical space of my classroom welcoming - as welcoming as it can be in a Eurocentric school environment. Objects and imagery from many cultures are on the walls and are part of the still lifes and functional objects that the students will draw or paint. For example, I have both plastic European brooms and those made from local organic materials that are used in many Pacific Islander homes.

I dress modestly, as a respected woman in most cultures would, and carry myself with pride and authority. I wear necklaces and other adornments from the cultures of my students. In my classroom, the speaking of other languages and the correct pronunciation of names of objects and places are fostered by example. I ask students to help me pronounce words correctly, and I encourage the rest of the class to also make an effort to get pronunciations correct, using my students' language skills as a valuable resource.

Art education in Aotearoa is a very teacher-led but student-centered process. The arts section of the New Zealand Curriculum provides a framework for arts educators to build their own individual programme based on their students' and the community's needs, as well as the faculty member's own teaching strengths. ${ }^{5}$ Students are expected to not only make art, but also to understand the art-making process and to understand artworks as social and historical texts. Unfortunately, this official document only suggests that artworks from all cultures - including Māori art from the past and present-may be included in art curricula. In other words, there is no edict requiring that an art-teaching programme must be more than a Eurocentric imagining of the world. This perception of art-making is no longer acceptable in the art world; to assume it is good teaching practice is folly.

I have always designed my art-teaching programme to include opportunities for all students to explore their own identities. One way I have done this is by developing units based on art-production methods that can be found across cultures. In this way, their individual cultures are included, but as part of a matrix of interconnected humanity. For example, for the Māori and other Pacific cultures, weaving is a very important part of the material culture. Hand-woven objects are highly valued, both aesthetically and spiritually. A teaching unit on weaving in Oceania can be extended to include forms from other cultures, such as Middle Eastern rugs, Swedish tablet weaving, and Filipino pina weaving. Contemporary and traditional practitioners can be found as role models and artistic examples. When I present a unit on weaving, I ask practicing weavers_including Alexis Neale, a contemporary Māori artist who combines weaving and printmaking - to come and demonstrate their art in my class. I have had grandmothers from the Cook Islands share their knowledge of rito weaving and Tongan mothers showing their kiekie. 


\section{Sunderland $\mid$ Singing in Harmony}

I also take my classes outside the classroom, to visit the Auckland War Memorial Museum, which has a large selection of tukutuku woven panels and whariki woven mats, plus an extensive collection of other Pacifica textiles. Other opportunities also exist: the Aucklandbased group The Pacifica Mamas is a collective of older women originally from Sāmoa, Tuvalu, Tonga, Tokelau, Kiribati, and other island nations who present their handcrafts and music to groups. ${ }^{6}$ The Te Whare Raranga traditional weaving school, part of the New Zealand Arts and Crafts Institute at the Te Puia cultural center in Rotorua, is another invaluable asset to teachers. The opportunities to include each student in experiential learning are endless and diverse, if teachers are willing to make that effort.

As a naturalized New Zealander, I felt my first loyalty must always be to the Māori culture, and I was always the second in command to the Māori teacher in charge of this mission. Having previously been a caterer, I was the ringa wera (cook) on school trips and made sure the students got nutritious Indigenous food. I have taught in boys' schools for the last twenty years, and we all know how important food is to teenage boys and how evocative it can be of memories of home. Māoritanga (Māori culture), as with most Polynesian cultures, has a strong tradition of hospitality or manaakitanga. I am ashamed to say my spoken Māori was never strong or confident, but there was always good food, and plenty of it.

Each school year in New Zealand begins with Polyfest, the largest cultural festival in the South Pacific, with over 10,000 students participating. Students practice their performances before and after school and on weekends, eager to share their pride in their culture. I participated fully in my school's Māori cultural group. I was often the kaikaranga, the first person the students saw on their first day of school, who called them onto the grounds to be welcomed into the school community. Since parents attend this welcoming event as well, they are able to see and recognize those teachers who fully participate in this welcoming ritual and those who hang back. In all the schools I have worked in, there was seldom support from the majority of staff for either the Māori or Pacific Island groups. Few teachers gave their time, especially for weekend camps or trips to cultural events. Experiencing a teacher who willingly participates in your culture strengthens ties between teachers and learners and between schools and Pacific Islander communities. In most schools in New Zealand, teachers are expected to take charge of a sports team either as a coach or as manager. Surely, this time given by teachers outside the classroom should have a broader scope than Eurocentric competition and include cultural and artistic activities as well.

In recent years, the Ministry of Education has recognized the value of these performances and students can now earn academic credits in both the performance and preparation aspects of their cultural performance group. Being the head of the Art Faculty meant that I had access to and the ability to produce much of the regalia needed for these performance groups. I was able to integrate the design and production processes into the student program and I endeavored to keep as much of the finished concepts in the students' 


\section{Sunderland $\mid$ Singing in Harmony}

ownership while keeping the other participants-parents, teachers, and school management-on board with the final outcomes. This was a real juggling act that often needed more finesse than I naturally possess. I did this for all of the groups in my school to the degree that was needed. This included organizing puipui flax skirts, silk-screening tapeka waistbands and lavalava wraps, and lending 'ie toga fine mats for students who didn't have their own. There was also the making of teki feather headdresses and then figuring how to attach them to a group of boys who had just newly shaved their heads so they would all match-and me with a pocket full of hair clips. All this work was important, but just as important was being there and being a positive and encouraging presence. Seeing the hard work, practice, and passion that goes into these performances, there is no way anyone could say these students are not prepared to strive for excellence.

The value to the students of learning in these experiential environments facilitates the assimilation of knowledge through the body and all the senses in a direct and unmediated way. Experiential education offers opportunities for ideological concepts to become realities. The next time you go to an art gallery, take along a reproduction of a work you plan to see, either on paper or on your phone. Compare this reproduction, no matter how good, with the actual piece in front of you; there is no comparison.

My knowledge is my koloa, my treasure. Sharing that treasure, and having students return that gift with their own gift of growing and learning, has been the keystone of my teaching: making each art lesson as real and meaningful as I can by enabling hands-on or inperson experiences such as inviting artists into my classroom and taking students out into the world to broaden their experiences. By sharing as much as I can, I hope to communicate the joy I find in learning and to empower my students to be lifelong learners and to see value in themselves and others.

What a wonderful resource we have in the children and families that still speak their mother tongue, who can tap into cultural traditions, and can make and explore an identity that is vibrant and alive. More and more young educators are bringing this richness to their teaching practice. I am proud to have been an agent for change and inclusiveness, but I am prouder to see a young generation of Pacifica and Māori, some of whom were my pupils, take up the challenge and help open up the sky for all children.

Laura Sunderland graduated from the University of California, San Francisco in 1977 with a bachelor of fine arts degree focusing on textiles and ceramics. Upon immigrating to New Zealand in 1979, she began teaching in secondary schools, retiring in 2019. She attended Auckland College of Education, receiving her diploma of teaching in 1986. She has served as chair of the Auckland Art Teachers Association and contributed to Ministry of Education curriculum development focusing on inclusion of Pacifica students. In 2019, she spent a term teaching in Pukapuka in the 


\section{Sunderland $\mid$ Singing in Harmony}

Northern Cook Islands. Today, she lives off the grid on Rakino Island in New Zealand's Hauraki Gulf.

\section{Notes}

${ }^{1}$ Abraham H. Maslow, “A Theory of Human Motivation," Psychological Review 50 (1943), 370396.

2 John Dewey, Art as Experience (New York: Tarcher Perigee, 2005), chapter 3; David Kolb, Experiential Learning: Experience as the Source of Learning and Development (Upper Saddle River, New Jersey: Prentice Hall, 1985), 197-234.

3 "Treaty of Waitangi" (website), last modified May 14, 2012, http://www.treatyofwaitangi.maori.nz.

${ }^{4}$ New Zealand Ministry of Education (Te Hāhuhu o te Mātauranga), Ka Hikitia - Ka Hāpaitia: The Māori Teaching Strategy (Wellington: Learning Media Limited, 2000), 5-8.

${ }^{5}$ New Zealand Ministry of Education (Te Hāhuhu o te Mātauranga), The Arts in the New Zealand Curriculum (Wellington: Learning Media Limited, 2000), 1-12.

${ }^{6}$ For more information on the Pacifica Mamas, see "Who We Are: The Pacifica Mamas," Pacifica Arts Centre, https://www.pacificaarts.org/who-we-are/the-pacifica-mamas/ (accessed Sept. 16, 2021). 


\title{
ELA TO`OMAGA KAIKILEKOFE Learning to Surf (Se'e) on a Wave, from Island to Urbanesia
}

\begin{abstract}
This paper looks at the role of artists and art instruction in New Caledonia, with particular emphasis on workshops used to teach traditional arts in a contemporary Pacific context. It articulates realistic insight into the life of Pacific artists and their work as and with tagata fenua (the Kanaky people of New Caledonia) and Polynesian participants from Uvea, Futuna, Tahiti, and other islands. Workshops at the Siapo Art Centre are designed to find ways to adapt the cultural environment to urban situations with the support of local associations, the government, and social agencies in order to develop long term initiatives. By focusing on the Kupesi Contemporary Artist in Residence program at the University of New Caledonia-Higher School of Teaching and Education (École Supérieure du Professorat et de l'Éducation, UNC ESPE) center, as well as other projects, this essay provides a window into the role of public art education in the Pacific.
\end{abstract}

Keywords: New Caledonia, siapo, arts organizations, contemporary Pacific art education and lifestyles, art, education

URBANESIA: a reference to an urban city lifestyle

URBANESIA: the many islands of Polynesia, Melanesia, and Micronesia

Creatively speaking, my day starts out like a normal day, surfing against the winds and the currents under the Pacific sun. As with surfing, I enjoy catching a ride on a huge wave in my art education practice - a huge wave of fresh thoughts, spontanous ideas influenced by our Polynesian environment and way of life. Eventually, as a project develops over time and with community support, these ideas manifest to become art-based events and/or play an integral role in community happenings. It is for this reason that I introduce teaching experiences in the context of contemporary art-making in the Pacific Islands. I will focus on a visual arts program I participated in to provide a closer look at the teaching of art by two Polynesian contemporary artists in Nouméa, the largest city and Kanak capital of New Caledonia.

For this particular program at the University of New Caledonia (UNC) teaching center, Patrice Kaikilekofe ${ }^{1}$ and I collaborate to share ideas, individual skills unique to our lifestyles, and artistic teaching capacities; we highlight cultural aspects of traditional carving, Polynesian 


\section{To'omaga Kaikilekofe | Learning to Surf}

tapa (barkcloth), and contemporary printmaking techniques, as well as acknowledge our creative part in the renaissance of tapa and its modern interpretations today. ${ }^{2}$ Using contemporary materials such as wire, paper, commercial textiles, and acrylic paint in our education programs, we provide a deeper sense of Pacific art in today's modern society for our students (Fig. 1). We utilize historical artistic developments from artists who are influencing a younger urban generation, such as world-renowned, New Zealand-born, Sāmoan Hip-hop choreographer Parris Goebel. We also introduce new, hybrid art practices into creative industries, such as those of Tongan master carver and visual artist Sopolemalama Filipe Tohi.

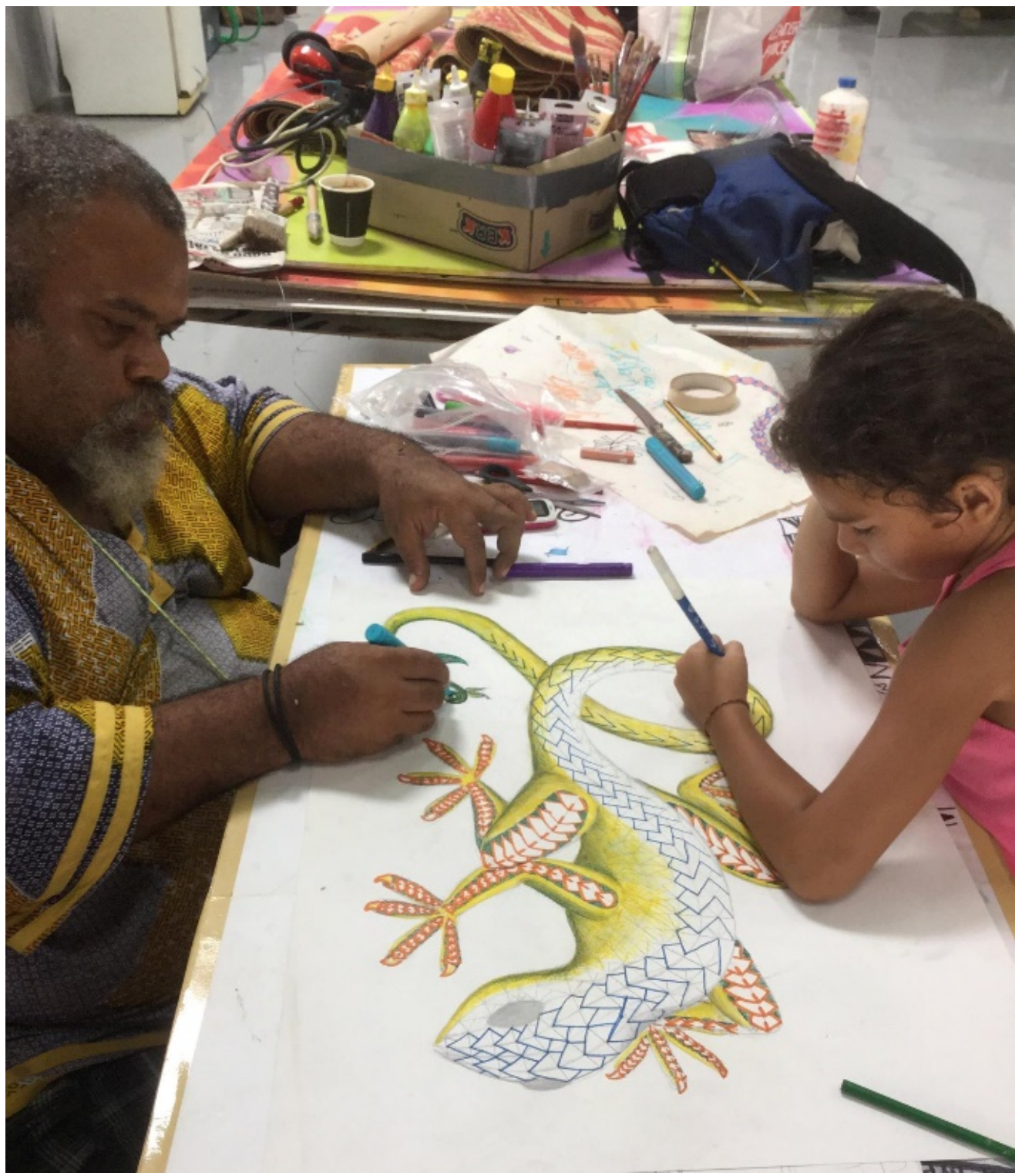

Figure 1. Jean-Philippe Tjibaou (Kanak artist from Hienghen) drawing with a young participant, at "Elevation Day," Hip-Hop Artist in Residence Program, Siapo Art Centre, Païta, New Caledonia, 2016. Photograph by the author. Courtesy of Siapo Art Centre 


\section{To“omaga Kaikilekofe | Learning to Surf}

It is vital for us as active artists to stay true to who we really are when we engage in education and teaching, so we can bring positive change to misinformation about contemporary Polynesia, Melanesia, and Micronesia. The history of colonialism in the Pacific Islands is relevant and part of what is happening to us; those stories play out in our art today. Sometimes art education may seem superficial, but for me it is vital for our well-being, from all sides of the spectrum. Exercising our capabilities academically to maintain in-depth discussion and critical community development allows us to be more open and visible, and we can find ways to creatively surf ... meaning, to learn to speak openly and express ourselves.

Challenging misinformation about Polynesia that is often conveyed in schools, we strive to encourage more positive and constructive attitudes about and usage of contemporary art practices. Due to the remnants of colonialism, as well as restrictive attitudes here in New Caledonia, education about our Pacific culture is superficial. Thus, the capacity or academic leverage to maintain in-depth discussion and critical development is lacking. Therefore, as practicing artists, we work towards endorsing an open approach to teaching and, in doing so, changing our traditional and contemporary knowledge of art, culture, and society. We also take a more naturalistic approach towards agriculture, through both sustainable and eco-friendly means based on our centuries-old Polynesian way of life. In our workshops, we use both traditional and urban forms of Oceanic languages, which is a continuous linguistic interaction. We recognize words and sounds that echo from island to island, as they sustain our verbal communications. This is the kind of dialogue that stimulates daily conversations as descendants of the greatest navigators of the Pacific Ocean. This is music to our ears, mingling and reconnecting us as Oceanic people. It also triggers the power for Moana cultures to evolve, reviving Polynesian art history and practices as we strive to remove the stigma concerning our traditional cultures that is perpetuated through the current, oldfashioned educational system. I encourage and support a more positive and realistic perspective to preparing teaching methods and materials. Thus, the focus of creativity is centered in and around contemporary Pacific art history. Being part of community-based art projects is vital; it enables us to support and encourage traditional and contemporary Pacific artists to teach in educational environments, and to advocate this approach as a mandatory practice (Fig. 2).

Experiencing general aspects of village life and family knowledge brings out diverse perspectives. Such endeavors are assets to shaping and forming ideas for artistic compositions. How we associate and identify with a mountain, petroglyph, or a wooden sculpture brings significant meaning to humanity. Colonization in the present has helped us to forget who we are, and the forces of urbanism have brought the earth down to her knees. For ex- 


\section{To'omaga Kaikilekofe | Learning to Surf}

ample, we draw on traditional cultural references when teaching about how plants and vegetables relate to health and wellbeing. The impact of native trees, carving a canoe, one's family identity, and inherited symbolism connect us to certain animals and to the sea; all these are relevant to cultural knowledge and personal wellbeing. References to the natural environment of the Pacific region, our connection to the land of our ancestors, and comprehension of Indigenous knowledge are key to and incorporated in our teaching process. These include educational, mathematical, navigational, and spiritual, as well as scientific information and research. These elements are sustainable enough to build a strong, supportive, healthy community deeply rooted in Polynesian culture.

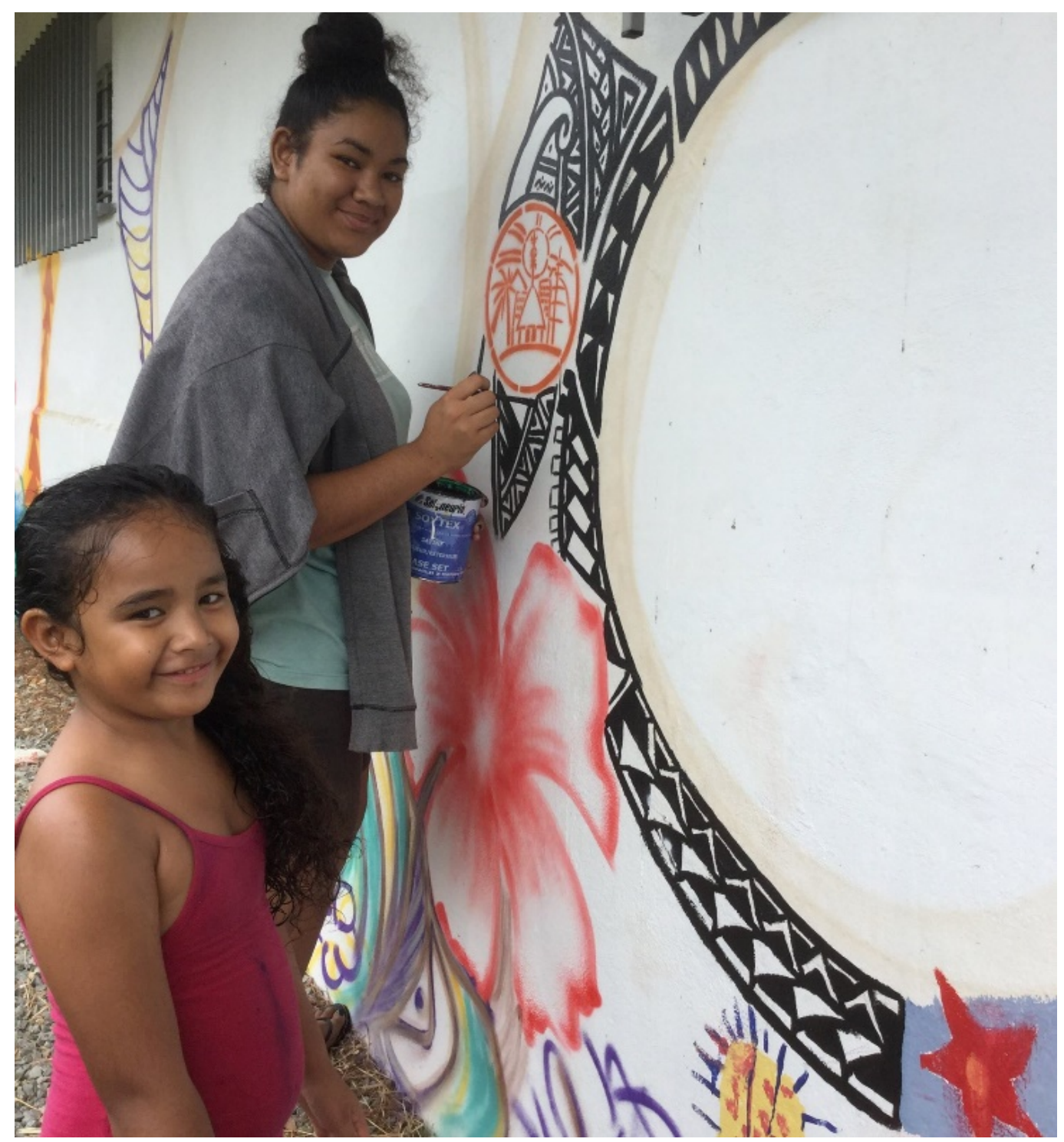

Figure 2. Mural workshop participants at "Elevation Day," Hip-Hop Artist in Residence program with SELEKA artists from Tonga, Tavita Latu, and Taniela Petelo, Siapo Art Centre, Païta, New Caledonia, 2017. Photograph by the author. Couresty of Siapo Art Centre 


\section{To'omaga Kaikilekofe | Learning to Surf}

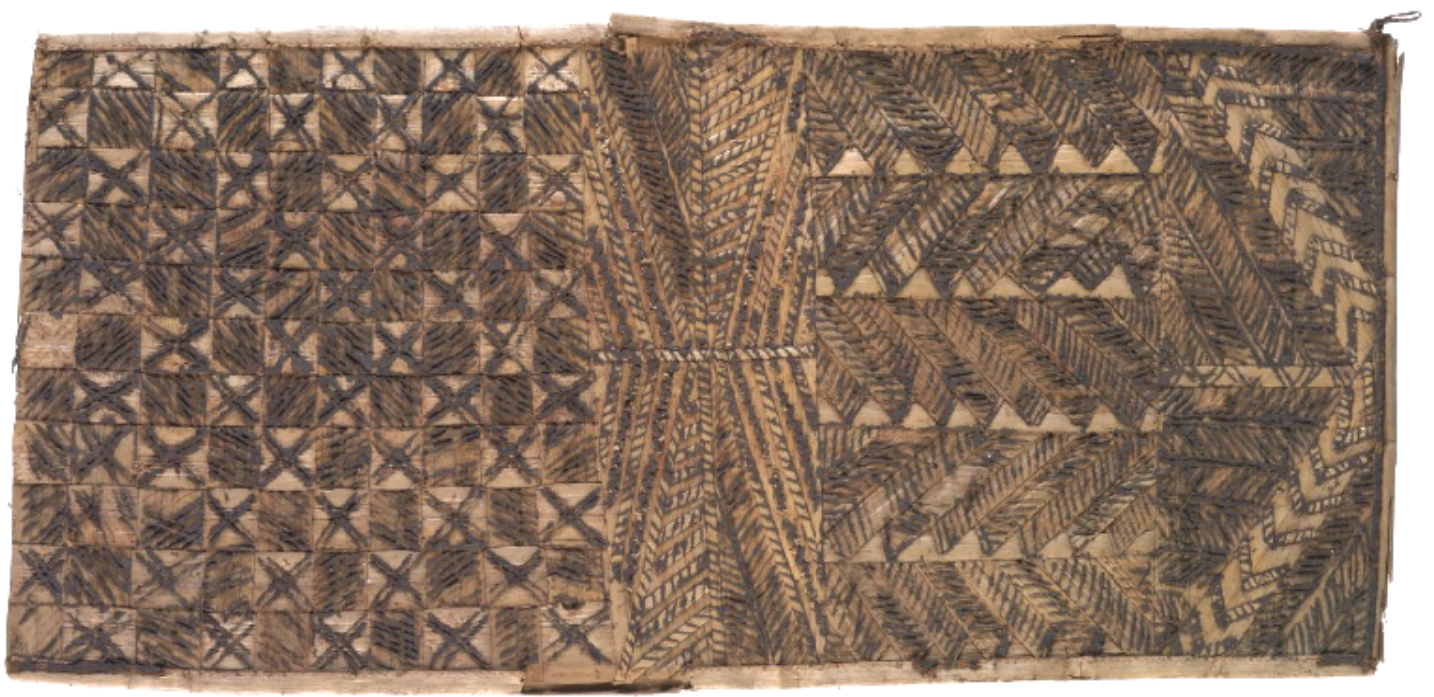

Figure 3. 'Upeti fala (tapa pattern board), Sāmoa, maker unknown. Purchased 1916. Pandanus, 965 x 490 mm. Courtesy of Museum of New Zealand Te Papa Tongarewa (FEo01129; CC BY-NC-ND 4.0)

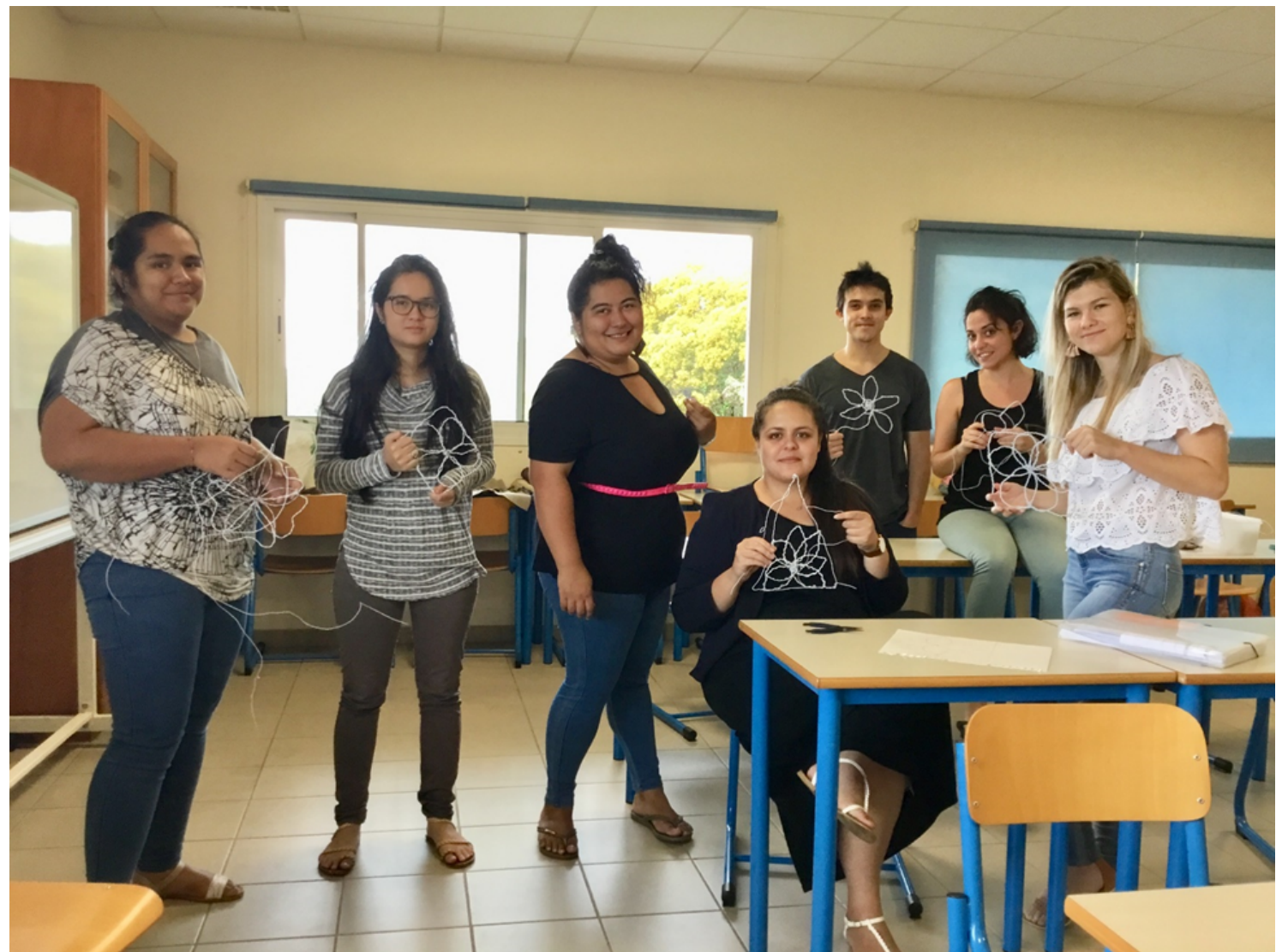

Figure 4. Students making contemporary kupesi using wire coiling techniques as part of an in-house graduate teachers training school, Higher School of Teaching and Education (ESPE), University of New Caledonia (UNC), June 2019. Photograph by the author. Courtesy of Siapo Art Centre 


\section{To‘omaga Kaikilekofe | Learning to Surf}

The Siapo Art Centre has been a community arts organization for the last five years. It has come a long way since its inception as a local Indigenous Pacific entity and community arts hub that functions independently. The word siapo, Sāmoan for tapa or barkcloth, is a reference to the specific fibers on each of our Pacific islands that we use for traditional or contemporary forms of tapa-making. Thus, the word represents our shared Indigenous cultural heritage and identity. As director of the Siapo Art Centre, Patrice Kaikilekofe is a key facilitator of community art programs, engaging with local youth who fall between the gaps of the educational system in and around the region. The Centre organizes visual art exhibitions, art, music and dance workshops, along with sports and cultural events. ${ }^{3}$

In 2019, the Centre initiated the Kupesi Contemporary Artist in Residence program, a three-week workshop at the University of New Caledonia. In the program we focused on the teaching of two traditional tapa impression techniques, but applied to paper instead of barkcloth. One technique we taught, kupesi, is based on the wood-carving methods from the island of Uvea (Wallis Island). The other technique was inspired by traditional tapa motifs and patterns in Tonga and Sāmoa where designs made from coconut fiber cord, bamboo strips, pandanus leaves, and coconut midribs are sewn onto pandanus leaves to create an 'upeti fala (Fig. 3). To create the designs, a piece of cloth is placed over the relief pattern and wiped with pigment. The pattern of the underlying matrix comes through in much the same way as when one does a pencil rubbing of a coin. In the workshop, modern materials were used to form the individual motifs, inspired from traditional island basket-making and upeti (Fig. 4).

As each day of the workshop passed and the weeks progressed, a high percentage of the students developed a strong grasp of the skills of a craftsperson as they created designs using animals, insects, and objects (Figs. 5-6). The students had a strong, innate sense of cultural symbolism, seen in their use of forms and objects from their Pacific heritage and religious beliefs, including traditional tatau (tattoo) symbols and patterns (Figs. 7-8). Their motifs were very descriptive interpretations of their culture and identity. These are some of the visual ideas and identity traits that we see in Nouméa today. These are the expressions of art in which students and community members find the comfort and confidence to strengthen our cultural well-being. It is the students' desire to know and experience more, that curious nature, that drives them to learn about traditional and contemporary art practices in the Pacific Islands. Art-making is also a positive exercise for us to acknowledge and respect each other culturally, as a diverse society, in New Caledonia and the Pacific region in general. 

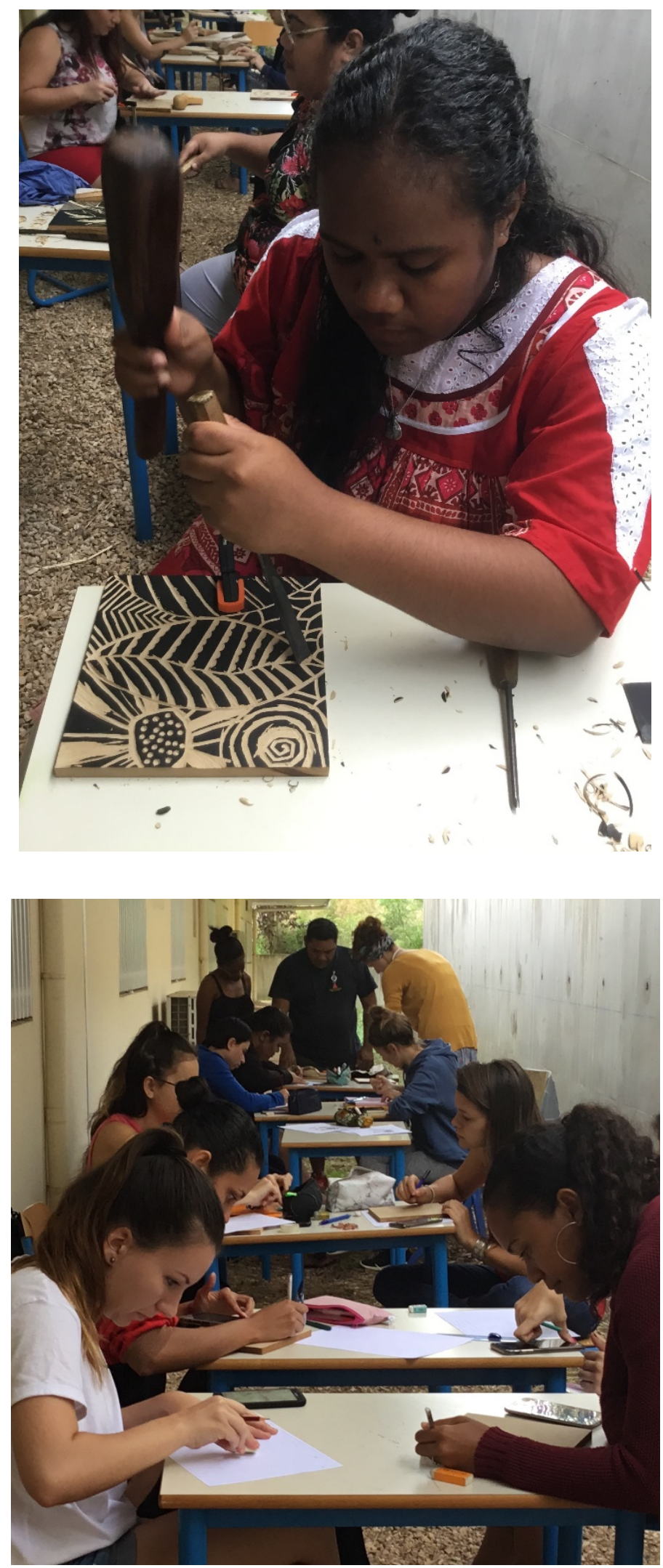

Figure 5 (top) and Figure 6 (bottom). Students in a kupesi woodblock carving and printing workshop led by Patrice Kaikilekofe (standing in the back), UNC campus ESPE site, 2019. Courtesy of Siapo Art Centre 

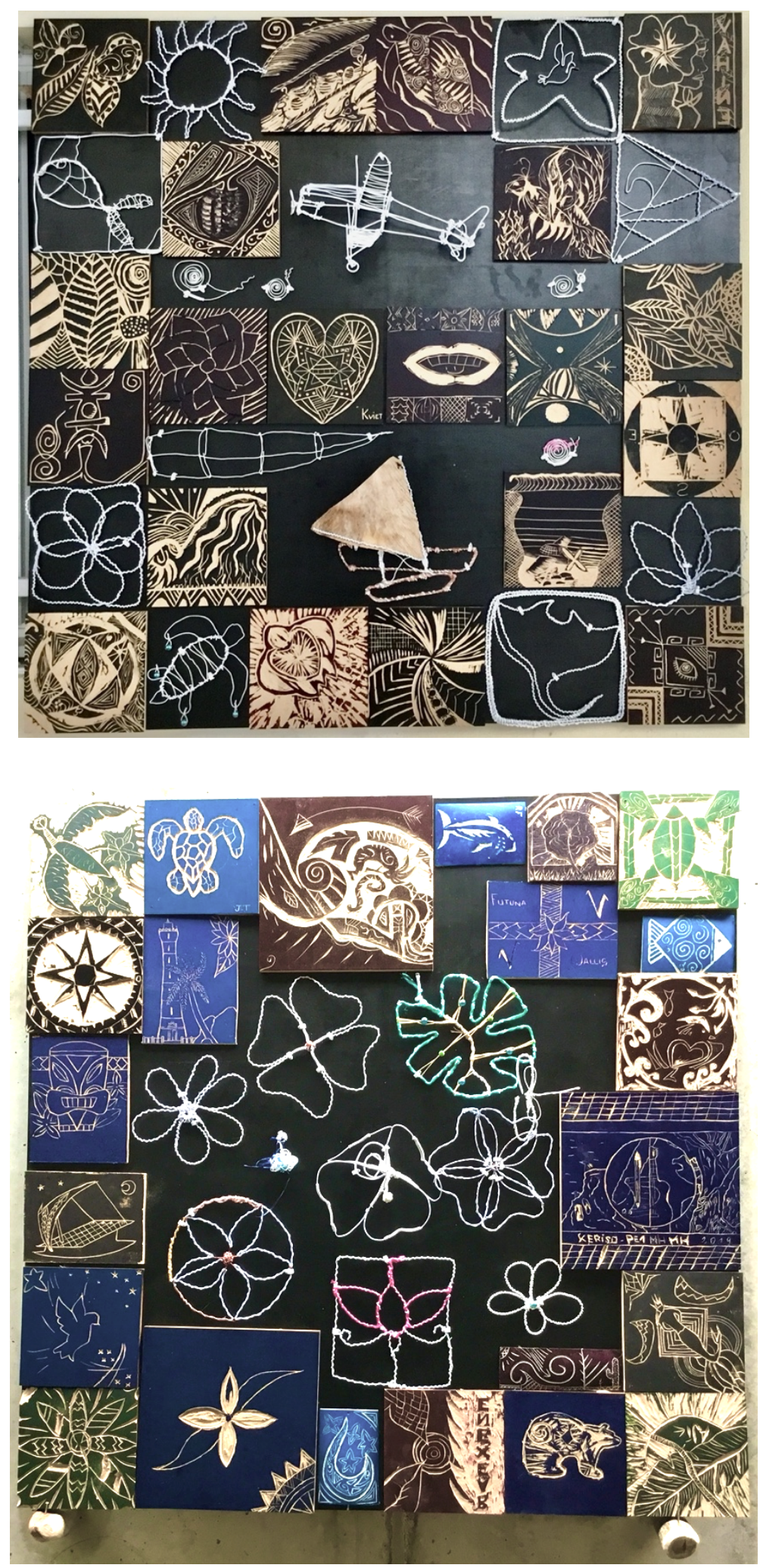

Figure 7 (top). Navigation, 2019. Figure 8 (bottom). Tapa, Kupesi Pacifique, 2019. Collaborative student work using wire, plastic raffia, pearls, feathers, coconut tree bark, ink, and machine- and hand-pressed woodblock prints, $122 \times 61 \mathrm{~cm}$ each. Contemporary 3D tapa art composition workshops led by Ela To'omaga and Patrice Kaikilekofe, UNC campus ESPE site. Courtesy of Siapo Art Centre 


\section{To'omaga Kaikilekofe | Learning to Surf}

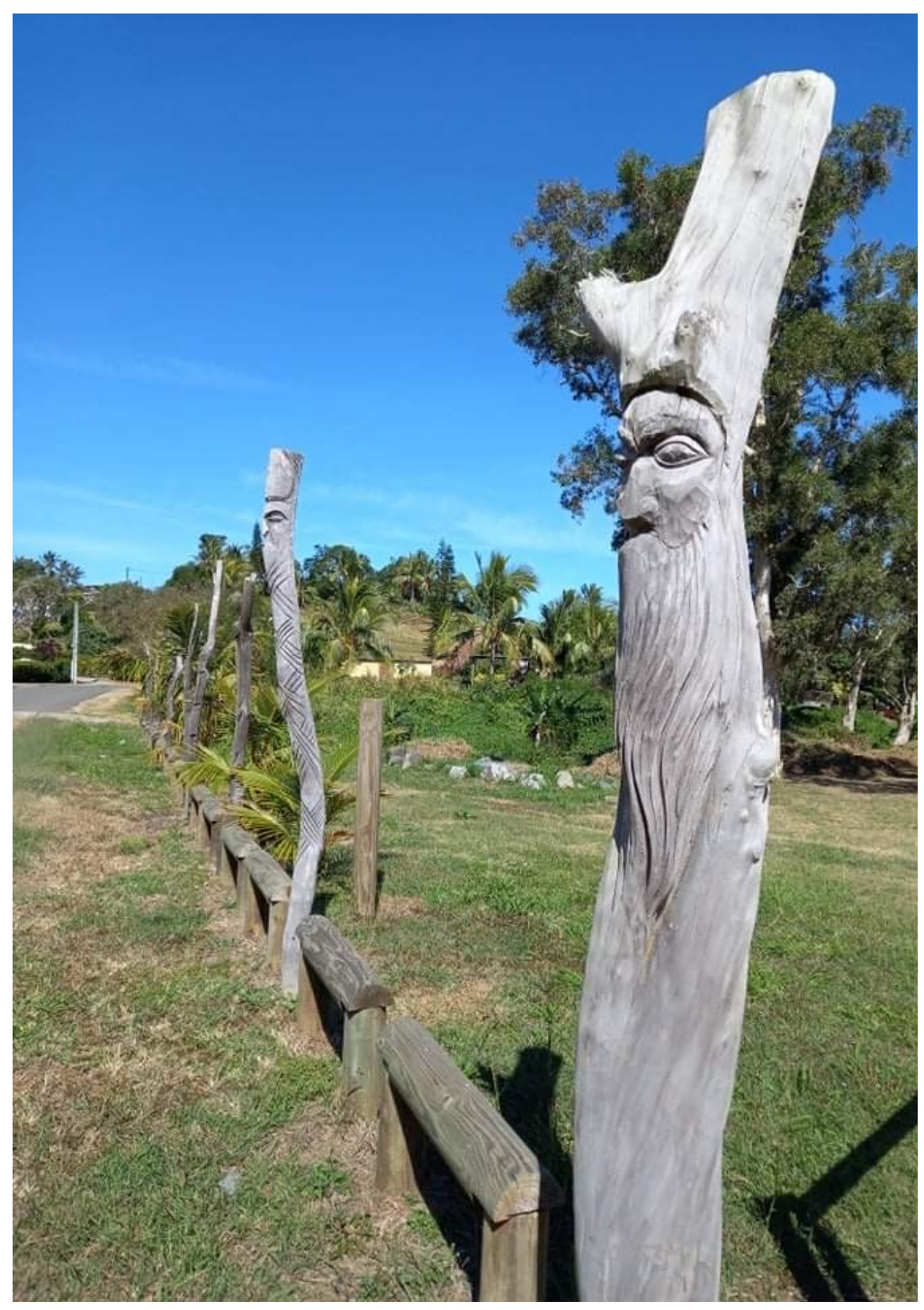

Figure 9. Sculpture works by artists Steeve Pwere Kwido, Basil Sionepoe, and local youth from the region

Details on carvings: Kanak ancestry

Siapo Art Centre, Maison des hautsdu-musée, Païta, New Caledonia, August 31, 2021. Photograph by Siapo Pacific Arts correspondent Ela To'omaga Kaikilekofe

Community Acknowledgments: Thierry Koindredi, Nenukwa Kanak representative, Païta The Païta City Council Mark Richer, The Dock, Païta Association Siapo, New Caledonia

Today at the Siapo Art Centre, there are newly installed carvings-made with the help of local youth - that greet the public at the gate (Fig. 9). Planted alongside them is vegetation, such as Araucaria conifers, yams, taros, bananas, and sweet potatoes, which introduces visitors to the Kanak people, their way of life, and the history of the local community. The cultivation of traditional Kanak plants and flowers on the Centre's grounds has been made possible under the direction of local visual artist Steeve Pwere Kwido, a Kanak traditional carver and contemporary visual artist from the Uindo/COO Tribe of Thio. The plant cultivation program includes a wide variety of plants, some of which are used even today for the purposes of healing and protection. The garden also thrives with the support of the wider community donating plants and trees, adding to a bounty of fresh island fruit and a range of delightful 
vegetables. These are all planted for people to enjoy and to sustain our community by allowing people to harvest food if they are in need. Our plans for the near future are to plant flowers for cultural adornment purposes and a variety of trees and plants that can be used in traditional tapa-making.

Since 2015, the Siapo Art Centre has been part of Quinzaine du Hip Hop (Hip-Hop Fortnight), a community youth program that sponsors events highlighting urban culture throughout the country. Every April there is always a sense of innovation, motivation, and the drive to go forth as artists, administrators as the community begins collaborating in preparation for the annual program (Fig. 10). These events and happenings have matured and evolved each year, promoting interconnected community and a growing society in New Caledonia.

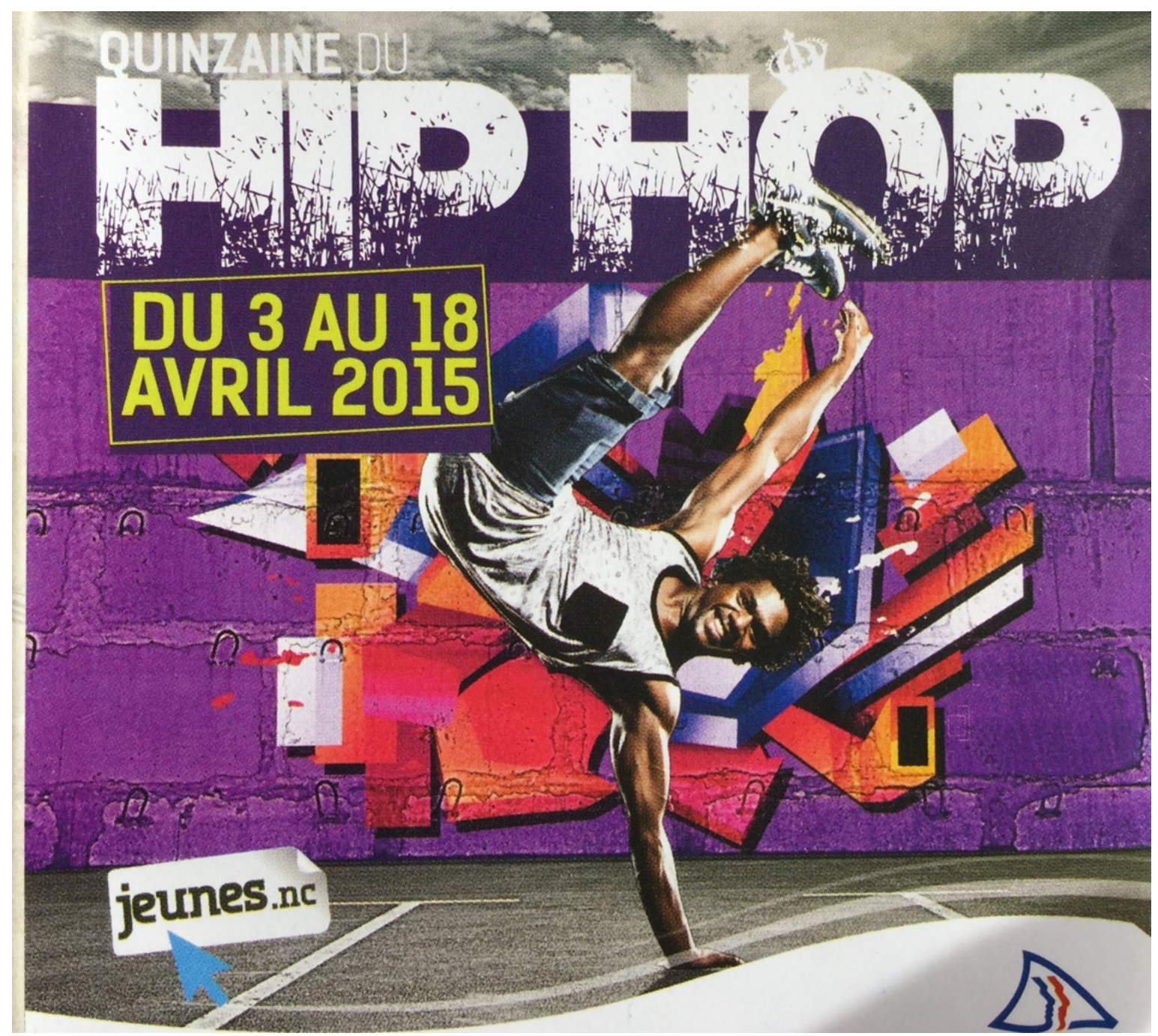

Figure 10. Poster for Quinzaine du Hip Hop (A Fortnight of Hip-Hop), 2015. The event was part of the "Elevation Day" Siapo Art Centre Hip-Hop Artist in Residence program. Courtesy of QHH Southern Province, New Caledonia 


\section{To'omaga Kaikilekofe | Learning to Surf}

Upon reflection, I have gotten an immense sense of fulfillment contributing to siapo projects in my role as a Pacific arts regional liaison in New Caledonia. In this capacity, I support contemporary arts and cultural exchanges, connecting Indigenous people to specific island events and community groups. I also network and engage in artistic dialogue with territories of English, French, and Indigenous Polynesian cultures within New Caledonia, Uvea, and Futuna, exchanging links with English speakers throughout Polynesia by connecting with artists in Aotearoa New Zealand, Sāmoa, Tonga, Vanuatu, Futuna, Wallis, and Australia. Regional arts gatherings in the village or inner city provide us with opportunities to contribute what we know is essential in life, because such events are positive and generally get an open community response. Actively participating in art education helps to maintain cultural wellbeing; it brings Urbanesia into focus, through our connectedness to contemporary Pacific art practices. Another source of information is on the other side of the world-in Paris, France. SiapoParis works towards bringing Pacific communities together to share knowledge in supportive environments in and around Europe. ${ }^{4}$

Thus, if we can learn to catch creative waves.

Then we can creatively surf on ideas,

That can be heard in our music,

And seen in our contemporary visual art.

These designs can be read in our poetry

And listened to in our creative writing

In-between beats we can chant and dance,

As we celebrate together

As Tagata Fenua (people of the land).

— Ela To'omaga Kaikilekofe (2020)

Ela To'omaga Kaikilekofe is Sämoan from Falelatai Siufaga and Safa'atoa Lefaga. She was born in Aotearoa New Zealand and raised Sämoan. She received a certificate in craft art and design from Whitireia Community Polytechnic (currently known as Whitireia New Zealand). In 1995 she was commissioned by the Museum of New Zealand Te Papa Tongarewa to create a piece of body adornment made of copper wire that was exhibited in conjunction with Shigeyuki Kihara's Teuanoa' $i$ - Adorn to Excess exhibition (1999). In 2001, she moved to Nouméa, New Caledonia, where she works as a full-time creative. She received the Creative New Zealand Pasifika Arts Special Recognition Award in 2014 and was commissioned to create a sculpture titled Journey de la femmes to commemorate International Women's Day for Secrétiat de la Communaute du Pacifique, Ans Vata, Nouméa Nouvelle Caledonie in 2004. She is a founding member of the Siapo Art Centre. 


\section{To'omaga Kaikilekofe | Learning to Surf}

\section{Notes}

${ }^{1}$ As an artist, Patrice Kaikilekofe specializes in woodblock printing and papermaking. He was a participant in the exhibition Islands in the Sun: Prints by Indigenous Artists from Australia and the Australasian Region, National Gallery of Australia, 2001. Catalog edited by Roger Butler.

${ }^{2}$ The ESPE Higher School of Teaching and Education of the University of New Caledonia is dedicated to the training and support of future teachers in the professional world.

${ }^{3}$ The Siapo Association celebrated 20 years in 2019. The organization has an art center located in the small town of Païta, which has been active for the last five years. Thus, it was very sad to learn of the passing in May 2021 of Marc Richer, the Director of "The Dock," Païta's social and cultural center. We respectfully acknowledge him as a colleague of community arts initiatives and also as a dear friend to the many who worked with him. He was influential in the development of community art projects and initiatives, and a great driving force for the Siapo Art Centre in Païta. We are truly grateful for, and will always remember, his contributions to keeping the sustainable development of our art and society in the highest of esteem.

${ }^{4}$ Siapo-Paris correspondent Raphael Kaikilekofe has been leading community initiatives that support Pacific Island culture and contemporary visual arts. He is also a founding member and advocate of the Federation of Wallis and Futuna Associations in France. 


\title{
ANNE E. GUERNSEY ALLEN Who Speaks for Sāmoa? Some Reflections by a Pālagi Teacher of Pacific Art and Culture in the American Midwest
}

\begin{abstract}
This paper considers some of the pitfalls related to and practical considerations for teaching courses that address cultures to which the instructor does not belong. The primary focus, however, is on ethical matters that may arise in any university classroom, particularly in relation to the exhibition of art. Who, if anyone, has to right to speak for others and why do students assume it is the instructor? Whose voices or narratives are to be included? Who becomes the arbiter of authenticity in these cases? How do we counter stereotypes that arise when only a partial and filtered view of a culture can be presented?
\end{abstract}

Keywords: culture, ethics, teaching, art, education, authenticity, stereotypes

Several years ago, a student in my survey class on the arts of Africa, Oceania, and the New World wrote an extensive essay calling me an "academic vampire" who "sucked the life blood from the astonishing, spiritual cultures" we had covered in class. Knowing that he embraced the writings of Carlos Castaneda and saw Indigenous cultures as somehow purer than his own, I didn't worry much about the rhetoric. I did lament that my attempt to present the peoples of the Pacific, Africa, and Native America as real people - rather than as Euro-American romanticized fabrications - to my students, who are primarily Euro-Americans with very limited interactions with other cultural and ethnic communities, had failed. I have since come to realize that this student had at least one valid point in that I, as a pälagi (a Euro-American, or nonSāmoan), do make a living from the presentation of the art of peoples, cultures, and times that I will never encounter or for whom I am, at best, a visitor. I have spent much of my adult life studying the art of the various cultures of the Pacific region, especially Sāmoa. I see my primary role as a teacher: in presentations, publications, and especially in the classroom. It is in the latter that I can do much good, but also much harm. James Clifford asks, "Who has the authority to speak for a group's identity or authenticity?"1 He is concerned with what happens to objects and their contextual "practices once they are re-located in Western museums, ex- 


\section{Allen | Who Speaks for Sāmoa?}

change systems, disciplinary archives, and discursive traditions." ${ }^{2}$ However, he does not directly consider at least one particular area of Western discourse: the university classroom. This is where my love of the Pacific was born, in a course taught at the University of California, San Diego, by Jehanne Teilhet-Fisk. In addition, it is in introductory courses on art or anthropology where many Euro-American students have their only contact with this region's arts and cultures. So, the answer to the question I pose in my title, "Who speaks for Sāmoa?", is simple: in my classroom -in southern Indiana, for a group of undergraduate students who have generally never met a Pacific Islander and sometimes cannot even find Hawai' $\mathrm{i}$, much less Sàmoa, on a map—the answer is "I do." However, that response brings with it a myriad of practical and ethical dilemmas.

Teaching multiple worldviews to an often mono-worldview audience has several concrete challenges. One is that art history lecture topics are driven by what images are available; the accessibility of particular images is often the deciding factor. Another is that all Oceanic artworks - whether latmul men's houses, Sāmoan fale, Abelam bisj poles, or the Digital Marae of Lisa Reihana_are seen as having the same scale, either within a five-by-six-foot rectangular projection in the classroom or on a computer screen in my online courses. In addition, the context of movement and sound, so vital to so much Pacific art, is often missing. Even with videos, the full sensory experience of being there cannot be truly duplicated.

There is also the lack of basic geographic and cultural knowledge among the students. With this deficit comes the need to simplify and limit the material being presented. The work of philosopher Paul Ricoeur, as applied by Clifford Geertz, puts forward that a culture is always understood obliquely based on selected parts put into context. ${ }^{3}$ Ethnography and its sisterfield, art history, are thus processes not of explanation, but of interpretation. Michael Baxandall makes a similar case for museum labels as analysis. ${ }^{4}$ Unfortunately, this process of selection can bolster preconceptions of the primitive and the exotic. Such glossing promotes impressions of uniformity within and between cultures, thus seeming to endorse stereotyping as a way of thinking - a paradigm that my courses, at their core, try to combat. When students are asked mid-semester to pick a culture and a specific art form for their research paper, I still get "Polynesian tattoo" from some, even though the first three weeks of the twelve-week course have covered several Polynesian cultures individually. In their minds, Polynesia is a homogenous region, not an umbrella-designation that covers many distinct cultures.

A more troubling result is seen in subject-matter assessment data. At the beginning of each course, I present students with a worksheet made up of a number of statements with which they are to either strongly agree, agree, disagree, strongly disagree, or say that they have no position. Many of the statements are related to factual information about Pacific cultures and history, while some are common stereotypes, such as "Polynesian cultures (like Tahiti) practiced promiscuous sex" and "Most people in the Pacific did not have to work hard to 


\section{Allen | Who Speaks for Sāmoa?}

feed themselves." The students answer the same questionnaire again at the end of the semester, and most disagree more frequently or more strongly with the stereotyping statements. Yet, disconcertingly, a small number of students who initially agreed with the incorrect stereotypes "strongly agree" with them at the end of the course. Rather than having their stereotypes countered, their ideas were reinforced, possibly because the new concept threatened their sense of self in some way and they struggled with understanding that learning about the worldviews of others is not an attack on their own.

An additional concern is how one balances the destructive results of colonialism with an acknowledgment of the ongoing inventiveness of living cultures; how does a teacher communicate historical injustice without denying human agency? Clifford recognizes these as two "meta-narratives: one of homogenization, the other of emergence: one of loss, the other of invention." He uses the term "inventive syncretism," a concept that parallels the idea of "pragmatic creativity" developed by Heather Young-Leslie and Ping-Ann Addo in their edited volume on the role of cloth in Pacific cultures. ${ }^{6}$ In discussions of Pacific Islanders as active agents, creatively responding to and transforming outside influences and materials, my students struggle with whether Aboriginal Australian dot-painted tennis shoes, Ani O'Neill's soft sculptures of Tangaroa, and the fashion activism of the Pacific Sisters are true Oceanic art. Modern invention has too often become conceptually linked in students' minds with the loss of culture and thus is viewed as inauthentic.

I consider most of these issues practical matters, for they can be mitigated through adjusting the teaching process or classroom discussion. That is not to say that these problems are easy to solve or unimportant. However, in general, they do not call into question the very endeavor of trying to present a culture to which one does not personally belong. In this regard, Clifford identifies three problematic areas, among others: authority, voice, and authenticity. ${ }^{7}$ These areas are effectively interrelated within the context of a university undergraduate class in Pacific art and are impacted by the impression in students' minds that the professor is an omniscient expert.

Several factors lead to perceptions of the professor as a purveyor of truth and authenticity. One is the disparity in education between student and teacher. Students are often shocked to find out that, in total, I have spent twenty-seven years in school. Another is the power dynamic inherent in the classroom. Regardless of my outside interactions with students, the existence of a singular dedicated space for teaching - the classroom-positions me as the ultimate authority. The liminal doorway marks a transition to a formal spatial milieu. My location at the front of the room becomes a signification of my power. Even in an online course, I am the "man behind the curtain," the sovereign perceived, if not always seen. After all, I control their grades. I am not arguing here that there is no, or should be no, real difference between professor and student, but rather I am concerned with this dichotomy vis-à-vis 


\section{Allen | Who Speaks for Sāmoa?}

the right to speak for others. The perceived sanction to represent Indigenous cultures is further reinforced by my status as an author who has published works on Oceanic, Native American, and Mesoamerican art. Consequently, my position of authority is predicated on European-based values, not necessarily on those of the peoples under consideration. Yet I am seen to speak for them.

In the case of Sāmoa and other Pacific cultures, my status as expert is also strongly based on the influence that comes from direct experience. I have seen in person most of the artworks I present in class. More importantly, I conduct fieldwork in Sāmoa. This alone is a source of amazement for some of my students, for whom the fifteen-minute trip from campus to downtown Louisville, Kentucky, is a venture into the frighteningly exotic. Clifford sees fieldwork as "an unusually sensitive method" of cultural study. Although what he calls the "crises of authority" in ethnography has been dissected and debated in academia for many years, the reality in the classroom is too often one of perceived absolutes and a guarantee of authenticity. My apparent ability to "speak for Sāmoa" carries over into my role as interpreter of the works of other scholars. As Clifford reminds us, "ethnography is, from beginning to end, enmeshed in writing. The writing includes, minimally, a translation of experience into textual form." 8 These tomes are then re-translated by the instructor for presentation in the classroom. Thus, the students' experience of Pacific art and culture is filtered through multiple levels of mediation: the ethnographers, their writings, and the instructor's interpretation of those texts. All of these seem to "speak for" or represent a culture that is in absentia.

Linked closely to the question of authority is the issue of voice: whose stories should be told and who is actually speaking? In considering museum practices, Steven Lavine asks, "Whose voice is heard when a curator works through an established genre of exhibition? ... Can an exhibition contain more than one voice, or can a voice exhibit more than one message?" 9 The same questions can be posed concerning the teaching process. A primary challenge is to make room for diverse voices while not privileging one over another. Although the dominant history (in general, that of Euro-American colonialist powers) has often laid "claim

to completeness and universality," that view is no longer acceptable. ${ }^{10}$ There are many histories, local and global, with their own narratives.

Mikhail Bakhtin has pointed out that "language is not an abstract system of normative forms but rather a concrete heteroglot conception of the world. All words have the 'taste' of a profession, a genre, a tendency, a party, a particular work, a particular person, a generation, an age group, the day and hour." language used to reinforce dominant social groups and their views-the structure typically found in a university classroom, intended or not. In contrast, "heteroglossia" refers to the variability of voices and language present at the micro-level. ${ }^{12}$ Thus, languages are never neutral but ideologically positioned and express a myriad of worldviews. Yet, the typical American undergraduate often insists on a single concrete explanation. They are most at home with 
Christian iconography where a one-to-one meaning for a symbol can sometimes be provided. However, ethnographic writing and classroom presentations should never be viewed as neutral, authoritative statements. Yet, they are too often taken as such. The situation worsens when another stratum of authority is layered on, as the teacher becomes both translator and author and, thus, the arbiter of authenticity. I curate the "exhibition" of my lectures in my choice of what art and information to present and then provide the translation.

Ivan Karp has noted that scholars tend to view art exhibitions in one of two ways: as "a vehicle for the display of objects or a space for telling a story." "13 One of my colleagues in psychology has categorized me as a raconteur of tales. I regard art exhibitions, classroom presentations, and the discipline of history itself as forms of storytelling. Just as in Elaine Gurian's view, in which "the production of an exhibition is more akin to the production of a theater piece than any other form," teaching is also theater. ${ }^{14}$ Such an approach leads to another challenge: to make clear the limitations of this process as I am the editor, interpreter, and performer of these narratives.

Clifford's contention that "it is more than ever crucial for different peoples to form complex, concrete images of one another...; but no sovereign scientific method or ethical stance can guarantee the truth of such images" is at the heart of what I try to do. ${ }^{15}$ So where to begin? Susan Vogel's remarks concerning exhibitions give us a start:

The fact that museums re-contextualize and interpret objects is a given, requiring no apologies. They should, however, be self-aware and open about the degree of subjectivity that is also a given. Museum professionals must be conscious of what they do and why, and they should inform the public that what it sees is ... material filtered through the tastes, interests, politics, and state of knowledge of particular presenters at a particular moment in time ... not a broad frame through which the art and culture of the world can be inspected, but a tightly focused lens that shows the visitor a particular point of view. ${ }^{16}$

I attempt to bring this awareness to my teaching. On the first day of class, the students and I come together to consider "what's wrong with this class?" in a conscious act of deconstruction. I am careful to present multiple historical narratives (local and Euro-American), noting their intersections and divergences. I typically begin with those of Pacific or other Indigenous peoples because these will be the stories least familiar to my students. The comparative method in lecture and worldview homework assignments is used to help students see both the differences and similarities of Pacific cultures with their own. I also have one strict rule: no matter what one personally thinks, there is no room for ethnocentric moral judgments in my classroom. If a student desires a debate on the ethics of certain cultural practices and worldviews, I paraphrase Indiana Jones: "If you want truth, Professor Viner's philosophy course is right down the hall." 


\section{Allen| Who Speaks for Sāmoa?}

As an art historian who teaches both Euro-American and Indigenous art traditions, I agree with Svetlana Alpers that "the mixture of distance ... with a sense of human affinity and common capacities ... is as much part of the experience of looking at a Dutch landscape painting of the seventeenth century as it is of looking at a carved Baule heddle pulley of the twentieth." 17 In my classes, I attempt to establish a small understanding in my students of the connections we share as human beings while communicating the wondrous diversity of the world, past and present. Thus, when I speak for Sāmoa, I aspire not to be an authority, but to be an advocate. If I can give to my students something of what I have acquired from my small knowledge of the Pacific, then perhaps the inequities and failings of the processes used will be overshadowed by the gains. I tell my students that my purpose in teaching is to make them better global citizens. Thus, I believe that the risk is truly worth taking.

Professor Anne E. Guernsey Allen graduated with a PhD in art history from Columbia University. She has worked in the Fine Arts Department at Indiana University's Southeast campus since 1994 and has earned numerous awards for her teaching. Her research focuses on the architecture, textiles, and performance of independent Sämoa. She has taken students to Sämoa several times for cultural immersion experiences. She is the co-director of the campus Study Abroad and Global Awareness Program.

\section{Notes}

1 James Clifford, The Predicament of Culture: Twentieth-Century Ethnography, Literature, and Art (Cambridge, MA, Harvard University Press, 1988), 8.

${ }^{2}$ Clifford, Predicament of Culture, 215.

${ }^{3}$ Clifford Geertz, Local knowledge: Further Essays in Interpretive Anthropology (New York, Basic Books, 1983), 19-36.

4 Michael Baxandall, "Exhibiting Intention: Some Preconditions of the Visual Display of Culturally Purposeful Objects," in Exhibiting Cultures: The Poetics and Politics of Museum Display, ed. Ivan Karp and Steven Lavine (Washington, D.C. Smithsonian Institution Press, 1991), 33-4.

${ }^{5}$ Clifford, Predicament of Culture, 23.

${ }^{6}$ Heather E. Young-Leslie and Ping-Ann Addo, "Pacific Textiles, Pacific Cultures: Hybridity and Pragmatic Creativity," Pacific Arts, New Series, Vol. 3/5 (2007): 12-21.

${ }^{7}$ Clifford, Predicament of Culture, 21-54.

${ }^{8}$ Clifford, Predicament of Culture, 25.

${ }^{9}$ Steven Lavine, "Museum Practices," in Exhibiting Cultures: The Poetics and Politics of Museum Display, ed. Ivan Karp and Steven Lavine (Washington, D.C.: Smithsonian Institution Press, 1991), 151. 


\section{Allen | Who Speaks for Sāmoa?}

10 James Clifford, "Four Northwest Coast Museums," in Exhibiting Cultures: The Poetics and Politics of Museum Display, ed. Ivan Karp and Steven Lavine (Washington, D.C.: Smithsonian Institution Press, 1991), 242.

${ }^{11}$ Mikhail Bakhtin, The Dialogic Imagination: Four Essays, ed. Michael Holquist, trans. Caryl Emerson and Michael Holquist (Austin: University of Texas Press, 1981), 291.

${ }^{12}$ Bakhtin, Dialogic Imagination, 263-276.

${ }^{13}$ Ivan Karp, "Culture and Representation," in Exhibiting Cultures: The Poetics and Politics of Museum Display, ed. Ivan Karp and Steven Lavine (Washington, D.C.: Smithsonian Institution Press, 1991), 12.

${ }^{14}$ Elaine Heumann Gurian, "Noodling Around with Exhibition Opportunities," in Exhibiting Cultures: The Poetics and Politics of Museum Display, ed. Ivan Karp and Steven Lavine (Washington, D.C.: Smithsonian Institution Press, 1991), 188.

${ }^{15}$ Clifford, Predicament of Culture, 23.

${ }^{16}$ Susan Vogel, "Always True to the Object, in Our Fashion," in Exhibiting Cultures: The Poetics and Politics of Museum Display, ed. Ivan Karp and Steven Lavine (Washington, D.C.: Smithsonian Institution Press, 1991), 201.

${ }^{17}$ Svetlana Alpers, "The Museum as a Way of Seeing," in Exhibiting Cultures: The Poetics and Politics of Museum Display, ed. Ivan Karp and Steven Lavine (Washington, D.C.: Smithsonian Institution Press, 1991), 32. 


\title{
MICHAEL COOKSON, STUART KIRSCH, and JASON MacLEOD Angels in West Papua. In Memoriam Donatus Moiwend
}

\author{
Abstract \\ Obituary for Donatus Moiwend, West Papuan artist.
}

Keywords: Pacific Art, Donatus Moiwend, West Papua

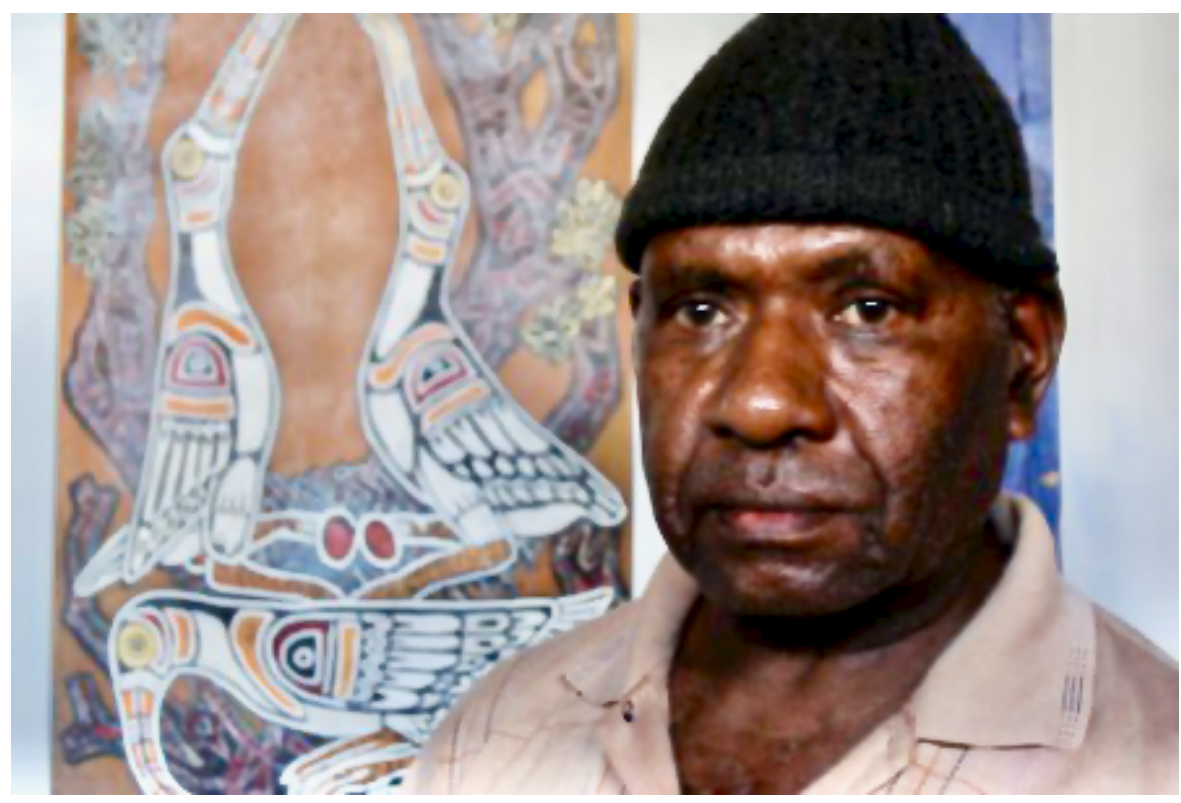

Figure 1. Donatus Moiwend. Undated photograph by Rosa Moyuend

It is with great sadness that we share the news that Donatus Moiwend, the visionary West Papuan artist, passed away in 2018 (Fig. 1). ${ }^{1}$ Donatus Stefanus Moulo Moyuend was born in Merauke around the end of World War II. He was a member of the Maklew clan, a sub-group of the Malind Anim (formerly written as Marind Anim). Moiwend was a largely self-taught artist who painted in a variety of styles. He also produced sculpture, adorned churches with his work, and even expressed his artistic vision in the landscape. Noting that there was already a Monet, a Manet, and a Bonnet, he playfully signed his artwork “Donet." 


\section{Cookson, Kirsch \& MacLeod | Donatus Moiwend}

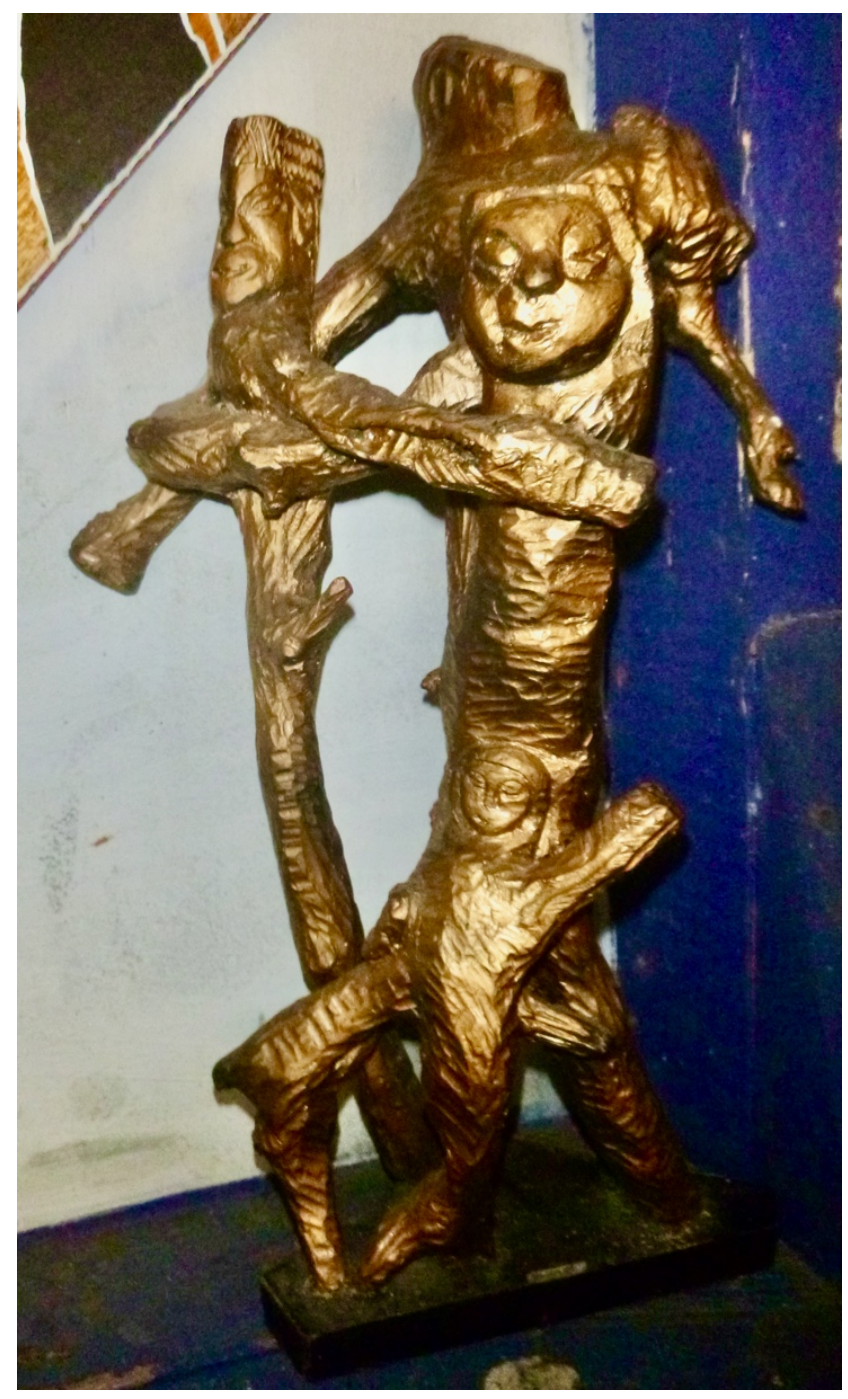

Figure 2. Sculpture in Donatus Moiwend's workshop in Sentani, West Papua (Indonesia). This carving from tree roots refers to the controversial family planning campaign conducted by the Indonesian government, which promoted two children per family. Photograph by Stuart Kirsch, 2014

Moiwend was an active member of the West Papuan cultural renaissance during the late 1970 s and early 1980s, which was led by anthropologist, museum curator, and ethnomusicologist Arnold Ap. Their activities included the revitalization of West Papuan folk music, dance, material culture, and design. The movement ended abruptly after Ap's arrest and death at the hands of the state in April 1984 in response to protests against the Indonesian occupation of West Papua. ${ }^{2}$ Moiwend was also detained by the Indonesian security forces at that time but was later released. He continued to produce paintings and sculpture with political messages, although he never explicitly discussed politics, choosing instead to communicate through his art (Fig. 2).

Moiwend once described his approach to art in the following terms: "I see a lot (lihat banyak), listen a lot (dengar banyak), read a lot (baca banyak), then do a lot (berbuat banyak)." 


\section{Cookson, Kirsch \& MacLeod | Donatus Moiwend}

He added, "This is also my approach to life." Many of Moiwend's works reflect his close observation of nature. For example, one of his paintings was inspired by a puddle teeming with tadpoles, all kicking and shoving each other out of the way. It reminded him of the friction and strife inherent in politics, especially the behavior of politicians, so he titled it Politics (Fig. 3). ${ }^{3}$ He believed "the role of the artist is to help us understand the fundamental nature of what we see."

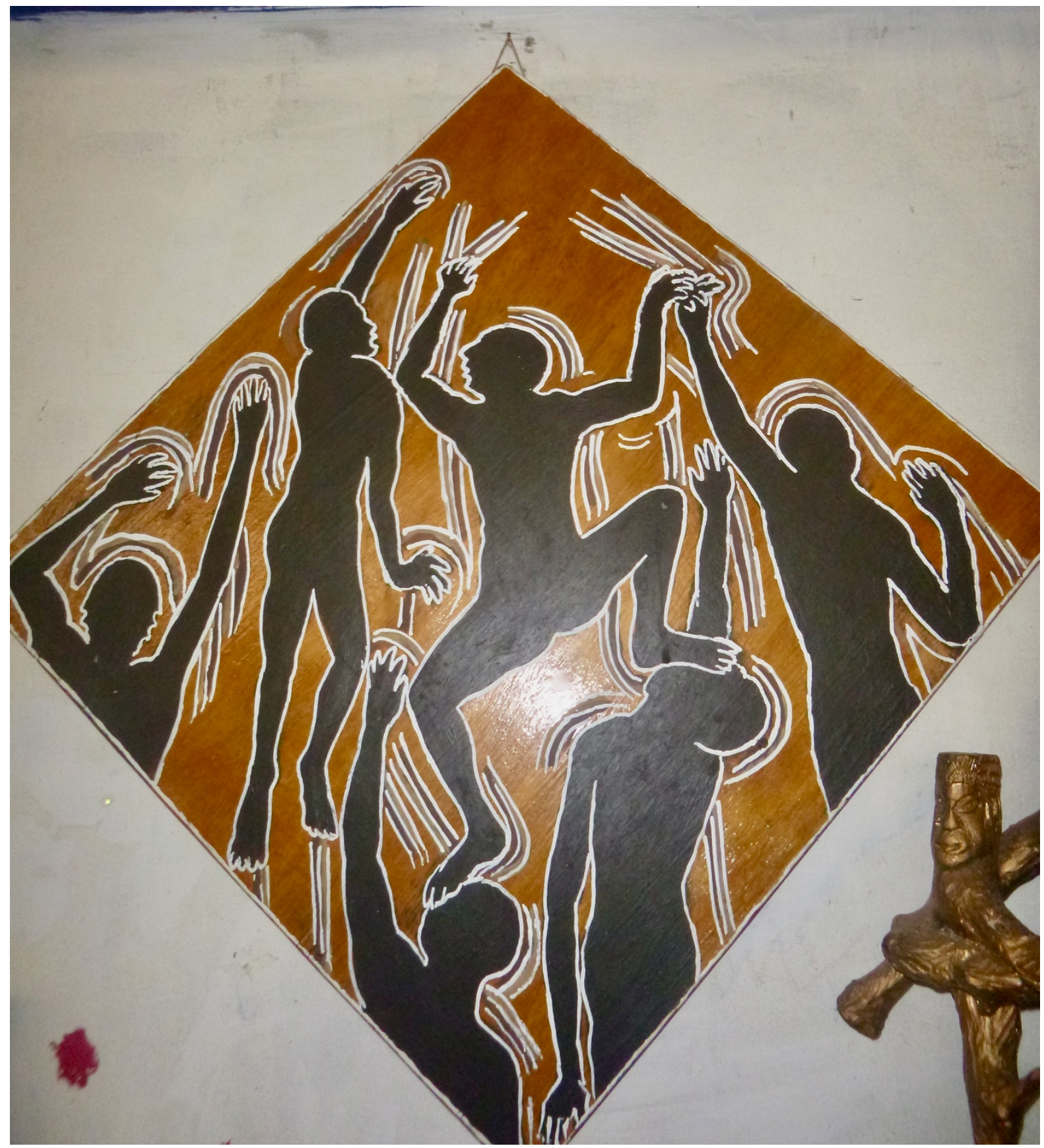

Figure 3. Donatus Moiwend, Politics. Photograph by Stuart Kirsch, 2014 


\section{Cookson, Kirsch \& MacLeod | Donatus Moiwend}

In 1967, Moiwend began work as a civil servant in the Indonesian government, based initially in Paniai, in the highlands, and moved to the capital of Jayapura in 1981. In 1979, he received an apprenticeship to study painting in Bali under the Dutch-born Indonesian artist Adrianus "Arie" Wilhelmus Smit, whose other pupils were associated with what became known as the "Young artists' style" in Indonesia. In the mid-1980s, Moiwend received further artistic training in Bogor, Java. A civil servant until his retirement in 2004, Moiwend shared his work in art exhibitions in West Papua and elsewhere in Indonesia, as well as in the Netherlands and other European countries. In 2015, he helped to establish, develop the curriculum for, and teach art to students at the Institut Seni Budaya Indonesia di Tanah Papua (Arts Institute ISBI Tanah Papua), in Waena, a sub-district of Jayapura.

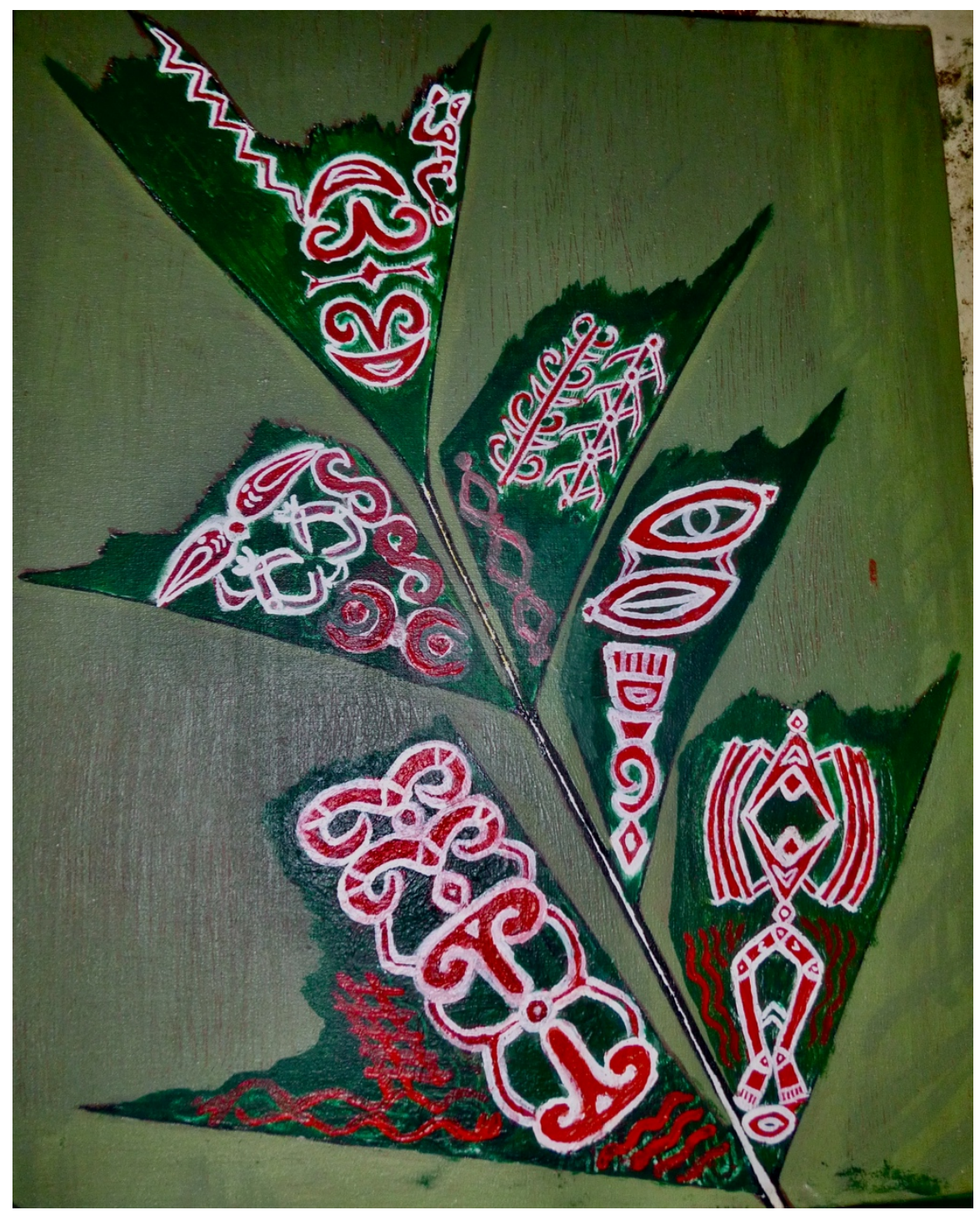

Figure 4. Donatus Moiwend, unfinished work with Asmat iconography, from his Leaves series. Photograph by Stuart Kirsch, 2014 


\section{Cookson, Kirsch \& MacLeod | Donatus Moiwend}

Moiwend was deeply influenced by West Papuan art, especially images and designs from his own Malind Anim culture; Asmat iconography, which he learned about while posted near Agats; and Sentani motifs, given that he spent much of his adult life in Jayapura (Fig. 4). He actively promoted West Papuan artists and traditions in local and regional art classes, exhibitions, and competitions. He noted, "Art has a role to play in helping Papuan youth develop their capabilities. It can also point out things that disturb us."

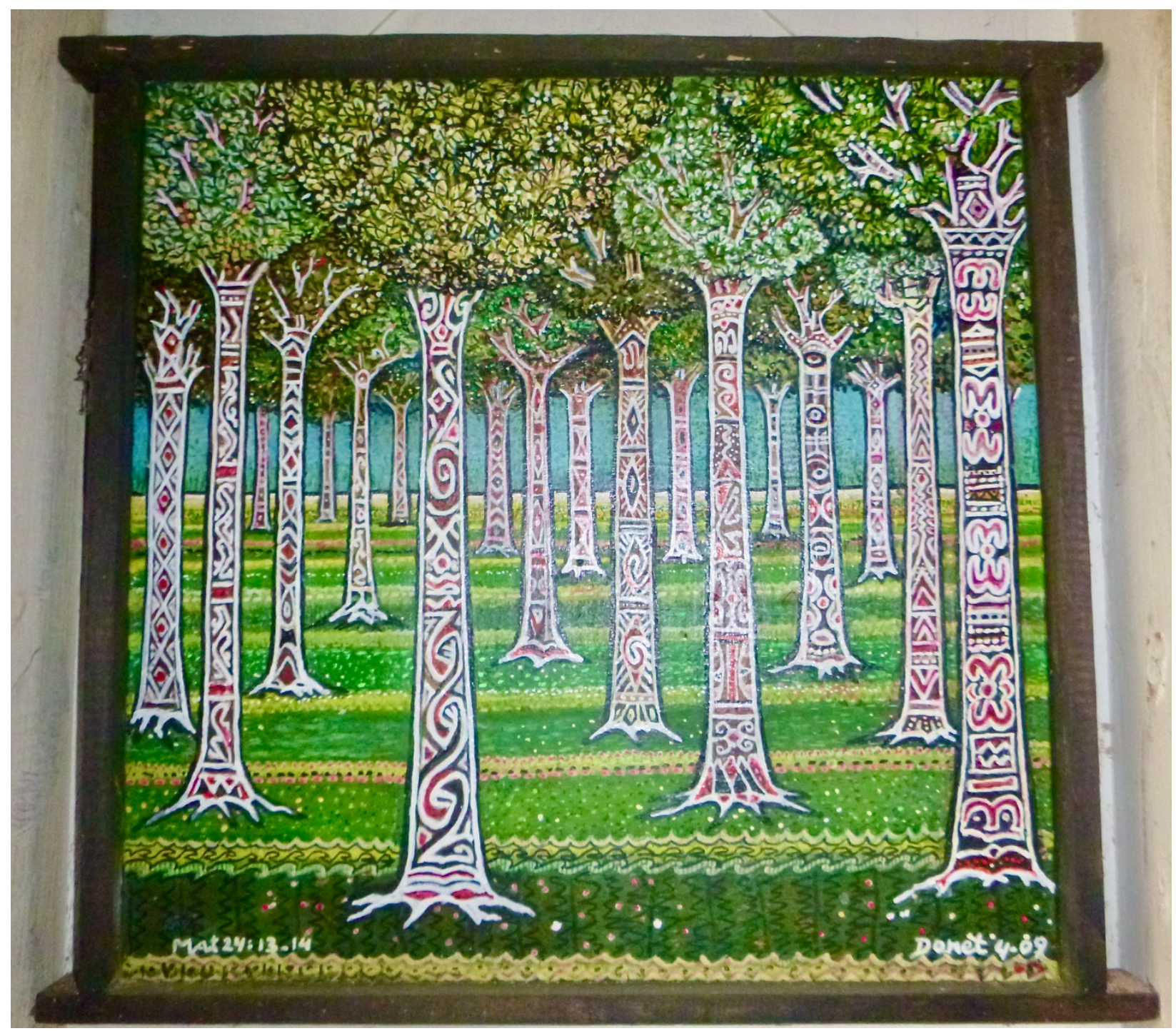

Figure 5. Donatus Moiwend, Untitled (Grove of Trees). This painting refers to the New Testament verses Matthew 7:17-20, which refer to good and bad trees, and how one will recognize them by the fruit they bear. The inscription in the lower left corner invokes Matthew 23:13-14, which refers to those who will be saved when the end comes. Photograph by Stuart Kirsch, 2014 


\section{Cookson, Kirsch \& MacLeod | Donatus Moiwend}

Moiwend's upbringing in the Catholic Church also influenced his art (Fig. 5). Many of his major works were commissioned for churches built by the Franciscan Order (OFM) in Papua, with which he had a longstanding partnership. He painted church walls in Port Numbay (Humboldt Bay), in Keerom, Pegunungan, Bintang, and elsewhere in West Papua, including the Cathedral of Christ the King in Jayapura, which unfortunately is no longer standing. His skills as a painter and carver are still evident in many of the architectural embellishments of a cathedral erected on the grounds of an orphanage run by the Sisters of St. Joseph (Kongregasi Suster Dina Santo Yoseph) in Sentani, where he lived and had an art studio during the early years of his retirement (Fig. 6). He also constructed a rock wall and cave in a small embankment beside the church in the hope that people would come to pray at the Grotto of Maria and the surrounding gardens, which he planted and maintained, providing them with an experience of spiritual peace, reflection, and sanctuary.

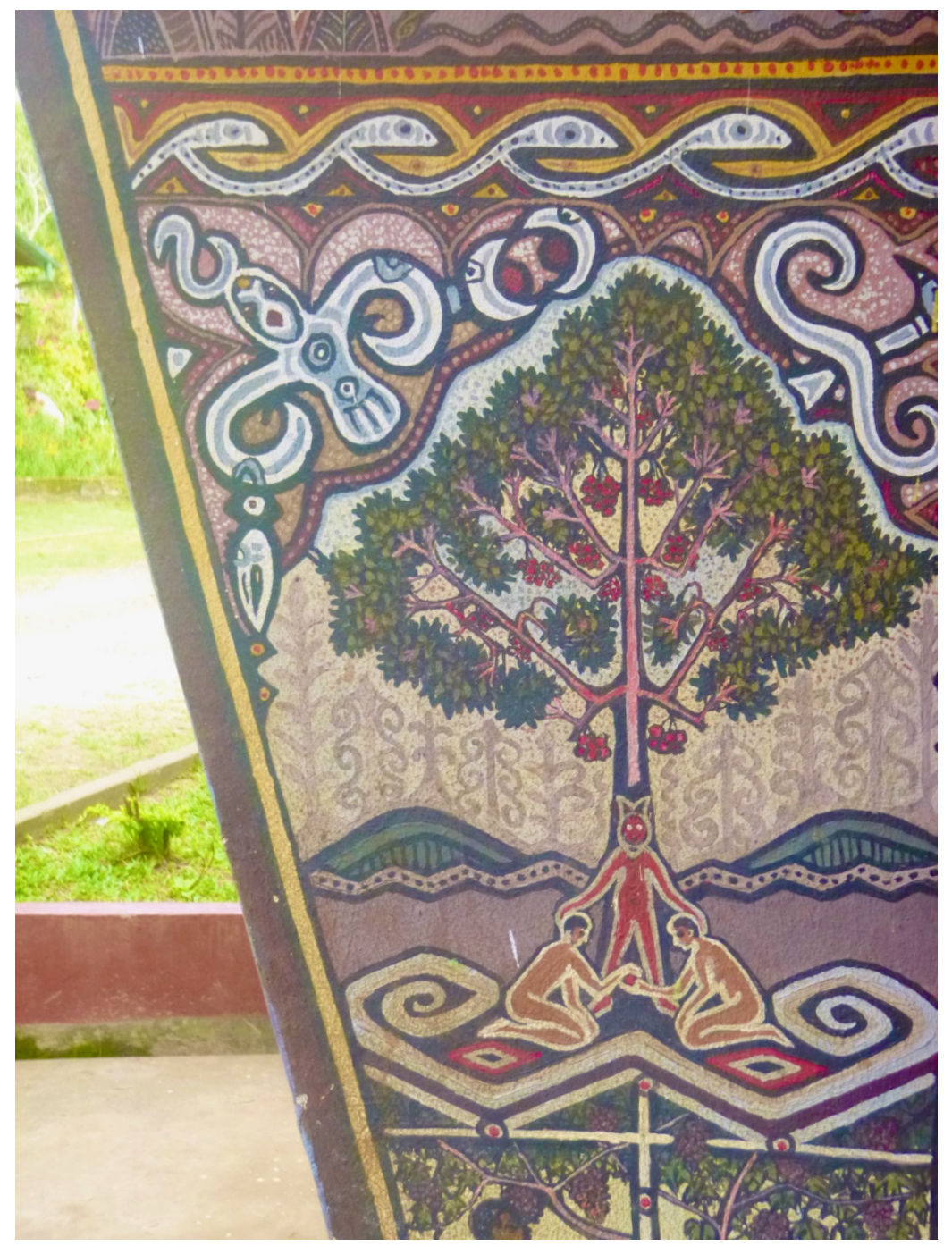

Figure 6. Donatus Moiwend, Adam and Eve and the tree of knowledge, painted on the exterior of the chapel at the Children's Orphanage of Putri Kerahiman in Sentani, where Moiwend had his workshop. Photograph by Stuart Kirsch, 2014 


\section{Cookson, Kirsch \& MacLeod | Donatus Moiwend}

He observed, "Through my art, I hope that people can encounter something of God, the spirit of life that pervades all things. Some people preach in the church but my art is my sermons. All of creation has to be treated with reverence. I use art as a voice to speak to others, but I also try to open myself to the deeper nature of being which speaks through my art." Moiwend's views on divinity were influenced by his membership since the 1980s in the Bahá 'í faith, which teaches the value of all religions, as well as the equality of all peoples.

Moiwend believed in the universal truth of the divine, but his art simultaneously conveyed a powerful sense of belonging and place in the Land of Papua (Tanah Papua), the spiritual home of the West Papuan people. This was evident in his 1980 painting of St. Francis of Assisi in Papua, surrounded by indigenous flora and fauna, including a cassowary, a marsupial, and a number of colorful birds endemic to the region, which bears a resemblance to Henri Rousseau's The Dream. His paintings of angels with Melanesian faces and hair are also emblematic of this relationship.

In the paintings by Moiwend in the now-demolished Cathedral of Christ the King in Jayapura, the Archangel Gabriel blows his trumpet and the Archangel Michael summons a choir of heavenly angels. The angels hover on the balcony wall above the congregation as they enter the cathedral, and all are West Papuan. That they are angels is apparent from their ornate wings. That they are West Papuan is evident from their black skin color and dark curly hair, as well as their tailfeathers from the Greater Bird of Paradise. The angels wear white tunics with broad red collars fringed with golden tassels, reminiscent of the red tunics worn for dancing and feasting on Biak Island. An image of the morning star, a powerful symbol of decolonization in West Papua, is affixed to the crown of their heads. ${ }^{4}$

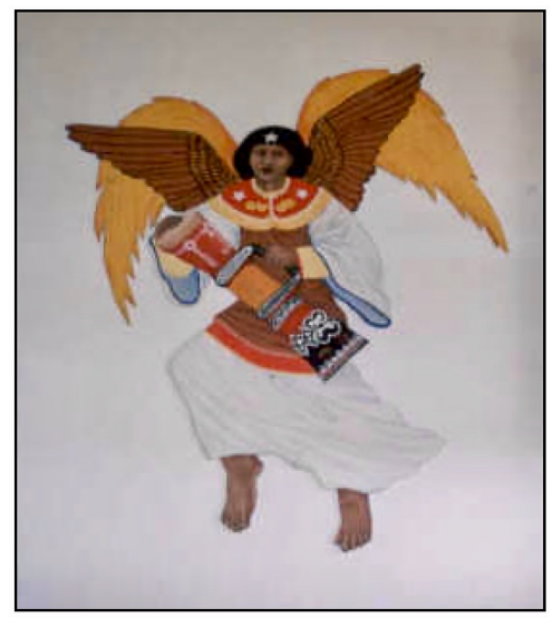

Figure 7. Donatus Moiwend, Archangel Michael on the interior of the Cathedral of Christ the King, Jayapura. Photograph by Michael Cookson, 2001. From Michael Cookson, Batik Irian: Imprints of Indonesian Papua, PhD thesis

(Australia National University, 2008), 312 


\section{Cookson, Kirsch \& MacLeod | Donatus Moiwend}

The Archangel Michael holds aloft and plays a Malind Anim hourglass drum, or tifa, decorated with motifs from the Asmat and the Malind Anim at the top and base of the drum (Fig. 7). For Moiwend, the tifa was the most important instrument in West Papua because it allowed Papuans to communicate to each other through the language of music. Like all of the other angels depicted in the church, Michael is skillfully painted. His gown floats in the air and his image appears to fly off the walls of the church.

If there are angels in Papua, Moiwend once opined, "surely they will appear in clothes as beautiful as the bird of paradise and as radiant as the realm of nature in Papua." He noted that when he began "painting angels with Melanesian faces, many people were confused, even angry. But as Papuans, we have our own religious ... stories and beliefs, ... [including] beings like angels. Why not black angels?"

And that, perhaps, is how we ought to remember Donatus Stefanus Moulo Moyuend himself: hovering over Tanah Papua, playing a Malind Anim tifa, while the Archangel Gabriel's trumpet sounds the call for transformation, heralding a better life and future for the people of West Papua. For Moiwend devoted his life to helping Papuans learn about and express their own cultures and traditions, with the aim of forging a path between the two.

Mike Cookson completed his PhD on political and social change in Indonesian Papua at the Australian National University in Canberra and has worked extensively in academic collaborations with universities in Indonesia, Papua New Guinea, and the Pacific Islands.

Stuart Kirsch teaches anthropology at the University of Michigan. He has worked with West Papuan refugees living in Papua New Guinea since the 1980s. He is the author of several essays on West Papua and its borderlands, including "Rumour and Other Narratives of Political Violence in West Papua" and "Ethnographic Representation and the Politics of Violence in West Papua," which appeared in the journal Critique of Anthropology in 2002 and 2010.

Jason MacLeod is a community organizer, educator, and researcher based in Australia and the cofounder of Make West Papua Safe. He is the author of Merdeka and the Morning Star: Civil Resistance in West Papua (Queensland University Press, 2015).

\section{Notes}

${ }^{1}$ This obituary originally appeared in several online forums in 2018 as "Angels in Papua. In Memoriam Donatus Moiwend" and in Bahasa Indonesia as "Malaikat-Malaikat di Papua. Mengenang Donatus Moiwend" (trans. Nisa Azam). It is based on interviews with Moiwend conducted by Mike Cookson, Stuart Kirsch, and Jason Macleod in 2006, 2014, and 2016. The authors are grateful to Donatus Moiwend's daughter Rosa Moyuend for sharing her many insights into her father's work and for her family's permission to reproduce the images in 


\section{Cookson, Kirsch \& MacLeod | Donatus Moiwend}

this text. We also thank the editors of Pacific Arts, Stacy L. Kamehiro and Maggie Wander, for their encouragement and assistance.

2 Diana Glazebrook, "Teaching Performance Art is Like Sharpening the Blade of a Knife," The Asia Pacific Journal of Anthropology 5, no. 1 (2004), 1-14, https://doi.org/10.1080/1444221042000201724.

${ }^{3}$ Moiwend generously allowed Stuart Kirsch to reproduce another version of this painting as the cover image for his book Engaged Anthropology: Politics Beyond the Text (University of California Press, 2018).

${ }^{4}$ Camellia Webb-Gannon, Morning Star Rising: The Politics of Decolonization in West Papua (Honolulu: University of Hawai'i Press, 2021). 


\title{
MAX QUANCHI "Fijian Islanders preparing for a feast" (1959): The Influence of Photography on Popular Opinions of the Pacific
}

\begin{abstract}
In 1959, a serialised, illustrated encyclopaedia, The Book of Knowledge, published a photograph captioned "Fijian islanders preparing for a feast," suggesting to readers that butchering a turtle prior to cooking was a common sight in the 1950 s and a cultural practice among modern-day Fijians. However, the photograph had been taken around the turn of the century by a British colonial official, Basil Thomson, and published elsewhere by him and others in the intervening fifty years. How much post-World War II illustrative photography of Pacific Islanders in encyclopaedias was misleading in this manner? How much illustrative (particularly photographic) material from an era long past was presented mid-century as being evidence of contemporary life in the Pacific? Or, was preparing a turtle for a feast a long-standing tradition and, therefore, the date of the photograph immaterial? This paper investigates these questions within the context of the creation of The Book of Knowledge and other such compendia, as well as EuroAmerican stereotypes of Fiji and the Pacific.
\end{abstract}

Keywords: Fiji, photography, representation, encyclopaedia, encyclopedia, stereotypes

In 1959, a photograph with the caption "Fijian Islanders preparing for a feast" was published in the serialised, illustrated, multi-volume, British encyclopaedia The Book of Knowledge (Fig. 1). In the photograph are three Fijian men-two of them holding knives-about to prepare three sea turtles for cooking. Two other Fijians peek out at the scene from a bure, a thatched Fijian kitchen, a composition ploy often used in photographs. From the caption, readers at the time would have likely assumed the turtles in the photograph were to be food for a wedding, a funeral, the installation of a chief, a chiefly visit to a village, or some other gathering or ceremony. The photograph had been provided to the encyclopaedia by a well-known British colonial official and author, Sir Basil Thomson. The accompanying one-page entry on Fiji had this photograph as its only supporting illustration. Presumably, editors chose this photograph as being representative of Fiji in the 1950 s and believed that it exemplified the customs, appearance, housing, and everyday lifestyle of Fijians. The editors and publishers expected 


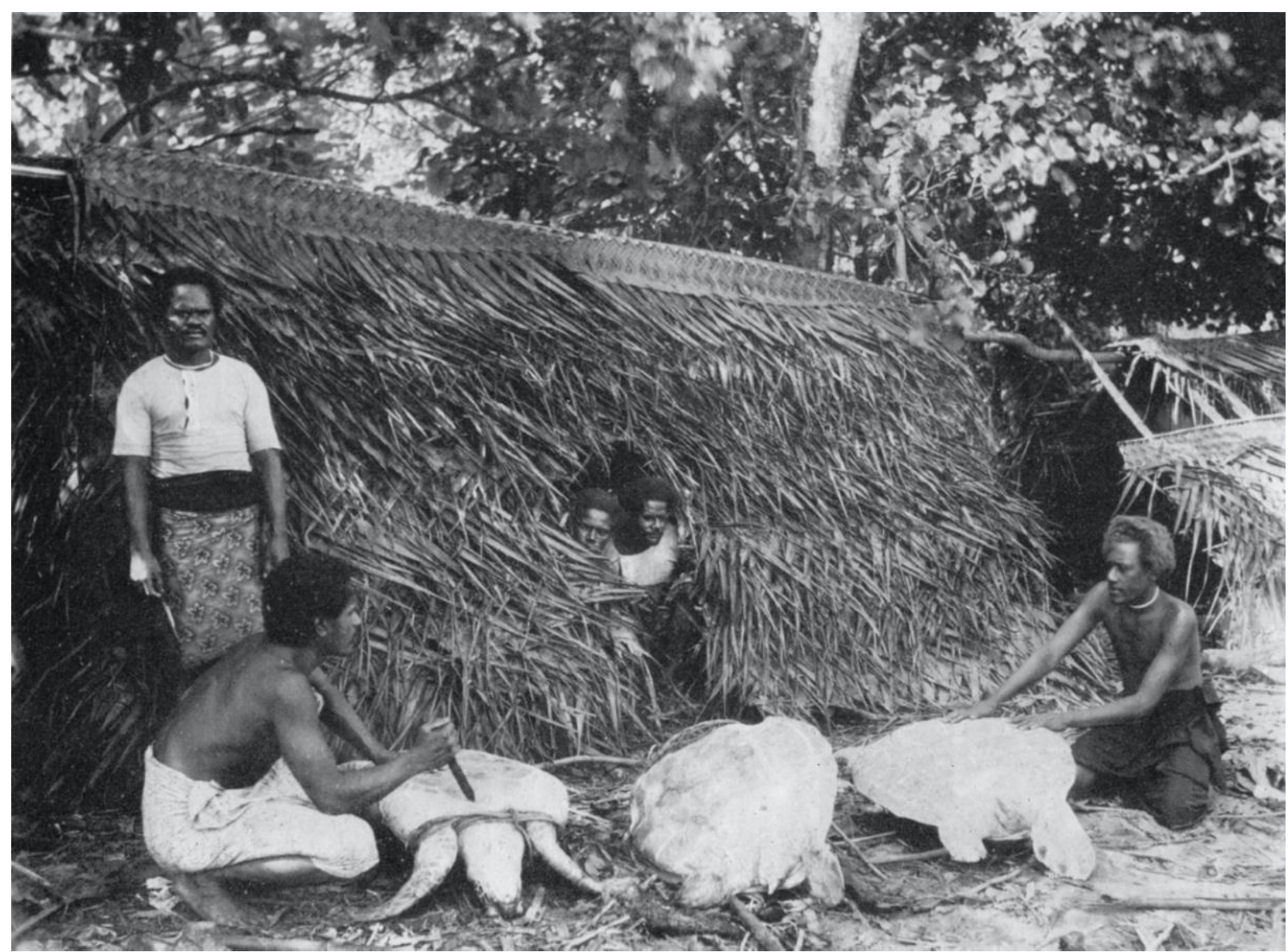

Figure 1. "Slaughtering the Turtle," photograph in Basil Thomson's The Fijians: A Study of the Decay of Custom (London: William Heinemann, 1908), 326

that the pairing of text and image across the encyclopaedia's eight volumes would inform young and old readers about the modern world, both near and far.

The pairing of text and image was, by the 1950s, the standard presentation style for encyclopaedias, which had been available worldwide since 1900. These reference series were amazingly prolific despite periodic downturns in sales caused by the Great Depression, World War I, and World War II. The Book of Knowledge first appeared in 1922, and there had been several editions since, edited by Harold B. Wheeler, John A. Hammerton, and others. In the United States, Grolier had published an encyclopaedia of the same name beginning in 1912, edited by Holland Thomson, which was also followed by many subsequent editions.

In 1959, The Book of Knowledge: A Pictorial Treasury of Reading and Reference for Young and Old, edited by Gordon Stowell, included 6,000 illustrations and was a typical example of this long-standing genre. Stowell was the author of ninety-eight books, a designer, an encyclopaedia editor, and the illustrator of children's books including A-Mazing Escape: A Bible Story, Kiku of Japan (How They Live Now), and The Wise Men Find Jesus. He also edited The 


\section{Quanchi| Fijian Islanders Preparing for a Feast}

Waverley Encyclopaedia: A Comprehensive Volume of Facts (1958), with 867 illustrations, and The New Universal Encyclopaedia (1959), with fifteen volumes. General-knowledge, serialised, pictorial encyclopaedias were aimed at encouraging the interest of young and adult readers in the contemporary world. Their summaries of near and distant countries and peoples were presented alphabetically and supported by photographs, maps, and statistics. However, in the instance of Fiji, readers were being misled, as the illustration accompanying the entry on Fiji was not a contemporary one, but a scene from seventy years earlier.

The man who took the photograph, Basil Thomson, did so either sometime between 1883 and 1889 in Nadroga-on the south coast of Viti Levu Island, Fiji, where he served as a magistrate-or elsewhere during his brief second visit to Fiji in 1903. The photograph was reproduced and sold as a postcard in the early 1900 s and appeared with a range of captions, sometimes accurately and sometimes inaccurately describing alleged events, Fijian rituals, or customs. ' For example, it was labelled and sold by J.W. Waters as "Preparation for a feast Fiji." Waters had operated as a photographer and postcard proprietor in Fiji since 1886 and Thomson noted in 1897 that Waters was the "cheapest and best." In 1913, Waters passed his business to Frederick William Caine, who republished the same postcard-reversing the image-as "Killing turtles for a feast, Fiji."” The original photographic print was later given or sold to postcard proprietors and publishers of books and serial encyclopaedia. Such plagiarising of Thomson's image was a common practice in the postcard and publishing industry.

Thomson included this photograph in his 1908 book, The Fijians: A Study of the Decay of Custom, with the caption "Slaughtering the Turtle."4 The same image appeared with his 1922 essay "British Empire in Australasia: Island Life in the Strange South Seas," published in the serial, pictorial encyclopaedia People of All Nations. Here the photograph was attributed to Thomson, appearing with the caption "There is no mock turtle at a banquet in Fiji. The mouth of a city alderman might water at this prospect of real calipash and calipee." 5 The photograph appeared again, twenty-five years later, in another serialised encyclopaedia, Lands and Peoples, with Thomson again acknowledged as the photographer, but the image re-captioned "Turtles for the table outside a Fijian Grass house." 6 In 1959, it was again recaptioned in The Book of Knowledge as "Fijian Islanders preparing a feast."

Sir Basil Thomson served as a British colonial official in Fiji, Tonga, and British New Guinea between 1884 and 1893, after which he returned to England. ${ }^{7}$ He lived among Fijians for short intervals for ten years, first as a stipendiary magistrate in various parts of the archipelago, then as commissioner of the Native Lands Court, and finally as acting head of colonial Fiji's Native Department. Some of his anthropological information and photography was collected when he returned to Fiji in 1903 to serve on a commission appointed to investigate the causes of a decrease in the Indigenous Fijian population. Thomson was the author of several books on the Pacific, including Diversions of a Prime Minister (1894); South 


\section{Quanchi| Fijian Islanders Preparing for a Feast}

Sea Yarns (1894); The Discovery of the Solomon Islands (1901); ${ }^{8}$ and Savage Island: An Account of a Sojourn on Niue and Tonga (1902).

Thomson, or his editors, were alert to the potential power of photographs to bring to life tales from the "South Seas," as evident in the prolifically illustrated essays he published in magazines including Lands and Peoples, Wide World Magazine, People of All Nations, and Countries of the World. ${ }^{9}$ This awareness was evident as early as his two-part illustrated article "Curiosities of the South Seas" from 1899. His seventy-five-page essay in the 1922 encyclopaedia People of All Nations was illustrated with ninety-one photographs. In 1926, his essay on "South Sea Islands: Palm-Fringed Edens of Oceania" in Countries of the World was illustrated with twenty-three black-and-white photographs, one full-page photogravure, and five full-colour plates. To this volume he also contributed an essay on the "Fiji Islands," illustrated with ten photographs. ${ }^{10}$ This instalment of Countries of the World was typical of the serial encyclopaedia format, with 103 pages, four maps, and 112 photographs. In addition to thirty-nine Pacific images, there were eighty-three photographs of South Africa, Spain, Stockholm, and South America. The 130 photographs published by Thomson in these few examples in the 1920 s is a clear statement on how photography of the Pacific had spread thickly across the publishing world during the colonial era. ${ }^{11}$

Thomson noted the importance of turtles in Fijian customs in a 1908 book, declaring,

In Fiji the royal fish is the turtle. Every considerable chief had turtle fishers attached to his establishment. He would allow them to take service with other chiefs for ten expeditions. The hiring chief paid them by results; for blank days they received nothing, but food and property were given to them for every catch, and a considerable present was made to them at the end of their engagement... The catch is announced by loud blasts on the conch, and the canoes are received with the same noise of triumph as when they brought back bodies for the cannibal ovens. The women meet them with songs and dances, and sometimes they pelt the crew with oranges and are chased from the beach with loud laughter. ${ }^{12}$

Thomson's choice for a frontispiece for this book, "Breadfruit," also appeared the previous year in the Cyclopedia of Fiji with the caption "Fijian breadfruit carrier" (Fig. 2). It was later sold as a postcard by others including F. W. Caine, who re-captioned as "A breadfruit seller." 13

The visual content in Thomson's published photography conformed to an editorial formula that had rapidly evolved after the halftone process revolutionized photography's use in newspaper and magazine printing. Each distant colony, country, or region was depicted in a formulaic manner. This included studio portraits of Indigenous people dressed in traditional costume, or exterior group portraits that doubled as scenic views by positioning the group in the foreground of a topographical feature, dwelling, or village. The photograph illustrations 


\section{Quanchi| Fijian Islanders Preparing for a Feast}

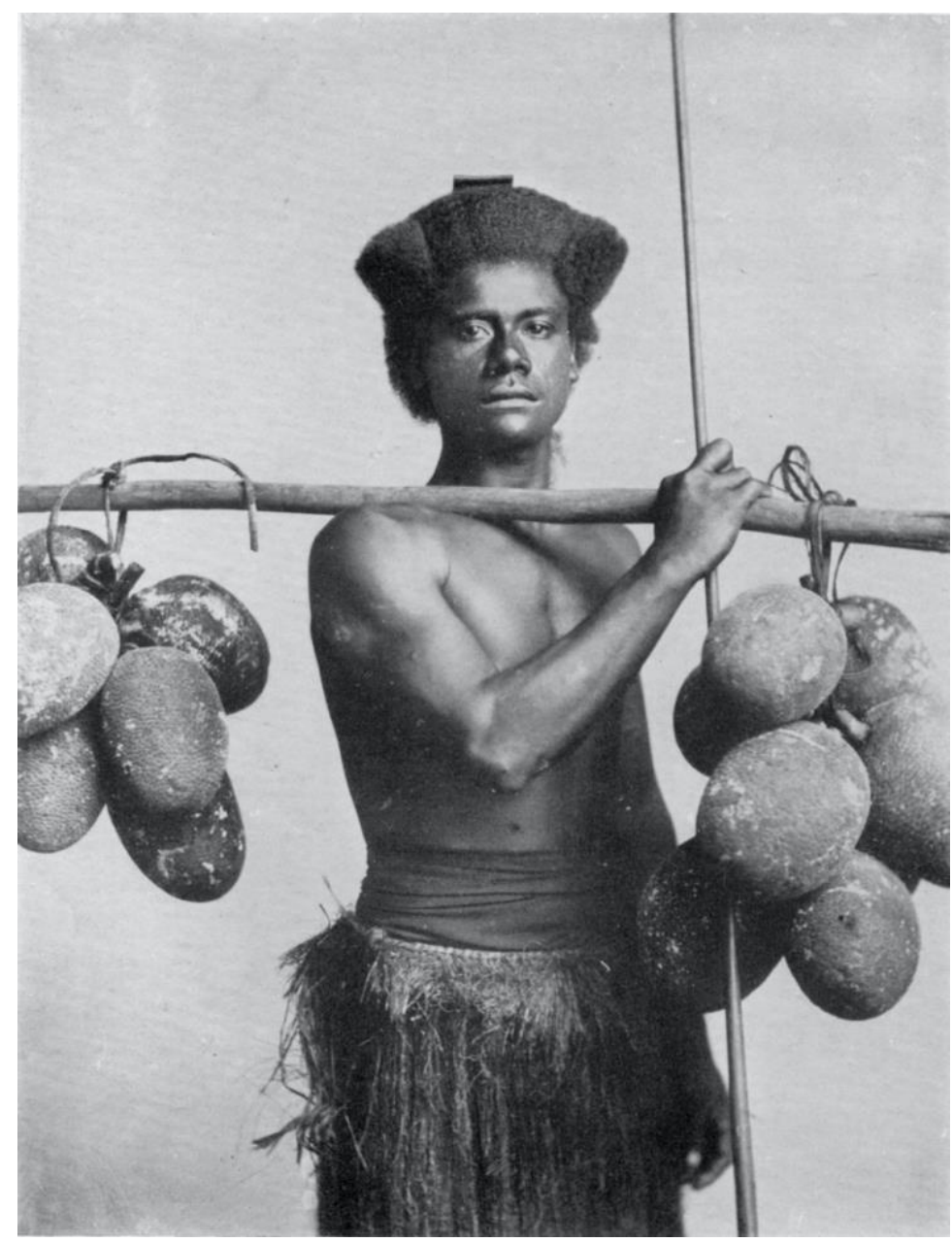

Figure 2. "Breadfruit," photograph in Basil Thomson, The Fijians: A Study of the Decay of Custom (London: William Heinemann, 1908), frontispiece

usually included static displays of material culture and symbolic aspects of European colonial infrastructure, such as roads, plantations, public buildings, and wharves. For example, under "Abyssinia," the first non-European country featured in The Book of Knowledge in 1959, a photograph of produce markets and "natives" pounding grain set against a barren mountain panorama-with a wireless station included to depict modernity-followed this formula. ${ }^{14}$ This type of photographic composition, with varying emphasis on one or another of these elements, can be found in published photographs taken in European colonies in the Middle East, Africa, and Asia.

For readers of illustrated encyclopaedia in the 1950s, entries on the "South Seas" confirmed the mental images of past eras, when the Pacific had been defined by a narrow set of myths highlighting idyllic coastal vistas, strange customs, and bustling European enterprise and empire building. This was the format for presenting the "graphic geography" that the 


\section{Quanchi| Fijian Islanders Preparing for a Feast}

well-known editor of a multi-volume encyclopaedia, John A. Hammerton, extolled for this type of publication. Hammerton was Britain's most successful creator of large-scale works of reference. He claimed that such works served three purposes, being a "complete encyclopaedia of graphic geography ... an educational work ... and a work of reference." 15 Readers looking at the South Seas illustrations of The Book of Knowledge probably did not realize that the editor's choice of illustration was often very outdated. British publications mostly excluded entries about Micronesia, as well as the areas of the Pacific inhabited and/or colonized by the French, the Japanese, and the Germans. For example, Micronesia-under German, then Japanese, control as a mandate after World War I-was not included in People of All Nations in 1926. French territories were similarly marginalized and treated derogatively, with New Caledonia described as "the most striking example of the French way of doing the wrong thing in colony making." 16 The smaller nations and island groups such as the Cook Islands, Nauru, Kiribati, Tuvalu, Tokelau, West Papua, and Niue were often ignored. In 1959, in The Book of Knowledge, only Sāmoa, Hawai'i, New Guinea, and Fiji were allocated separate entries. Sāmoa has a one-page entry with only two photographs: a photograph of smiling copra workers husking coconuts and a scene with three Europeans outside a plantation owner's substantial house. Sāmoans are said to be "very intelligent and appreciative of education." ${ }^{17}$ There is no indication that Sāmoa, three years later, would be the first Pacific nation to gain independence.

Thomson's image of preparing turtles for a feast depicts an earlier time, perhaps seventy-five years prior to being viewed in The Book of Knowledge. It was, therefore, a misleading representation of what the British Crown Colony of Fiji was like in the 1950 . Editors of encyclopaedia apparently were not concerned that images from earlier periods were inaccurately representing the countries and peoples they so proudly proclaimed their encyclopaedia was able to present to readers. Gordon Stowell, as editor of the 1959 Book of Knowledge, declared that the encyclopaedia had been "constantly reconsidered and rearranged" and "brought up to date in the fullest sense of that phrase." Photographs, he declared, were "chosen to illustrate articles" but also "to supplement in the most vivid way the information." ${ }^{18}$ The choice of older photographs also may have been deliberate, deeming it appropriate to include images that carried a timelessness and nostalgic romantic view of other cultures on the far side of the world. It might also have been argued by editors that Euro-American readers of The Book of Knowledge or similar types of illustrated compendia preferred this type of imagery, being trapped in an Orientalist manner of thinking about other cultures. If challenged, the editors might have argued that this version of island life was what post-World War II readers expected to see in an encyclopaedia entry on Fiji. The older photographs may also have been less expensive or easier to obtain for publication.

A contrary analysis might argue that the seventy-year lapse of time between when the photograph of the Fijian men with the turtles was taken and when it was published is 


\section{Quanchi| Fijian Islanders Preparing for a Feast}

immaterial. In rural Fiji in the 1950s, the clothing, demeaner, and tribute practices depicted in the image were, in fact, unchanged from the early 1900s. Thatched bure were still visible across most of rural Fiji in the 1950s, and the customary practices related to turtles, such as ritual preparation and feasting, were also unchanged. Most Fijians in the 1950 s still lived in villages and followed long-standing customs of marriage, tribute and association, housing, and food practices. ${ }^{19}$ Thus, choosing this village scene can be seen as an appropriate choice for a single illustration to represent a Fijian way of life that had been protected under a benevolent British administration since 1874 .

Why did The Book of Knowledge choose a tribute of turtles, a bure, and Fijians if only one illustration was to be included in the Fiji entry? This choice was remarkable because by the 1950 s there were 6,000 or more existing postcards of Fiji produced between 1900 to 1930, and thousands of other, already published photographs of Fiji from which to choose. There was also material available from stock photograph companies such as Exclusive News Agency (ENA), which had provided five of the images accompanying The Book of Knowledge's "Pacific Islands" entry, and from retired colonial officials, travelers, and professional photographers in England. And there were recently-taken photographs from professional photographers, travel companies, government agencies, and the military available for use. In the 1950s, the popular illustrated magazine Walkabout, covering Australia and the nearby Pacific Islands, was not using old photographs but was instead relying on contemporary photographs to fill its pages. Why, then, was The Book of Knowledge using a seventy-year-old photograph when there were images of the recently inaugurated Miss Hibiscus beauty contest that would have given a contemporary, modern understanding of what was happening in Fiji in the 1950s?

By the 1950s, numerous contemporary images of Fiji were available. Fiji's colonial government also had an official photographer, Rob Wright, who was taking photographs for travel promotion and other official purposes. ${ }^{20}$ In 1963, Pacific Islands Monthly called Wright the South Pacific's best-known photographer, and Encyclopaedia Britannica selected two of his pictures to appear among the "Best Two Hundred Press Pictures of the Decade." ${ }^{21}$ Four years after The Book of Knowledge, using an outdated Fijian image, was published, twenty-six contemporary photographs by Wright were used by Alan Burns in the book Fiji, in the Corona Library series on British colonies. Burns's book was based on his 1959 visit to Fiji for a British commission of enquiry into the natural resources and population trends of the colony, and is evidence that some publishers were alert to the need to provide updated, current images. Even the 1922 edition of New World of Today, with fifty-nine photographs in its Pacific entries, had used forty-six newly chosen and recent images, repeating only thirteen photographs from the 1904 edition. With all the available imagery, the choice of potentially outdated photographs was problematic at best.

By the late 1950s, half the population of Fiji was of Indian descent, a fact not reflected in photographs of Fiji appearing in British publications. Thus, the post-girmit (indentured 


\section{Quanchi| Fijian Islanders Preparing for a Feast}

labor) Indian population was excluded from the reporting on Fiji. Hypothetically, it was probably a racist editorial decision, that a photograph of an Indian policeman, an Indian shop owner, or an Indian farming family near Labasa was not considered an appropriate editorial choice as an image to represent Fiji. Racism, marginalization, and disenfranchisement likely influenced editorial choices, but in the absence of editors' diaries or notes, this is conjecture based solely on the images themselves. It also was misleading for the editors to suggest to readers that a nostalgic, bucolic, rustic lifestyle prevailed when already many Fijians were living and working in towns. Indeed, by the 1950s, Fijians were squatting on the suburban margins and there was a sizable immigrant population from Rotuma, Tonga, the Solomon Islands, Kiribati, Banaba (on Rabi), Tuvalu (on Koia), and Wallis and Futuna. Choosing a village setting ignored the fact that Suva and Lautoka were busy port cities in the 1950 s and Ba, Labasa, Sigatoka, and Savusavu were growing into small towns. Fiji in the 1950 s had an airport, major wharves, colonnaded public buildings and hotels, railways, and streets lit with electric lights. But perhaps this was not the "Fiji" editors thought readers wanted to see in 1959. The post-war British Empire was being transformed, so perhaps there was, in the selection, a political message that the British population needed colonial stability. A year later, Britain declared that they were leaving Fiji, setting in place a decade of turmo il and unrest as Fijians and Indians struggled to form political parties, decide on a voting process, and write a constitution. The editorial decision to use "Fijian Islanders preparing a feast" had probably taken place several years earlier, prior to the political upheaval of decolonization. However, an alert editor might have chosen a more pertinent image such as a portrait of an Indigenous or Indo-Fijian community or political leader, such as A.D. Patel, Ratu Lala Sukuna, or Ratu Kamisese Mara, to educate readers that there was a next generation ready to take over once the British departed.

There also may have been an editorial post-war reaction identifying a need to return to normality after the disruptions of the 1930 s and World War II. Scenes of happy "natives" in a nostalgic, pastoral scene suggesting timelessness and tradition were something that young British readers and war-weary adults could smile and nod appreciatively at, as they conveyed the idea that the world, largely under British rule, was still a safe and predictable place. As an instrument of propaganda, promoting successful colonies in a wide empire, a photograph of "happy natives" suggested stability and that the world was returning to a pre-war agenda and policies. Specifically choosing images of Indigenous Fijians, who appeared to be engaged in ostensibly traditional actions, for the encyclopaedia would signify to readers how benevolent, paternal, and protective the British colonial regime had been in preserving a traditional Fijian way of life, and how normality had now returned after the disruptions of war. Fiji had been a British colony since 1874 , sometimes promoted as the epitome of progress and an ideal colony. ${ }^{22}$ It was described by Fijian leader Ratu Sukuna as a three-legged stool: Fijians on the land, Indians providing the labor, and Europeans providing the capital and managing the 


\section{Quanchi| Fijian Islanders Preparing for a Feast}

government. ${ }^{23}$ An alternative reading of the three-legged-stool analogy is that the three legs were the agents that protected Fiji from the unwanted consequences of joining the modern world: chiefs, Vanua (the land,) and the British. This idealized but non-existent colony was therefore depicted through an image of happy islanders preparing turtles for a feast. All these motivations, and others, may have been in place when the editor or sub-editors of The Book of Knowledge chose Thomson's turtle photograph.

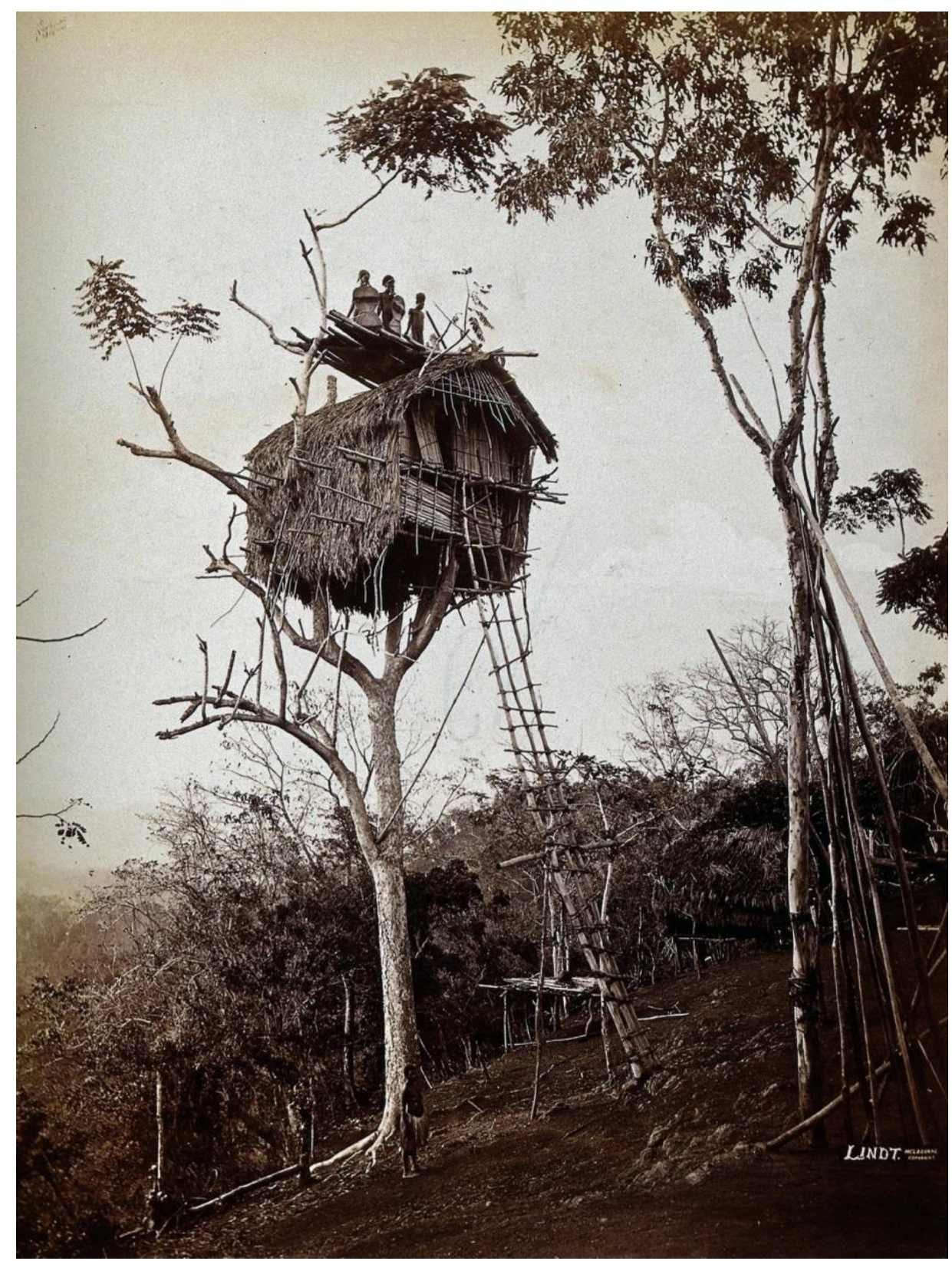

Figure 3. John William Lindt, Koiari tree house, photograph in Picturesque New Guinea (London: Longmans Green, 1887), plate XIV 


\section{Quanchi| Fijian Islanders Preparing for a Feast}

The 1959 Book of Knowledge also included an entry on New Guinea, with two representative illustrations similarly reinforcing stereotypes. ${ }^{24}$ One is a classic and oftenreproduced photograph showing one of a cluster of Koiari tree houses in the hinterland of Port Moresby (Fig. 3). It was taken by John William Lindt in 1885, and seventy-four years later, readers were being led to believe that Papuans still built tree houses for defensive purposes or, in a more grossly generalizing manner, that many or all Papuans and New Guineans lived in tree houses. ${ }^{25}$ The second photograph in the entry on New Guinea depicts three small boys fishing with miniature bows and arrows in rock pools on a reef in Mailu, a site on the southeast coast of Papua that was frequently photographed beginning in the 1880 s. This photograph suggested to readers that in 1959 these Indigenous practices were unchanged and prevalent.

Choosing illustrations for an encyclopaedia was a mid-twentieth-century editor's predicament: how to visually summarize a whole territory or colony using one or two images, and how to convey a sense of the present without using outdated images from decades earlier. This task was achieved in The Book of Knowledge in the much longer, eight-page entry on the "Pacific Islands" by including a pull-out map of the Pacific showing the most recently determined boundary and name changes. This entry also relied on a page of reproductions of recent postage stamps depicting a variety of Pacific people, fauna, and places. It applied a collage effect, with six photographs including a half-length portrait of a Marquesan male, a harbor scene in the Bismarck Archipelago, a harbor scene in Tahiti, a group portrait of Solomon Islanders, a village setting in Kusaie (Kosrae), and a beach scene with two outrigger canoes. ${ }^{26}$ Only the Tahitian scene had been photographed pre-1900. This gallery of portraits, body ornamentation, villages, canoes, and coastal scenery presented a fair representation of what the archipelagic island Pacific was like in the 1950 s.

The images for the entry on the "Pacific Islands" included the North Pacific, then a United States Strategic Trust Territory and an area often overlooked in British publications. The text also suggested quite correctly that the widespread and predominantly coastal village life of islanders and their reliance on the sea, fishing, and canoes was continuing. The island images had been provided by a stock photograph company, ENA, and the Royal Australian Air Force (RAAF). The scene in the Bismarck Archipelago in the Pacific Islands entry, provided by the RAAF, can be dated as post-World War II, but the origins of the other images are harder to determine and are possibly from the pre-war period. The photographers are not identified. Larger and more populous, New Guinea had a its own entry in Volume 5, though a photograph of a New Zealand radio station was incongruously included. Readers flipping the pages of the 1959 Book of Knowledge would have recognized a sense of timelessness, a hint of the longstanding fatal impact theory, and an inference that islanders who were changing or allegedly disappearing "used to look like this."

Readers may have been aware that the photographs were not all from the 1950s; however, casual readers flipping through the heavily illustrated pages of places, countries, 


\section{Quanchi| Fijian Islanders Preparing for a Feast}

and sites in a pictorial encyclopaedia probably did not query the dates of the images. The images' truthfulness and reliability came from their being published in an encyclopaedia, with the medium's imprimatur of officialdom and the generalized acceptance that the contents represented fact and truth. A survey of photography used in the boom period of serialised illustrated encyclopaedia (1900-30) suggests that the editors of The Book of Knowledge were aware of a need to provide up-to-date images and, consequently, mostly chose current material. ${ }^{27}$ Re-republishing Thomson's turtle scene can, therefore, be judged as either the result of editorial laziness or as an aberration. The inclusion of Thomson's turtle scene was meant to be educational and informative, but alternatively was outdated and not appropriate for publication. Its use suggests a range of contextual situations and priorities, primarily about European preoccupation with reasserting empire after World War II. The choice of images also repeated the long history of visual misrepresentation of the islands that stretches into the modern era. Although encyclopaedias were still influential in the 1950s, their market was declining. Therefore, the choice to not publish contemporary photographs in the 1959 Book of Knowledge may also be reflective of its publisher's cost-cutting measures, or a reliance on a few trusted suppliers of images, which was limited to available options.

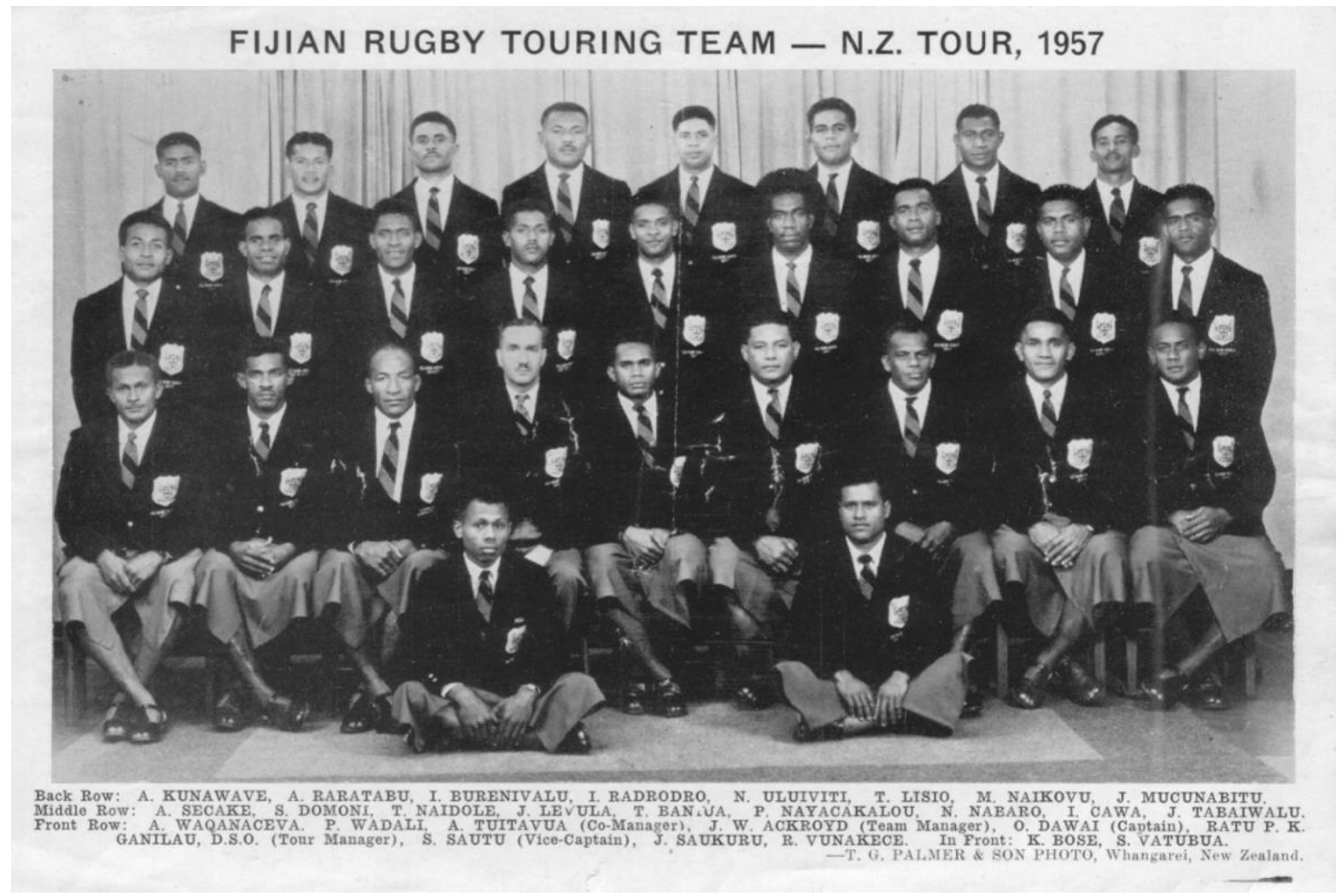

Figure 4. T. G. Palmer \& Son, Fijian Ruby Tourism Team - N.Z. Tour, 1957. Photograph, 1957, Whangarei, New Zealand. Courtesy of Wikimedia Commons 


\section{Quanchi| Fijian Islanders Preparing for a Feast}

Consider how an alternative image, such as "Fijian Rugby Touring Team-NZ Tour 1957" (Fig. 4) might have conveyed very different message about Fijians to readers of The Book of Knowledge. ${ }^{28}$ This photograph would have shown readers that Fiji was part of the wider world of modern sport in the 1950s, far removed from the stereotypes of Fijians being ancient cannibals living in tribal villages. It would have shown that wearing ties was common, at least when Fijians went on to the world stage, not just for church as was the practice at home in Fiji. While more acceptable because it was current, the photograph does not include any IndoFijians or other minorities, women, or non-iTaukei (Fijian landowners,) and ignores the popularity of other sports, such as soccer, or events, such as the Miss Hibiscus Festival. As historians have noted, Fiji also faced race riots and oil strikes in 1959, and diplomatic events a year later would see the United Kingdom announce it was leaving Fiji. ${ }^{29}$ The image also misrepresents the Fiji of the time by suggesting that Fiji was secure in the British Empire, and that when back at home the young men were modern in their fashion, dress, and deportment.

Compared to The Book of Knowledge, Walkabout magazine's choice of photographs representing Fiji was far more contemporary and reflective of current trends. In 1957, Walkabout published three articles on Fiji with seven photographs including images of cane trains, traffic policemen, sulu-wearing constabulary, a large meke (dance) in a village, and a ceremonial arrival of the Governor being carried on a litter across a beach in Kadavu. ${ }^{30}$ These were contemporary events that depicted the Fiji of the 1950s. Although Mitchell Rolls and Anna Johnston argue that in Walkabout the Pacific was "a utopian space of fantasy and projection and simultaneously a site where Australians could explore other primitive cultures," the problem is that we have few archival traces of how readers and viewers reacted to specific images in publications. ${ }^{31}$

It is difficult to decide whether Thomson's 1880 os scene of preparing turtles for a feast was an appropriate representation of Fiji in the 1950s. The use of "Fijian islanders preparing a feast" does depict a Fijian custom regarding turtles, but it also misled readers by not acknowledging the political, social, and demographic changes in post-World War II Fiji. The Book of Knowledge's brief post-World War II summary for the entire Pacific mentioned only that United Nations trusteeships had been declared over some islands and that some islanders were serving on legislative advisory councils. The year in which The Book of Knowledge was published with Thomson's photograph was a year on the cusp of global change. The twentieth-century colonial world was taking on a new shape as emerging nations accepted or unilaterally declared their independence. France was about to leave most of its African colonies, Britain was about to declare its lack of interest in colonies east of Suez, and in 1960 the United Nations declared in the often-cited General Assembly resolution 1514 (XV), that all colonized subject peoples had the right to be free from foreign rule. ${ }^{32}$ Readers in 1959 would have noticed the disparity between The Book of Knowledge's romantic story of Fiji's origins, European exploration, and promising export crops and what they read in newspapers 


\section{Quanchi| Fijian Islanders Preparing for a Feast}

of the day, which presented another Fiji-one worried about race riots, lightning sugar strikes, and two major commissions of inquiry into economic and social problems, natural resources, and population decline. Fiji was on edge with unresolved electoral and constitutional proposals, and indigenous Fijians were despairingly watching Indo-Fijians fill professional ranks as public servants, lawyers, doctors, nurses, and accountants. Despite being published in a rapidly modernizing, post-war era when old empires were crumbling, The Book of Knowledge in 1959 relied on obsolete tropes of Indigenous Fijians as treacherous cannibals instead of portraying them as law-abiding people who served Britain loyally in World War II. The Fiji entry was clearly about a time before, not the present.

Readers in 1959 would have been familiar with The Book of Knowledge's conventional format, used by pictorial, serialised, encyclopaedia stretching back fifty years. The fortnightly or monthly arrival of the next issue of an illustrated serial encyclopaedia had been an amazingly influential publishing venture affecting popular opinion in the first half of the twentieth century. It had educated several generations of Euro-American readers about distant worlds such as the Pacific Islands, but by 1959 the format had become an anachronism, harking back to old times and former imperial glories. A portrait of Ratu Lala Sukuna debating the fate of Fiji, looking decidedly modern and dressed in his pocketed sulu and tie, rather than a preparation for a turtle feast, would have been a better choice of illustration.

Max Quanchi has taught Pacific history at Queensland University of Technology, University of Papua New Guinea, and University of the South Pacific. His research is on the history of photography in the Pacific. He has guest-edited special issues on photography for Pacific Studies, the Journal of Pacific History, and the Journal of New Zealand and Pacific Studies. Since 1996 Dr. Quanchi has convened panels on photography at the semiannual Pacific History Association conferences. He has published several books, including the monograph Photographing Papua: Representation, Colonial Encounters and Imagining in the Public Domain (2007), which focuses on the colonial frontier in Papua New Guinea. His most recent publication is An Ideal Colony and Epitome of Progress: Colonial Fiji in Picture Postcards, coauthored with Max Shekleton (2019).

\section{Notes}

${ }^{1}$ Elsie Stephenson, Fiji's Past on Picture Postcards (Suva: Caines Janiff, 1997), 253; Max Quanchi and Max Shekleton, An Ideal Colony and Epitome of Progress: Colonial Fiji in Picture Postcards (Suva: University of the South Pacific Press, 2019), 128.

2 Basil Thomson, "Curiosities of the South Seas," The Wide World Magazine 3 (May-October 1899), 376-83, 509-16, https://archive.org/details/wideworldmagazinozlonduoft/mode/2up; Stephenson, Fiji's Past, 86. 


\section{Quanchi| Fijian Islanders Preparing for a Feast}

${ }^{3}$ Publishing a previously released postcard in reverse was a common tactic. Stephenson, Fiji's Past, 253, 325, 338; John Dear, The Picture Postcards of Fiji (London: Pacific Islands Study Circle, 2004), 16.

${ }^{4}$ Basil Thomson, The Fijians: A Study of the Decay of Custom (London: William Heinemann, 1908), 326. He also included twelve other photographs, many later also made into postcards. 5 Basil Thomson, "British Empire in Australasia: Island Life in the Strange South Seas," Peoples of All Nations 2 (1922): 897-972.

"Calipee and Calipash-The first is the name given to the meat attached to the lower, and the last to the meat attached to upper shells of a turtle.

"Calipash is a corruption of carapace, the upper shell of the turtle; but it is used to signify only the green fat or gelatinous matter which adheres to the upper shell, while calipee is the name given to the yellow fat or gelatin which is attached to the under shell." Definitions from "Calipee and Calipash--Defined," Gjenvick-Gjønvik Archives, accessed Sept. 23, 2021, https://www.gjenvick.com/Epicurean/CookingTerms/CalipeeAndCalipash.html. 6 "Sunshine Islands and Savages: The Untamed Life of the South Seas," Lands and Peoples: The World in Color, vol. 5, ed. Gladys D. Clewell and Holland Thomson, (New York: The Grolier Society, 1947), 305-21, 319.

${ }^{7}$ After returning to England, Thomson worked as a writer, prison warden, World War I spy, and director of a post-war security agency. He was knighted in 1926. Noel Rutherford, “Thomson, Sir Basil Home (1861-1939)," Oxford Dictionary of National Biography, https://doi.org/10.1093/ref:odnb/36499.

8 This publication used seventeen photographs provided by Charles V. Lucas and James Edge-Partington.

9 Thomson, "Curiosities," 509-16; Thomson, "British Empire in Australasia," 253, 897-972; Basil Thomson, "South Sea Islands: Palm Fringed Edens of Oceania," Countries of the World 37 (London: Waverley Book Company, 1925): 2925, 3753-6, 3768, 3789, and the cover; Basil Thomson, "Fiji Islands: Archipelago Born of Coral and Volcano," Countries of the World 38 (London: Waverley Book Company, 1926): 1869-80.

${ }^{10}$ Eight of these photographs were listed as having been supplied by the "Fiji Government." His "turtle" photograph was not included.

11 Thomson used his own photographs in his articles, but also acknowledged others who had provided additional images, either knowingly or plagiarized by those sources, including Reverend George Brown, W.N. Beaver, Thomas McMahon, C.W. Collison, J.W. Beattie, H.A. Markham, J.F. Goldie, Douglas Rannie, Reverend W Gunn, R.M. Clutterbuck, W.S. Knox, Osmonde Pope, a picture library (ENA), York and Son, and the Field Museum, Chicago. ${ }^{12}$ Thomson, The Fijians, 322. The Fijian government placed a one-year ban on the harvest of marine turtles in 1995, followed by a three-year ban from May 1997 to December 2000, and a moratorium from February 2004 until December 2008. In 2014, a full ban was enacted and remains in place.

${ }^{13}$ Thomson, The Fijians, 3; Cyclopedia of Fiji (Sydney: The Cyclopedia Company of Fiji, 1907): 3; Stephenson, Fiji's Past, 324.

${ }^{14}$ Gordon Stowell, ed., The Book of Knowledge: A Pictorial Treasury of Reading and Reference for Young and Old (London: The Amalgamated Press, The Waverley Book Company, 1959), 1:5-8. 


\section{Quanchi| Fijian Islanders Preparing for a Feast}

15 John A. Hammerton, "From the editor," Countries of the World 37 (London: Waverley Book Company, 1926): inside cover.

${ }^{16} \mathrm{~J}$. A. Hammerton, ed., People of All Nations: Their Life Today and the Story of Their Past (London: Fleetway House, 1922), 2340.

${ }^{17}$ Stowell, The Book of Knowledge, 6: 494.

${ }^{18}$ Stowell, The Book of Knowledge, 1: vii, viii.

${ }^{19}$ Marshall D. Sahlins, Moala: Culture and Nature on a Fijian Island (Ann Arbor: University of Michigan Press, 1962).

${ }^{20}$ Wright filled this role from 1940 to 1969. Sir lan Thompson, Fiji in the Forties and Fifties, ed. Peter Thompson (Auckland: Thomson Pacific, 1994); "Rob Wright Fiji Photographs, 3. Fiji's Scenery," Just Pacific (website), accessed September 25, 2021, http://www.justpacific.com/fiji/fijiphotos/wrightpics/scenery/index.html.

${ }^{21}$ See Rob Ewins, "Rob Wright Fiji Photographs," accessed Sept. 25, 2021, https://www.justpacific.com/fiji/fijiphotos/wrightpics/index.html and post on Robertson Ramsay Wright, Fiji Museum Facebook page, June 13, 2013, https://www.facebook.com/fijimuseum/photos/robertson-ramsay-wright-mbe-known-toone-and-all-as-rob-wright-was-born-in-sigat/539340589459462/.

${ }^{22}$ Quanchi and Shekleton, An Ideal Colony,128-29.

${ }^{23}$ Lala Sukuna, Fiji: The Three-legged Stool: Selected Writings of Ratu Sir Lala Sukuna, edited by Deryck Scarr (Sydney: Macmillan 1983).

${ }^{24}$ Stowell, The Book of Knowledge, 5: 395-97.

${ }^{25}$ Rupert Stacsh, "Korowai Tree Houses and the Everyday Representation of Time, Belonging, and Death", Asia Pacific Journal of Anthropology 12 (no. 4, 2011): 327-47; Max Quanchi, "Tree Houses, Representation and Photography on the Papuan Coast 1880-1930," in Art and Performance in Oceania, ed. Barry Craig, Bernard Kernot, and Christopher Anderson (Bathurst: Crawford House Press, 1999): 218-30.

${ }^{26}$ Stowell, The Book of Knowledge, 6: 24-31.

${ }^{27}$ Max Quanchi, "Learning by Looking: For example, at Peoples of all Nations; European Education and Serial Encyclopedia," Pacific Geographies 45 (January/February 2016): 11-16, https://doi.org/10.23791/451116.

${ }^{28}$ Wikimedia Commons contributors, “File: 1957 Fiji rugby union team.jpg," Wikimedia Commons, The Free Media Repository, accessed September 20, 2021, https://commons.wikimedia.org/wiki/File:1957_Fiji_rugby_union_team.jpg\&oldid=490121399.

29 James Heartfield, "The Dark Races Against the Light: Official Reaction to the 1959 Fiji Riots", Journal of Pacific History 37 (no. 1, 2002): 75-86; Brij V. Lal, Broken Waves: A History of the Fiji Islands in the Twentieth Century (Honolulu: University of Hawai'i Press, 1991); Brij V. Lal, Levelling Wind; Remembering Fiji (Canberra: ANU Press, 2019).

30 Richard Harrington, "Where the Rails are Free (Viti Levu, Fiji Island)", Walkabout 23 (no. 1, January 1957): 41-2; Richard Harrington, "Fiji's Famous Constabulary", Walkabout 23 (no. 4, April 1957): 36-8; Sarah F. T. Hanna, “Life on a Fijian Island”, Walkabout 23 (no. 9, September 1957): 14-5.

${ }^{31}$ Mitchell Rolls and Anna Johnston, Travelling Home: Walkabout Magazine and Mid-Twentieth Century Australia (London: Anthem, 2016): 183-6. 


\section{Quanchi| Fijian Islanders Preparing for a Feast}

32 "Declaration on the Granting of Independence to Colonial Countries and Peoples," Resolutions adopted without reference to a Committee, 1514 (XV), General AssemblyFifteenth Session, accessed Sept. 23, 2021, https://undocs.org/A/Res/1514(XV). 


\title{
DEBORAH WAITE
}

\section{Canoe Carvings from Western Solomon Islands: The Operative Efficacy of Simultaneous Visual Presences}

\begin{abstract}
This article considers a group of late nineteenth-century canoe carvings from Western Solomon Islands. They are so stylistically similar that they could have been carved by the same person, although that information is now lost. Functionally, the carvings' imagery points to cultural parallels in a manner that gives them an operative efficacy, not just to the canoes to which they were lashed, but also to the vessels' occupants and owners. This connectivity would have prevailed, not only during a war expedition when the canoes were in use, but before and after, when the carvings were put on and taken off the canoes. The carvings were likely stored in the houses of the canoe owners or in mortuary shrines, establishing a spatial-social cyclicity.
\end{abstract}

Keywords: Solomon Islands, canoe carvings, operative efficacy

This paper focuses on fourteen canoe carvings from New Georgia Island, Western Solomon Islands. Ten of these carvings are now in the Pitt Rivers Museum, Oxford University, England, and two are in the Kulturen Museum, Basel, Switzerland. Another belongs to the Museum of Anthropology, University of British Columbia, Vancouver, and one is in the Auckland War Memorial Museum, New Zealand. ${ }^{1}$ Among the many carvings once lashed to prows and sterns of war and fishing canoes from Western Solomon Islands, these carvings merit consideration as a cohesive group as four features unite them.

First is an emphasis on two-dimensional, low-relief carving. Secondly, color plays a distinguishing role. Red, blue, and white, as well as some black and major unpainted areas, characterize these carvings in contrast to the many uniformly black or dark brown carvings that prevail in Western Solomon Islands. ${ }^{2}$ A third visual factor that unites these works is the prolific use of low-relief design elements depicting shell rings and shell body ornaments. These motifs are rendered on the framing borders of the canoe carvings, as well as on the bodies and heads of images. Shell rings are ubiquitous in the islands. Among the many shell ornaments worn in the western islands, the triangular-shaped barava, in particular, is privileged as an image among these carvings. A shell barava can be worn by people as a chest ornament. ${ }^{3}$ A row of these barava would be lashed to a stick concealed within the two 


\section{Waite Western Solomon Islands Canoe Carvings}
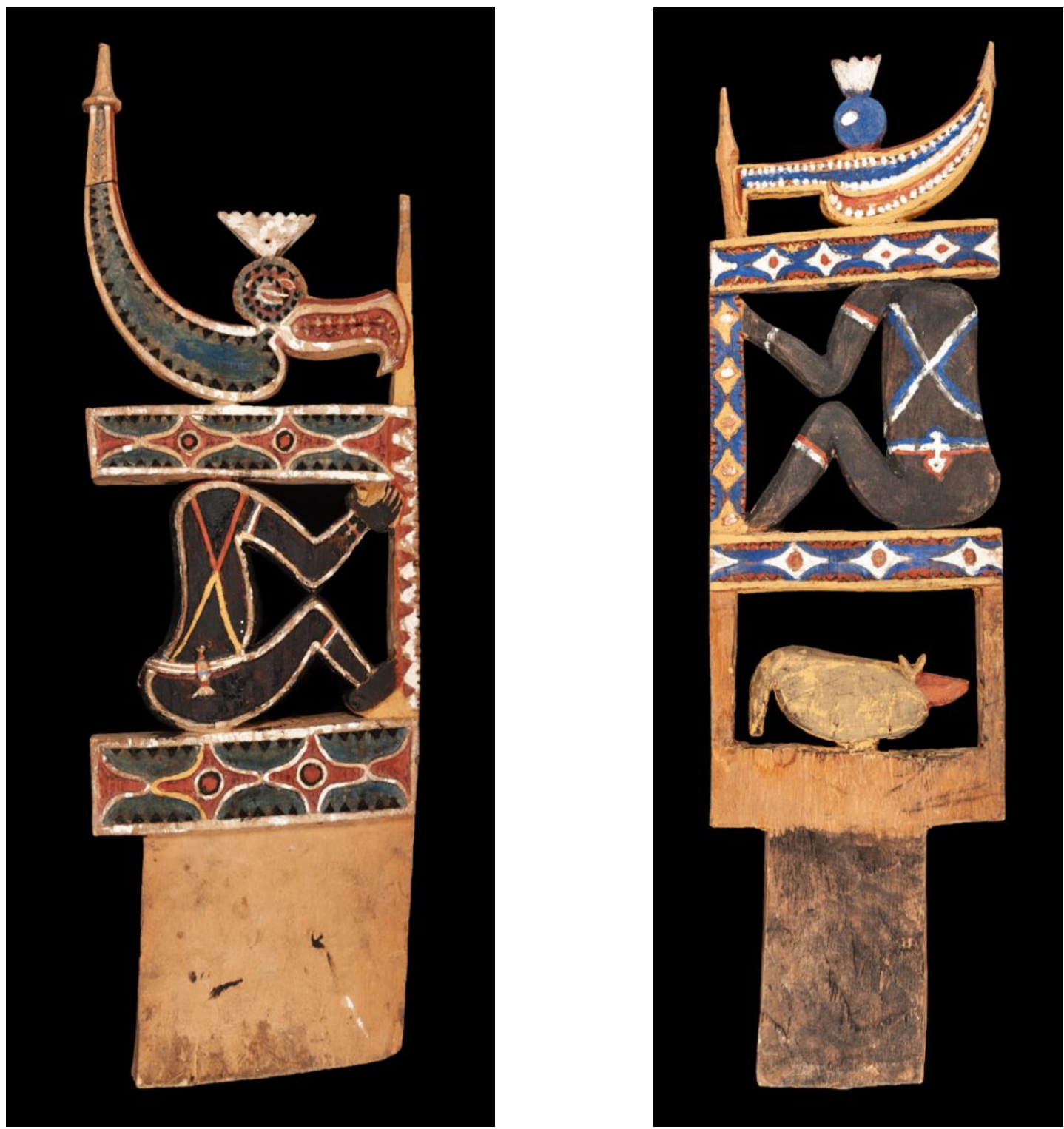

Figure 1 (left). Canoe prow figure of Kesoko. Ngarisi District, Ramada, New Georgia Island. H. 78.8.cm. Collected by Henry Boyle Townshend Somerville, 1893-4. Photograph by Suzy Prior. Courtesy of the Pitt Rivers Museum, University of Oxford (DII 1895.22.161)

Figure 2 (right). Canoe prow figure of Kesoko. Ngarisi District, Ramada, New Georgia Island. H. $55.3 \mathrm{~cm}$. Collected by Henry Boyle Townshend Somerville, 1893-4. Photograph by Suzy Prior. Courtesy of the Pitt Rivers Museum, University of Oxford (DII 1895.22.162)

halves of the bowsprit, so that they projected in a row from the canoe prow. Images of barava and the objects themselves often appear on canoe ornaments from Western Solomon Islands, but in the particular group of canoe carvings under discussion the barava may become integrated as design elements. Notched or serrated designs that occur on the head ornaments known as kapkap (in Solomon Islands, dalo) also recur as relief ornaments on different carvings in this group. ${ }^{4}$ The fourth motif that ties this group together is the spiral. 


\section{Waite $\mid$ Western Solomon Islands Canoe Carvings}

Among these canoe carvings, the spiral either functions as a support or is integrated as a design element. Spirals are not uncommon among canoe prow or stern carvings from the Western Solomon Islands, especially among fishing canoes. However, as we will see, it is the manner in which the spiral is integrated with other designs that typifies some of the canoe carvings in this group.

The choice of imagery for the artworks under consideration associates them with other canoe carvings, as well as many other Western Solomon Islands artworks. Their visual treatment, however, differs. Predominant are two versions of seated anthropomorphic figures: one with a human head and the other with a frigate bird head. Hybrid human-bird images are a common phenomenon in art from New Georgia and might allude to a sea/reef spirit called Kesoko, who is closely tied to spearfishing and net fishing. Kesoko has a man's body but his mouth is like the beak of a frigate bird. Such hybrids predominate in this particular cluster of canoe carvings (Figs. 1-6). Two canoe prow carvings that represent human skulls or heads (Figs. 7-8) reiterate a common theme among war canoe carvings from Western Solomon Islands. However, the examples in this group differ markedly in visual treatment from others in the choice of relief imagery that decorates the heads, as well as a strong emphasis on two-dimensionality. Also included in this group of canoe carvings are the frigate bird and the crocodile, both prevalent among many images from Western Solomon Islands but associated here with the spiral (Figs. 9-10).

In short, several features recur and appear to collectively define the carvings to be considered in this paper. It is their interactional recurrence that defines the group. Exploration of these features will necessitate considerable detailed examination of both visual and contextual matters. A final note: geography also binds these carvings, as all were produced and used within the Marovo and Ramada (Munggeri region) districts of New Georgia Island. They were "collected" during a period extending from 1893 to the early $1920{ }^{5}$ "The carving now in the Auckland War Memorial Museum (Fig. 6) has no regional or collection data. However, it appears to constitute a variant of Kesoko sea spirit imagery not otherwise present in the group but visible among net floats and painted canoe paddles from Western Solomon Islands. Yet in most other ways, it corresponds in style and imagery to the rest of the group.

At the risk of overstating the obvious, these carvings are objects. Each was carved in low relief on both sides, usually with identical imagery, and when lashed to a canoe prow or stern, its presence and communicative power were thus visible from all directions as the canoe moved through the water (Figs. $7 \mathrm{a}$ and $7 \mathrm{~b}$ ). This function was accomplished by paired head carvings lashed to the ends of other canoes, facing fore and aft or, in some cases, in four directions - the better to perceive any negative force (enemies, storms, and the like). ${ }^{6}$ The relevance of this functional role of canoe ornament as object should be kept in mind during the upcoming sections of visual analysis of form and imagery. Objectification theory, which 


\section{Waite | Western Solomon Islands Canoe Carvings}
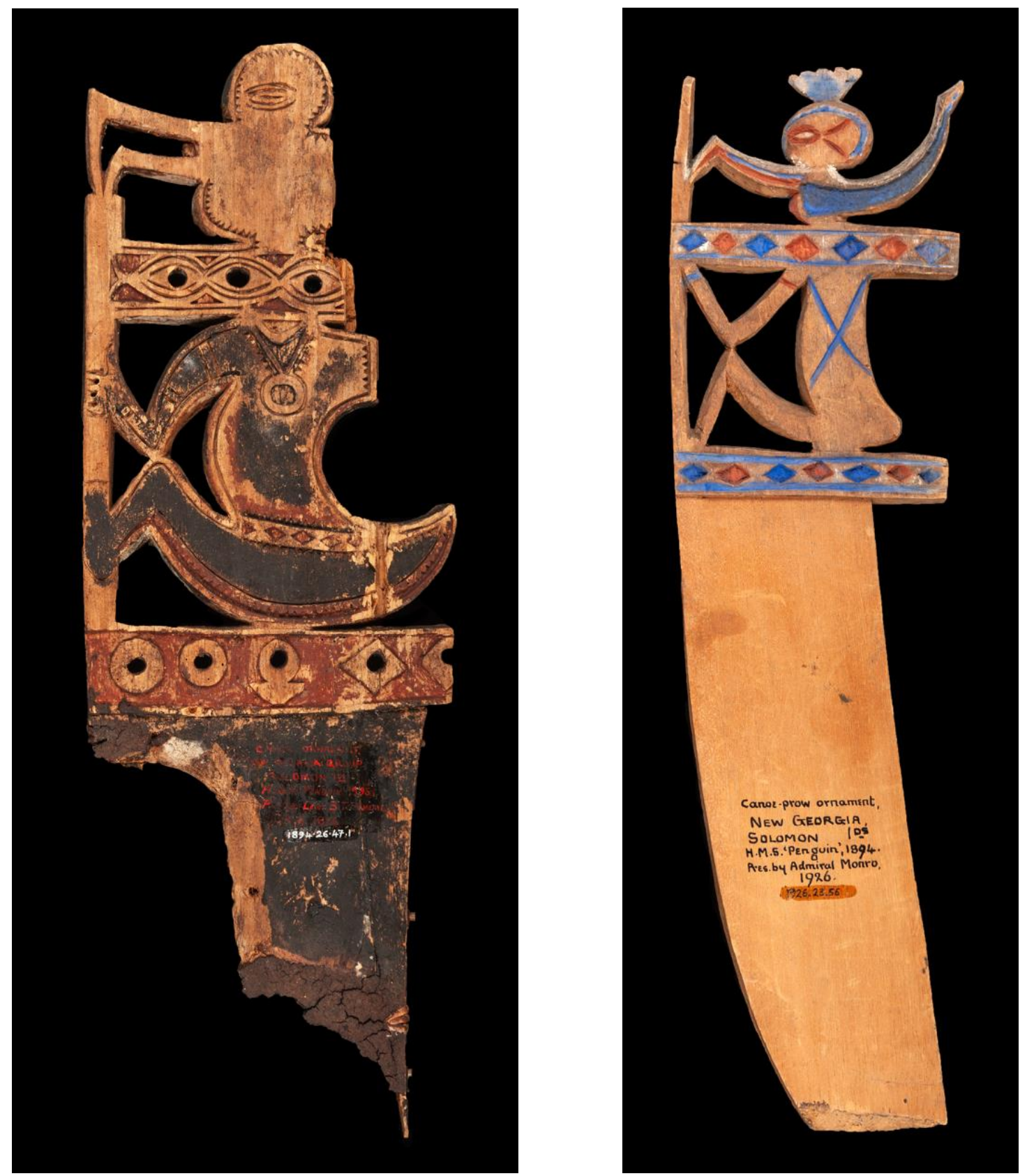

Figure 3 (left). Canoe prow figure of Kesoko. Ngarisi District, Ramada, New Georgia Island. Gr.h. $41.7 \mathrm{~cm}$. Collected by Henry Boyle Townshend Somerville, 1893-4. Photograph by Suzy Prior. Courtesy of the Pitt Rivers Museum, University of Oxford (1894.26.47.1)

Figure 4 (right). Canoe prow figure of Kesoko. Ngarisi District, Ramada, New Georgia Island. H. $37.6 \mathrm{~cm}$. Collected by Henry Boyle Townshend Somerville, 1893-4. Photograph by Suzy Prior. Courtesy of the Pitt Rivers Museum, University of Oxford (1926.23.56)

recognizes the active, affective role of an object and its visual components, provides a framework for these considerations. ${ }^{7}$ The following is an examination of the canoe carvings in this focal group as arranged according to category or type. 

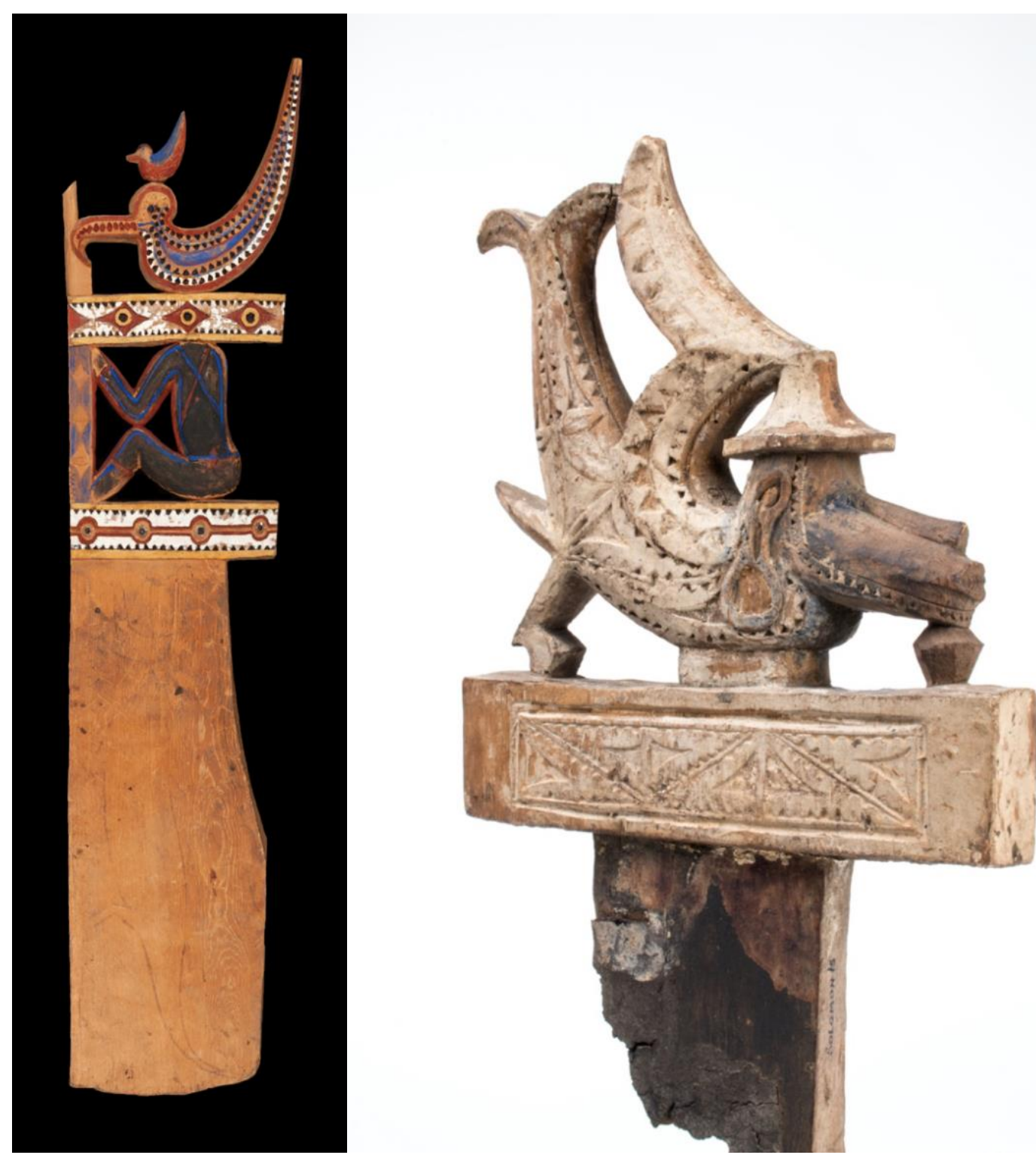

Figure 5 (left). Canoe prow figure of Kesoko. Ngarisi District, Ramada, New Georgia Island. Gr.h. $74.5 \mathrm{~cm}$. Photograph by Suzy Prior. Courtesy of the Pitt Rivers Museum, University of Oxford (1895.22.160)

Figure 6 (right). Carved canoe ornament, Solomon Islands. Courtesy of the Auckland War Memorial Museum Tãmaki Paenga Hira $(1981.164,49337)$

\section{Heads (Skulls)}

War canoes (tomako) from Western Solomon Islands traditionally bear several sculptures lashed to prow, prow peak, and stern. Carvings of anthropomorphic heads predominate as a theme for war canoes, once employed in headhunting raids, through the end of the nineteenth century. Lashed to every prow was a prognathic head or, more rarely, a complete 


\section{Waite | Western Solomon Islands Canoe Carvings}

seated figure with prominent head called nguzunguxu or totoishu (Roviana and Marovo districts, respectively). ${ }^{8}$ Attached to the tip of a prow immediately above the canoe figurehead would be small anthropomorphic heads carved back-to-back (mbeku); in some cases, heads of frigate birds appear, alluding to Kesoko. ${ }^{9}$ It is the prow peak carvings, in particular, that provide the Western Solomon Islands context for the two carvings representing heads or skulls in this discussion.

The two head/skull canoe carvings display features that epitomize many canoe prow figureheads and mbeku canoe prow peak carvings: an extended lower face, a long nose with upswept swelling nostrils, and an open, tooth-filled mouth. Tim Thomas has noted that the very names of the canoe figureheads incorporate these exaggerated features: "Nguzunguzu is a reduplication of the Roviana word for mouth, implying exaggeration. Toto isu comes from the Marovo words for nose (isu) and directional pointing (toto), meaning something like 'pointing nose." ${ }^{\prime 10}$ Both exaggerated features signal sensory efficacy: the ability to smell, sensitivity to the aromas of certain plants, and the devouring capacity of these guiding images that protected the occupants of a canoe from dangerous spirits that could include Kesoko. ${ }^{11}$

Several features distinguish these two particular canoe head carvings. Both are considerably larger than many of the surviving examples. They also exhibit a much more twodimensional approach to carving; they are flat profiles rendered on both sides in a manner that subtly conveys an illusion of three-dimensionality. From a distance, each is a single head that could be viewed from either side, corresponding in a sense to the paired threedimensional heads that face in opposite directions on other canoes. Low-relief carving on both represents images of shell barava, as well as rows of notched or serrated designs in a manner that covers the surfaces of the heads. Both of these designs appear on shell ornaments; a row of barava images frequently provides the outermost encircling motif on tridacna clamshell kapkap or dala. ${ }^{12}$

There may be minor differences in these relief designs on both sides of a single head (as seen in Figs. 7-8), but these differences are very small. On the Pitt Rivers head (Fig. 7), the designs occupy more of the surface of the heads than does the more discrete, shell-inlaid, facial ornament that is such a frequent feature of canoe carvings and other images from Western Solomon Islands. In addition, the Pitt Rivers carving exhibits the seemingly everpresent black or dark brown color of other carvings. This example is unpainted save for the red paint used for the barava-like shell ornaments and the circles that replace ears. The Vancouver example has a tight row of notched geometric designs that do correspond in position and proportion to facial painting: a row along the jaw and another along the middle section of the face (Fig. 8). Another row of tiny barava designs is carved along the upper forehead, emphasizing the curve of the skull. Much of the Vancouver skull is covered with a patina that mitigates color analysis, but traces of red are still visible on the upper skull and the color appears to outline the designs carved on the right side. 


\section{Waite | Western Solomon Islands Canoe Carvings}
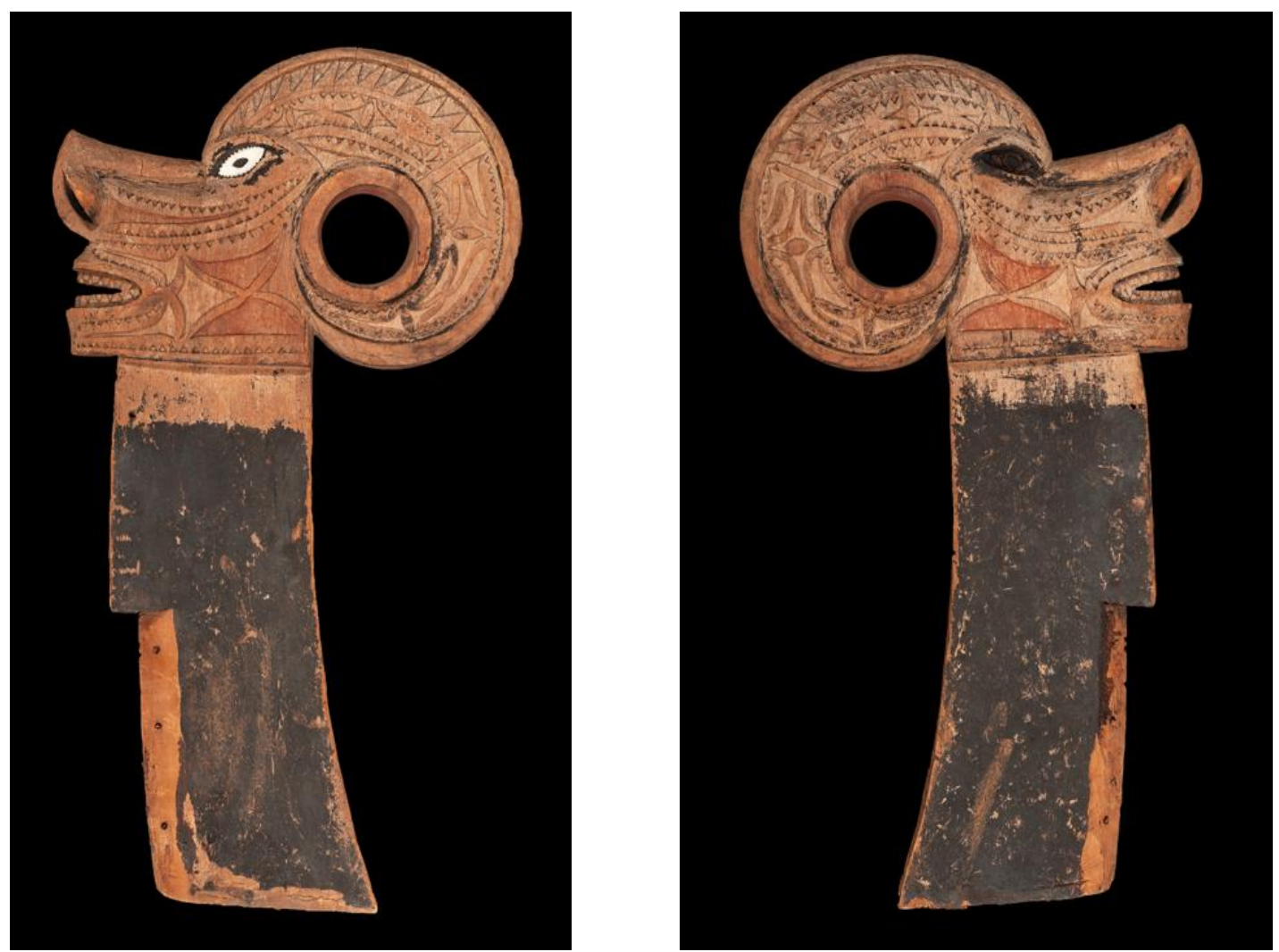

Figures $7 \mathrm{a}$ (left) and $7 \mathrm{~b}$ (right). Two sides of a canoe prow carving in the form of an anthropomorphic skull. Gr. I. $48 \mathrm{~cm}$. Collected by Charles Edward Monro, 1894-5. Photograph by Suzy Prior. Courtesy of the Pitt Rivers Museum, University of Oxford (DVIII 1926.23.54)

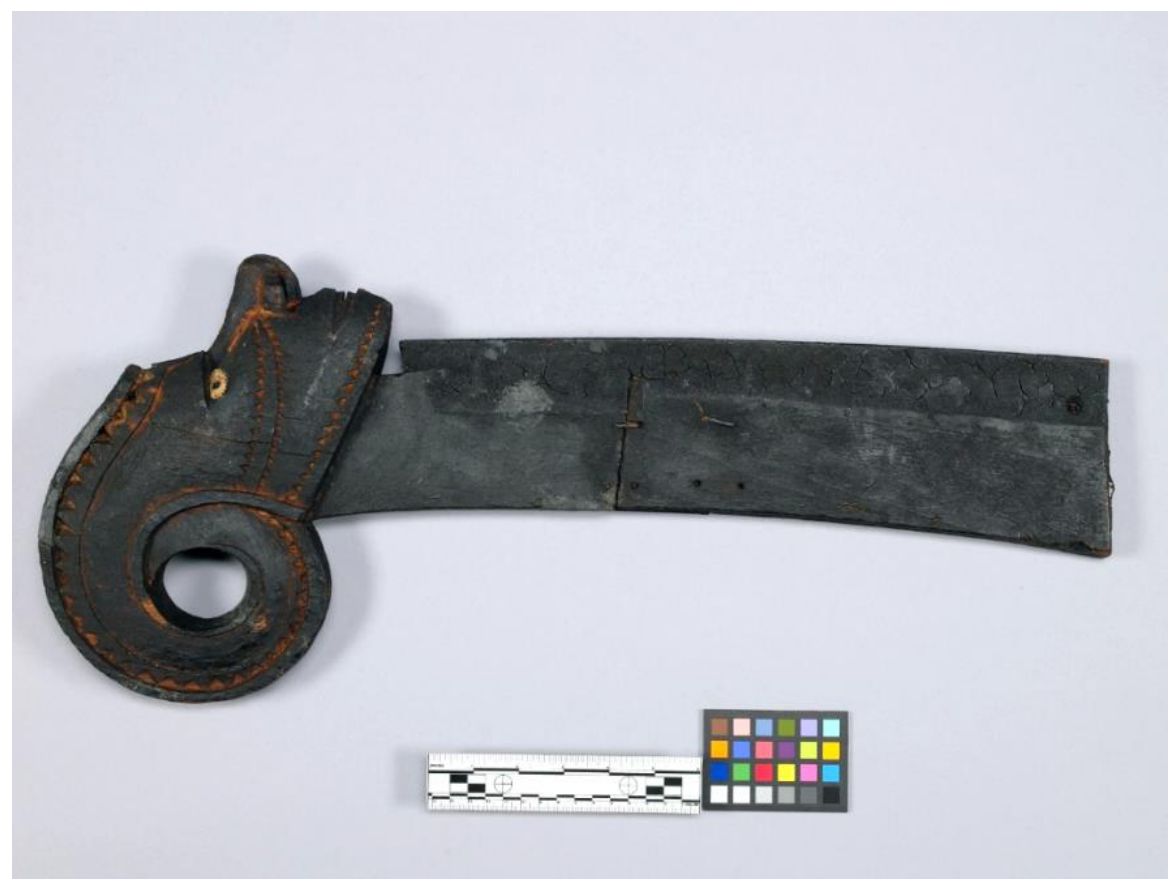

Figure 8. Canoe prow carving in the form of an anthropomorphic skull. Collected by Frank Burnett, 1909. Gr. I. Photograph by Jessica Bushey. Courtesy of the Museum of Anthropology, University of British Columbia, Vancouver (C361) 


\section{Waite | Western Solomon Islands Canoe Carvings}

Perhaps the most notable decorative feature of these two heads is the absence of ears and their replacement by large rings carved in low relief and with an open hole through the middle of the head. The ring is complete on the Pitt Rivers skull carving (Fig. 7) but incomplete on the Vancouver example (Fig. 8). However, enough of the latter is visible to make its presence felt, and the prominent holes in place of ears remains conspicuous. The apparent replacement of ears by rings has two potential cultural explanations. Firstly, it may be a direct reference to the social importance of hearing in this part of the Solomon Islands, as illustrated by ritual substitution of the ear for the body in post-funeral contexts and the multiple instances of the linkage of hearing (ears) with shell rings. ${ }^{13}$ More specifically is the treatment of skulls of high-ranking individuals (ancestral or conquered) in which shell rings were fastened to eye openings and at ear positions.

Hearing, Thomas notes, was regarded on New Georgia as comparable to affective sociality. ${ }^{14}$ Accordingly, ear ornaments worn by men were large and prominent. Large circular or oval ear ornaments adorn most canoe prow figureheads, as well as many other images, virtually dwarfing the actual ears and usually bearing inlaid nautilus shell. In one example of an anthropomorphic canoe carving that graphically illustrates the importance of ear ornaments, the figure is rendered frontally with elaborate nautilus shell insets (Fig. 11). It raises its hands to touch ear ornaments so large that they appear to flank the head. ${ }^{15}$

Several Solomon Islands customs recorded by Arthur Maurice Hocart on Simbo and Roviana (New Georgia) illustrate the association of hearing with ears and with shell rings, which served as social instruments of "hearing." "Effective sociality involved the ability to 'hear' the talk of chiefs and ancestral spirits ... in order to live well." ${ }^{16}$ Deaf people could not be chiefs and were often thought to be mad. One instrument used in the treating of madness was constructed with horizontally and vertically arranged sticks with two leaves of akaku "made into two rings and tied one on each side of the point of intersection "like the ears of a man.""17 In a former custom involving the sacrifice of an enemy in honor of a new canoe, body parts of the victim were cooked and eaten. An exception was the ears, which were cut in two and burnt at the skull house as the "body for you the spirits, be efficacious." ${ }^{18}$ In other words, ears were the body substitute employed as an affective offering that would guarantee cooperation from the spirit world.

Hearing was obviously an essential part of effective communication, and that was precisely the role of shell rings on numerous occasions. Divination with a shell ring (sabusabukai) involved "hearing" the words of spirits transmitted through the ring, which would be held out at arm's length. The spirit would be questioned and the ring, which would 

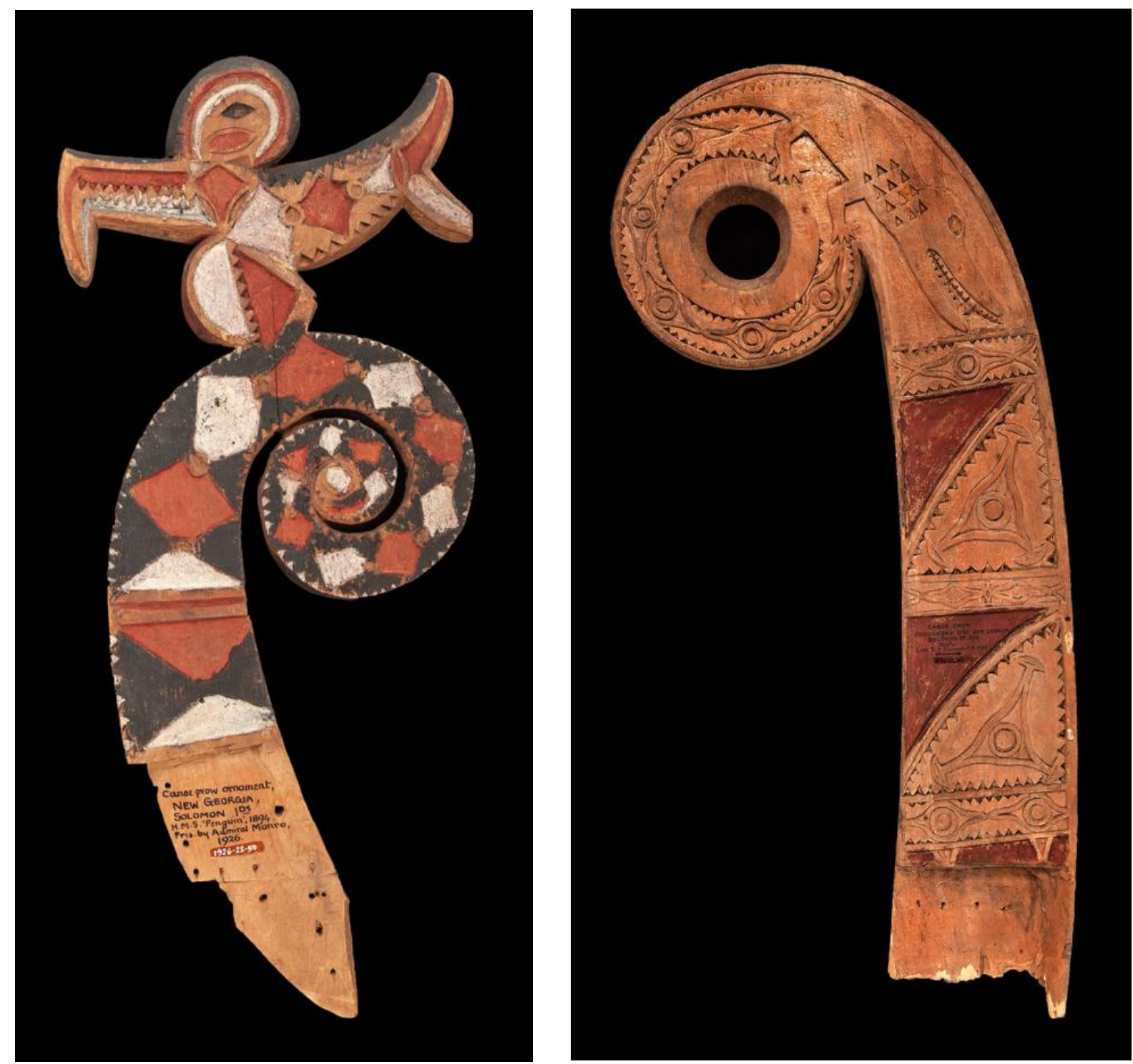

Figure 9 (left). Canoe stern (?) ornament, with frigate bird atop a spiral. Gr.h. $43 \mathrm{~cm}$. Collected by Charles Edward Monro, 1895. Photograph by Suzy Prior. Courtesy of the Pitt Rivers Museum, University of Oxford Museum (1926.23.57)

Figure 10 (right). Canoe stern carving with spiral and crocodile. New Georgia Island. $\mathrm{H} .70 \mathrm{~cm}$. Collected by Henry Boyle Townshend Somerville, 1893-4. Photograph by Suzy Prior. Courtesy of the Pitt Rivers Museum, University of Oxford (1895.22.165a) 


\section{Waite | Western Solomon Islands Canoe Carvings}

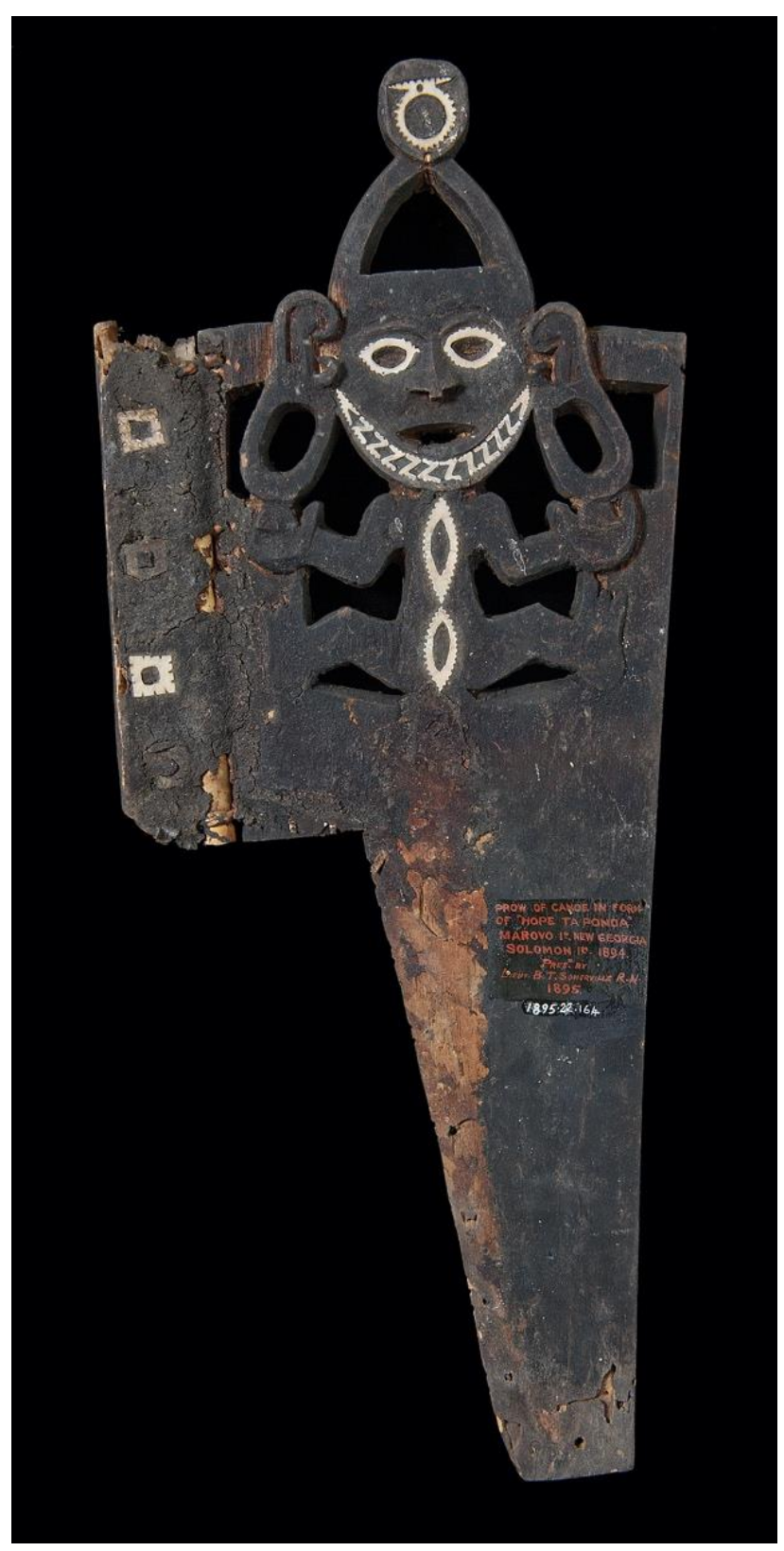

Figure 11. Canoe prow carving. Marovo, New Georgia. Collected by Henry Boyle Townshend Somerville, 1893-4. Photograph by Suzy Prior. Courtesy of the Pitt Rivers Museum, University of Oxford (1895.22.164)

cause the arm of the medium to rotate, indicated a response. ${ }^{19}$ One example of the divination process employed for curing illness involved a diviner named Kundaite who was able to catch the penupenu,

a diminutive parcel made up of leavings of the sick man-bits of tobacco peels, or else hair, nails, etc. of a patient which were stolen by spirits and return it [the penupenu] to the patient. Kundaite paid one arm ring to the spirits saying ... 


\section{Waite Western Solomon Islands Canoe Carvings}

this is your arm-ring, ye spirits, let me go and heal, do you redeem this armring. ${ }^{20}$

Numerous instances of shell rings offered to spirits prior to, during, and following bonito fishing expeditions further illustrate their use as efficacious social devices. ${ }^{21}$

But perhaps most directly relevant for these two canoe head carvings, on which rings carved in low relief substitute for ears, is the data obtained by Hocart from Simbo and Roviana islands involving the deposition of the corpse and skull of a chief. Richard Walter, Tim Thomas, and Peter Sheppard have summarized Hocart's data as follows:

After death, the body of the deceased was dressed in finery, then wrapped in pandanus leaves and placed in the bush to rot, sitting upright facing west. Their belongings were broken - the equivalent of the body's decay. During this time the maqomaqo [the person's soul-shadow] would fly up into the rafters of the deceased's house. After four nights had passed, it would be called down and ritually 'caught' within a shell ring and zipolo leaf (Dracaena sp). . . . [T]he shadow of the dead was transformed into a ring so that the tomate [potential evil aspect of the spirit] could not take personal form and wander. After a few weeks the skull was removed and left in the sun to bleach until the eighteenth day, when it would be placed in a skull house at a shrine, accompanied by the maqomaqo ring ... on the thirty-sixth day, ceremonies were held to ensure the departure of the soul shadow [maqomaqo] to the after-world ... The tomate would remain, indexed by the skull housed on the shrine, potent and dangerous, but trapped and able to confer blessings. ${ }^{22}$

These and other ritual practices were held to ensure the formation of "an efficacious ancestor," the capturing of the "potent part of a dead person within the material locus of a shrine, resident but safely immobile among the living. However, in order for the tomate to be truly effective and respond to the wishes of the living, it needed to be complete. This entailed assembling its parts into a coherent body." This included placement of artifacts around the skulls, some lashed to the skull, and others that had been smashed soon after death. All "worked as visible indices of the tomate's power." 23

Part of this process involved the placement of shell rings in lieu of ears and over eye openings on these prominent skulls. This is the practice most directly relevant to the two canoe carvings (Figs. 7-8). Shell rings of different sizes were fastened together in a mesh over the ancestral skull (e.g., Fig. 12). ${ }^{24}$ Their presence on these two canoe head-carvings-along with large, low-relief, carved facial designs spread over the head, referencing shell ornaments that are lashed over skulls-would appear to correspond to this practice. These details indicate that the two canoe carvings in question may have been intended to represent or embody ornamented ancestral skulls. 


\section{Waite | Western Solomon Islands Canoe Carvings}

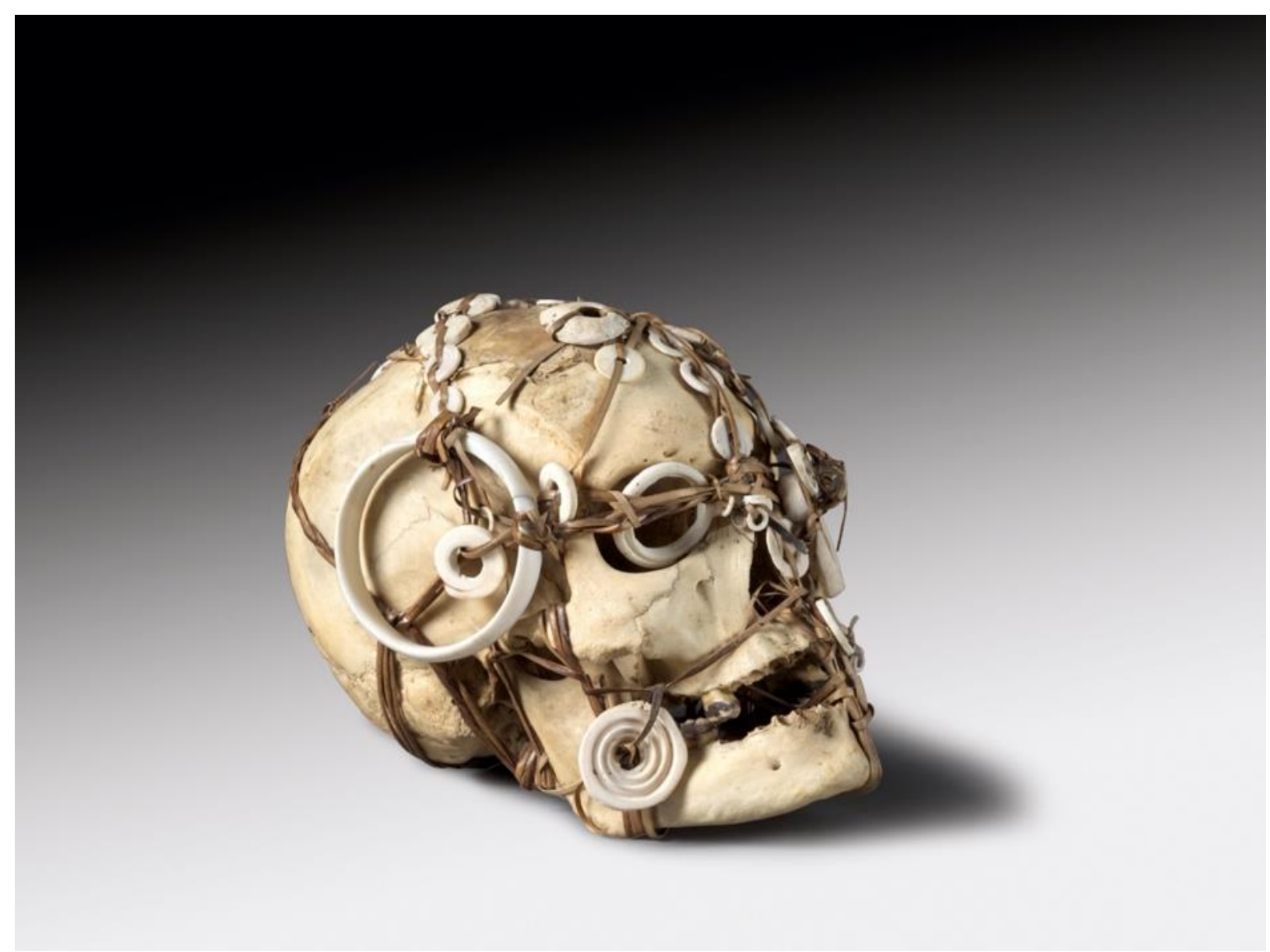

Figure 12. Skull with attached shell rings. Courtesy of the South Australia Museum, Adelaide

There is, of course, a difference between actual skulls to which shell rings have been attached and the two canoe skull carvings. The ears are removed as part of the process of defleshing the skull. The ear canal through the skull is not left open but filled, resulting in a flat surface rather than a hole, and is covered by rings. The holes on the two skull canoe carvings would seem to be explicable in terms of a desire on the part of the sculptor to create simultaneous presences of ear and ornament: a ring with a hole in the center also serves visually as the innermost portion of a spiral design created through the low-relief ornamental carvings adorning the canoe heads. Comparison with other spiral canoe carvings later in this paper will support this thesis. Through choice of designs, especially shell rings, the absence of ears, and, quite possibly, even color, the decorated skull carvings may emblematically recall specifically deceased ancestral chiefs, a cluster of social customs, and the skull shrines themselves. Such associations would augment the extreme power and efficacy of any canoe to which they were fastened. 
Waite | Western Solomon Islands Canoe Carvings

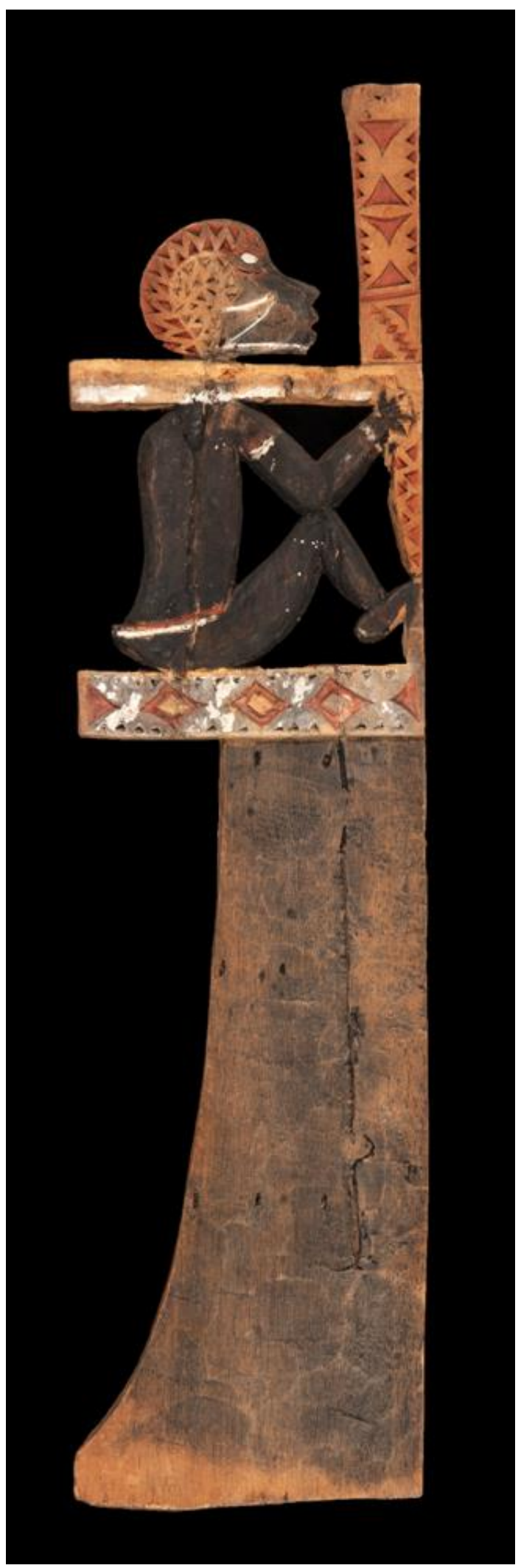

Figure 13. Canoe prow figurehead with a seated anthropomorphic figure. H. $47 \mathrm{~cm}$. Collected by Charles Edward Monro, 1894-5. Photograph by Suzy Prior. Courtesy of the Pitt Rivers Museum, University of Oxford (VIII 1926.23.55) 


\section{Waite | Western Solomon Islands Canoe Carvings}

\section{Anthropomorphic Figures}

One of the five, seated anthropomorphic figures in the group possesses a human head versus a frigate bird replacement (Fig. 13). Because of the head distinction, it deserves separate consideration, despite many parallels with the five hybrid figures (Figs. 1-5). Like the other carvings, this one is flat and has the same details carved and painted on both sides; all were obviously intended to be viewed from either side when in position on a canoe. One vertical and two horizontal bars make up the frame enclosing the figure. The total height of the carved section is $21.5 \mathrm{~cm}$. Pairs of low-relief carved triangular barava images adorn the vertical bar, as well as the lower horizontal bar on which the figure sits. The middle bar rests on the shoulders of the figure, separating head from torso. The figure holds the bar with his hands, touches it with his feet, and appears to look directly into it. Barava carvings on the lower bar have been painted white; those on the vertical bar are (at least at present) unpainted. The barava ornaments clearly displayed on this and the other figural carvings correspond vividly to the shell barava that project from the prow of a war canoe immediately below the carving that would have been lashed to the prow tip. ${ }^{25}$

Certain features link the head of this figure with the two skull head carvings just considered, while others differ. The head shares the jaw extension or prognathism of the two, but the nose and red-painted mouth lack the prominent definition (including presence of teeth) characteristic of the previous separate head carvings. However, as seen in Figures 7 and 8, low-relief designs wrap around the skull. The designs rendered on the skull of this figure could be described as a form of serration (zigzag) that does not have an exact equivalent on the heads of other carvings of anthropomorphic figures from the region, including canoe prow figures, or nguzunguzu. An upward-curving (spiral-derived) shape outlined in white paint extends along the lowermost row of facial designs toward the inner face, while another white line extends along the lower face round the chin. These patterns recur among shell inlaid facial decoration. This face, unlike the two larger heads, has no ears or circular earrings.

The profile, seated posture of this figure and the hybrid human-bird Kesoko have multiple visual references among carved imagery from Western Solomon Islands. The posture recurs with frequency among wooden spirit images, as well as tridacna clam shell openwork carvings termed barava, the same name that was given to the small triangular shell carvings (Figs. 11, 13). ${ }^{26}$ All images that assume this position replicate a posture customarily taken by exposed corpses in these islands into the early twentieth century and beyond in some regions. It is probably safe to say that this profile, seated position may allude to a burial posture. ${ }^{27}$

Vertical and horizontal framing elements on this canoe carving, as well as on the hybrid Kesoko canoe carvings, may also conceivably allude to burial practices, during which some 


\section{Waite | Western Solomon Islands Canoe Carvings}

sort of supportive structure for a seated corpse was usually necessary. On Simbo Island, as reported by Graham Officer in 1901,

between Narovo and Levi, [I] saw spots among the rocks above high water mark where bodies are placed. Samoi [an informant] tells me all a man's property is placed beside his body. He is placed in a sitting position with elbows bent, hands up to shoulder and two stakes placed as a support behind body... in from 10 to 15 days, head is removed and placed in a tambu house. ${ }^{28}$

Hocart noted the same custom in 1908 on Simbo:

Nga's body was placed in a wooden framework, apparently called era in a tree on the north side of Narovo Bay [Simbo island] ... the body is placed in a sitting position with the knees drawn up ... broken shell rings, shields and other belongings may be left beside the corpse or in a special stone chamber [also] called era. $^{29}$

Much more recently, Edvard Hviding recorded that in the Marovo district of New Georgia Island, a body was placed in a seated position between buttresses of tangovo, a wood utilized for prows and sterns of canoes. ${ }^{30}$

The two-dimensional, frame-like structure on all of the seated canoe images (anthropomorphic figures with human, as well as frigate bird, heads) can reasonably be viewed as a two-dimensional translation of a normally three-dimensional support for a seated corpse. The separation of head from body, a consistent feature among all seated figures in the group of prow ornaments under consideration, would thus denote the customary burial tradition of separation of head from torso. However, at the same time, it could also denote the practice of headhunting that resulted in another sort of separation. ${ }^{31}$ All accounts of burials mention the placement of shell valuables beside or in front of a corpse. When shell valuables were placed in front of the skulls after their separation from the bodies, these objects were not just former possessions, but could be viewed as "body parts" that "allowed [the deceased] to take in the world and cause things to happen, a collection of senses and efficacies." 32

Shell rings were utilized as a means to transfer efficacy in life, as well as after death, when at one point the soul-shadow of the deceased individual was captured in a shell ring prior to its journey to the afterworld. ${ }^{33}$ Despite the records of accumulations of shell valuables placed in front of corpses, among the canoe carvings under consideration it is images of triangular-shaped barava and, to a lesser extent, shell rings that have prominence. This choice coincides with the similar prominence of barava on canoe prows and of both barava and rings on serembule or vovoso-sticks that were reputedly placed in war canoes during expeditions 


\section{Waite | Western Solomon Islands Canoe Carvings}

and moved to mortuary shrines when not at sea. The shell valuables lashed to sticks in essence constituted collective social bodies emblematized through shell valuables. ${ }^{34}$

\section{Kesoko Canoe Carvings}

Six canoe carvings in the group under consideration depict the seated, hybrid, anthropomorphic figure with a frigate bird head that has been documented as the sea spirit Kesoko. Innumerable canoe carvings, as well as other carved and painted images, appear to refer visually to the same hybrid being. The examples considered here demonstrate just how the iconic features of Kesoko were variously rendered. Other associated features merit attention, including recorded oral traditions involving Kesoko and just how these narratives compare and contrast with the visual representations. The seated Kesoko canoe figure is the only carving type considered in this paper that has been visually recorded in position, lashed to the tip of a canoe prow. Artist Norman H. Hardy's painting, for example, depicts a fleet of canoes, one of which bears a canoe prow carving representing Kesoko lashed in position. ${ }^{35}$

\section{Visual Ingredients of Kesoko Carvings}

The substitution of a frigate bird image for an anthropomorphic head appears to be the main requisite for a Kesoko image; the frigate bird (mbelama) is readily recognizable by its hooked beak. Among Kesoko carvings in the group under study, the figure is represented in profile and seated within a partial frame made up of a horizontal bar for rest and a vertical bar, which approximates an extension of the canoe prow. The carvings in this group, like the anthropomorphic figure with anthropomorphic head (Fig. 13), are flat or two-dimensional. They are carved and painted on both of the sides, so as to be visible from more than one point of view. ${ }^{36}$ The same hybrid image featuring the frigate-bird substitute for the head also occurs on other objects such as fish net floats from New Georgia Island (especially the Marovo district), where it represents Kesoko. On at least one other island, Santa Isabel, the same design is given the name used among people from New Georgia for the prow figurehead: nguzunguzu. ${ }^{37}$

Just as is true of the figures with an anthropomorphic head as in Figure 13, shell valuables are depicted in low relief on the other Kesoko carvings, primarily along the vertical and horizontal bars. The triangular barava design predominates, but also present is the shell ring. Single barava function as head ornaments in three instances (Figs. 1-2, 4), where they appear atop the frigate bird heads. Rings, or circles, are a highly visible feature of another Kesoko carving (Fig. 3), appearing in a row on the horizontal bar that separates the frigate 


\section{Waite Western Solomon Islands Canoe Carvings}

bird from the anthropomorphic body, as well as along the bar on which the figure sits. Moreover, this figure wears a ring as a neck ornament. This canoe carving has unfortunately been broken, leaving unanswered questions as to its original intended configuration. The lower half of the frigate bird, a small portion of the upper horizontal bar, and a portion of the carving to the right of the body are missing. What does remain presents a curious suggestion regarding the body. The far-right edge of the torso inscribes a semicircle, and this is balanced by the curve of the left edge of the profile image. In all other seated images, the left edge of the torso is straight and upright. It is possible to read the upper right shoulder and torso as remaining fragments of a large circle whose inner rim constitutes the curving back of the profile figure. This is a tantalizingly suggestive reading of a figure that is, simultaneously, figure and shell ring.

In four of the canoe prow figures, the profile-seated bodies of Kesoko figures display crossed shoulder bands or bandoliers, possibly corresponding to a ceremonial "shoulder belt" called mamaroko that Hocart mentions as ritual paraphernalia donned by warriors prior to departure on an expedition (Figs. 1-2, 4-5)..$^{38}$ In each of these instances, the profile torso seems to be visually fused with a frontal view, displaying body ornaments that ordinarily would not be visible from a profile perspective. Thus, in these canoe carvings representing Kesoko, elements of human-related society are present in a reference to warriors.

Another canoe carving under consideration bears several visual features of other carvings in the group, but is quite different in other ways. The carving, now in the Auckland War Memorial Museum (Fig. 6), consists of a horizontal, bar-like base decorated with carved low-relief designs that resemble, in a generic sense, shell ornaments, but not barava. The designs carved on the body of the figure are the same notched, triangular forms rather than the triangular barava featured on the other carvings in the group. In contrast to other Kesoko carvings, this figure takes the form of a bird with upswept tail and wing and an anthropomorphic head that is extremely prognathic. It wears a small Western-style hat, a feature also seen on a few nguzunguzugu prow figureheads. ${ }^{39}$ Prominent round earrings hang from the ears. One (human?) leg extends down from the bird body. Like other canoe carvings, the figure is relatively flat and exhibits detailed, low-relief, decorative carving on both sides. This type of image, in which the body of the creature is a bird and the head anthropomorphic, does not occur in this particular group of carvings. However, it is very common among other art forms from New Georgia, specifically fish net floats and painted canoe paddles. Despite the lack of collection data, this canoe carving belongs stylistically to the New Georgia region, relates to the focus group examined here, and is probably another visual translation of Kesoko into canoe imagery. 


\section{Waite Western Solomon Islands Canoe Carvings}

Recorded Visual and Oral Traditions Pertaining to Kesoko ${ }^{40}$

Kesoko is a long-recognized reef spirit on New Georgia, Simbo, and other islands in the Western Solomon Island group. Navy Lt. Boyle Somerville collected many carvings from New Georgia in 1892-93. Anthropologist Hocart recorded information about both the spirit and its representative carvings on Simbo and Roviana in 1908. These two were the first to make graphic, as well as written records of oral traditions of both beliefs regarding the Kesoko and its images. Somerville commissioned a drawing "from a native of Mungeri (Munggeri district), New Georgia" depicting "a Boat with Native Fishing with a Kite." ${ }^{41}$ In the illustration, a seated figure with a bird for its head adorns the prow of a boat. In his "Ethnographic Notes on New Georgia, Solomon Islands," another version of the same sketch recurs along with a small drawing of the canoe carving depicted separately from the vessel itself. ${ }^{42}$ Somerville published these and other drawings as illustrations of his evaluations of local artwork in response to examination categories set out in the manual "Notes and Queries on Anthropology used by field explorers of that era." ${ }^{43}$

Somerville had this to say about the seated figure, which, he was told, was called Kesoko:

The figure consists, roughly speaking, of the body of a man, seated, with his elbow on his knee, wearing a big ornamental collar and surrounded by the head of a frigate bird. Both head and body largely conventionalized ... The figure also wears an ornamented waist cloth and is always depicted in exact profile, and highly coloured ... From his profile view having always been presented, and thus only one leg and one arm able to be shown, the belief now is that Kesoko has but one arm and one leg... ${ }^{44}$

Somerville follows this visual description with an explanation of Kesoko; this is the first conjunction of visual with oral tradition of the being.

[Kesoko] is said to live in the sea, and to be able to command the wind and the waves, to capsize canoes; and when this is accomplished, it falls upon the occupants and devours them ... it usually lives on fish ... plenty of men have seen it ... at almost any time it may be heard in its home under the edge of the coral reef, blowing out the air from its lungs (the air sucking and puffing through the holes in the reef). His power is combated, however, by Totoishu [a prow figurehead called Nguzunguzu in the Roviana district of New Georgia Island]." 45 


\section{Waite | Western Solomon Islands Canoe Carvings}

In his field notes, Hocart confirmed a similar descriptive identification for a carving and presented it in a small sketch that illustrates his concept of a Kesoko canoe image. According to the accompanying notes:

[Deputy Commissioner] Partington possesses in Gizo a Kesoko with a rod right across separating head from body: body [assumes] usual posture: head is that of mbelama [frigate bird]; it has a distinct mbelama beak; behind turned-up body ... it looks like a bird with big head and shrivelled body. ${ }^{46}$

Hocart returns to the same carving, as well as another from Vella Lavella island, in a published article in which he links these carvings to frigate bird carvings called Kesoko. He mentions "seeing a figure in a house on Vella La Vella [sic] island that was identified by our interpreter . . . as Kesoko. Now the head was that of a bird with the semi-human mouth of a nunjhnunju [nguzunguzu]." 47 Then at Partington's house, he mentions seeing the figure that he first drew and recorded in his field notes of 1908; in this published article, he describes the carving as

the figure of a seated headless man. On the neck of the man rested a platform, and on this platform the head of a sea-bird with hooked beak. To that head was attached an undersized body... on a Roviana canoe at the place where the Two Kesoko usually sit back to back, I saw two birds tail to tail . . . indicating that Kesoko has a bird form. ${ }^{48}$

In a previous reference in the same article but in a section devoted to fish-spearing, Hocart noted that "there is a being called Kesoko whose name has occurred in our angling charm. Roviana canoes sometimes bear two Kesokos back to back . . ." As an individual "Kesoko is invisible to men ..." but "has a highly prognathous face like the figure called nunjununju which is tied to the prow of a canoe." Other details include his having white hair and only one leg. He features in a rather long tale about competitive fishing involving characters known as One Leg and Three Legs. ${ }^{49}$

In a Roviana tradition, titled "Kesoko Pature," retold by G. Beti in 1977,

Kesoko was manlike in form but physically invisible. He could not be seen with the naked eye. . The nguzunguzu in front of a tomoko [war canoe] was an image of Kesoko as he kept a constant watch without ever closing his eyes. In this way Kesoko was believed to have functioned as a pilot of the great tomoko through unknown waters ... and ... to look out for enemies to see that none escaped. ${ }^{50}$ 


\section{Waite | Western Solomon Islands Canoe Carvings}

Despite invisibility, "the feet of Kesoko were short and his mouth was like that of a frigate bird or a seagull"- traits visible only to "those gifted with the ability to see spirits." The story continues, noting that Kesoko was

an expert fisherman and that was his main occupation. Kesoko would spear fish and let them rot in the sea. If people saw fish floating about in the water they would say, "It's Kesoko". . . At times his foot prints would be seen in the sand together with the trail of the spear he was dragging along ... Kesoko had been "the patron of fishing for the Vuraghare mbutumbutu [clan] of Roviana." 51

The remainder of the tale describes an encounter between two boys and Kesoko during which the spirit taught the youth how to spearfish and hunt for turtles. Ultimately, Kesoko led them in an attack on canoes from Lauru (Choiseul) island. The boys killed the canoeing islanders with their fishing spears, thus fusing what had once been two major social institutions: war and fishing.

Hviding's recordings of tales of the reef spirit Kesoko summarize other stories and augment them. "Localized manifestations of Kesoko are said to inhabit several locations on the outer barrier reef shores of Marovo and Roviana." 52 He recounts from Marovo the story of Veonona, a "sacred man who lived at Kololuka, near what is now called Vella La Vella [sic]." 53 In the story, Kesoko is described as a "sea spirit with one leg, with a face like a man but a beak like the frigate-bird, and who carries a fishing spear. . ." As for the relationship between Kesoko and nguzunguzu, the latter "was the guardian of seafarers and canoes particularly against Kesoko, a spear-fishing sea spirit." 54 His alleged powers are described in an account from an old man in Marovo Lagoon:

There are many spirits at sea, but Kesoko is one of the most bothersome. Kesoko lives everywhere we travel at sea, on fishing grounds, at ocean-facing beaches and out in the ocean. He can spoil our fishing, he can steal canoes that are pulled up on the beach, and he can bring a traveling canoe off its course. But Kesoko can only do this mischief when you and I, who are human, blink with our eyes. As long as our eyes are open, he cannot do anything or come near us. Kesoko is invisible. This is why we hang the toto isu [Marovo name for nguzunguzu canoe prow figurehead] on the bow of our canoe. The toto isu never blinks, its eyes are always wide-open and staring ... Kesoko cannot even get close to a canoe as long as the toto isu stares... ${ }^{55}$

These early accounts clearly refer to several visual elements that define Kesoko images. Most specific is the presence of a frigate bird, as well as antagonistic, yet analogous, associations with the spirit of nguzunguzu, the prow figurehead. Features such as having one leg and white hair also occur in descriptions from active oral narratives. When a narrative is translated into 


\section{Waite | Western Solomon Islands Canoe Carvings}

the visual, the frigate bird presence prevails - together with prognathism, the extension of the lower face that is featured among many images in this region-not just the nguzunguzu prow figurehead.

Thus far, this paper has dealt with canoe carvings depicting ornamented skulls and seated anthropomorphic figures, only one of which did not display the sea spirit Kesoko as a hybrid image with a human body and frigate bird head. This sequencing provides context for the hybrid Kesoko images, as well as recorded Kesoko descriptions. Thus, the visual expression of Kesoko includes references to any deceased beings-human or otherwisemanifested particularly in the body that has been configured as a seated profile figure. Another human referent, shell valuables worn by the living and viewed as comprising the bodies of their former owners after death, are featured on these Kesoko carvings. Their presence on the carvings may have referred visually not to Kesoko spirits alone, but to the owners of the canoe carvings and perhaps even the canoes to which they were lashed.

\section{Canoe Carvings with Spiral Motifs}

A brief look at four more carvings will further explicate the operative power of the group of carvings addressed in this paper. One features a frigate bird atop a spiral (Fig 9), two have a spiral form on which the relief-carved image of an animal-a crocodile or a griffinpredominates (Figs. 10, 14), and the fourth is a double spiral ornamented with shell rings and topped by a bird. ${ }^{56}$ The spiral is the common denominator in these examples. Spirals were frequently used in canoe prow and stern carvings from various Western Solomon Islands, especially among fishing canoes. This is illustrated in a 1908 drawing depicting canoes by an

artist called Angga and commissioned either by Hocart or William Halse Rivers. ${ }^{57}$ The significance of spirals on canoe carvings is a topic that lies beyond the scope of this paper, but perhaps it was used to mimic the crest of a wave.

Spiral with Frigate Bird

In the first of these examples, a frigate bird with a recognizable hooked beak is perched upon a spiral (Fig. 9). Both spiral and bird are similarly ornamented with low relief paired designs that replicate shell barava. Each barava design within a pair is linked to its opposite by a small shell ring. As for the bird, it graphically depicts the frigate bird (mbelama) that was so frequently a substitute on the head of Kesoko images. This particular bird plainly has not only the typical hooked beak, but also a full extended chest (its gular pouch), 


\section{Waite Western Solomon Islands Canoe Carvings}

indicating that it is a male. Frigate birds on two of the Kesoko carvings (Figs. 3-4) also have this feature. Frigate birds (family Fregatidae) are seabirds that are

found across all tropical and subtropical oceans. All have predominantly black plumage, long deeply forked tails and long hooked bills. Females have white underbellies and males have a distinctive red gular pouch which they inflate during the mating season to attract females. Their wings can span up to 23 meters ( $\left.7.5^{\prime}\right)$, the largest wing area to body weight ratio of any bird. ${ }^{58}$

Behavioral characteristics of the frigate bird include their ability to soar for weeks, spending most of the day in flight hunting for food. Their main prey are small fish that swim with larger predators, such as tuna. Frigates will also snatch chicks and eggs of other seabirds, such as boobies and petrels. They are definitely predators, a quality that makes them an appropriate choice for power-laden images on either headhunting or fishing canoes. Frigate bird images also appear on fishing net floats and painted paddles, as well as canoe carvings.

The bird on the carving in Figure 9 stands alone and is not a feature of a Kesoko image. Most birds depicted on spiral canoe carvings represent various other birds, whereas this carving features the frigate bird, the largest and most powerful bird of the ocean..$^{59}$ If the spiral represents a crested wave, this canoe carving might metaphorically depict a warrior as a frigate bird. Perhaps it alludes to the owner of the war canoe to which the carving was intended to be lashed and his role as leader of warriors seated in the canoe atop a wave and united with the power of the sea. The barava and rings carved on all the surfaces of the spiral and bird could refer to the warrior and other human canoe occupants, as well as their ancestors-in short, a corporate ancestral body.

Two spiral carvings now in the Pitt Rivers Museum (Figs. 10, 14) stand out among the numerous single and double spirals on canoe carvings from Western Solomon Islands. In both cases, the spiral was not intended as a support for an anthropomorphic figure or bird. Most support spirals are relatively narrow and may or may not be decorated. Supportive spirals sometimes appear quite delicate in comparison to the image that they bear. These two carvings are considered together here because both are dominated by animals: one indigenous to the Solomon Islands and the other a foreign creature from European mythology. Somerville, collected both spiral carvings at the same time, between 1892 and 1893, in Mungeri district, Marovo.

The spiral canoe stern with a crocodile (Fig. 10) has carved imagery along both sides. Uppermost on one side is the image of a crocodile inserted into the upper curving section of the spiral. A relief band encircles the innermost curve of the spiral, visually transforming it into a ring. Both ring and crocodile have equal prominence. The crocodile is rendered immediately above the ring upon which he places one foot. Their close visual juxtaposition is entirely 


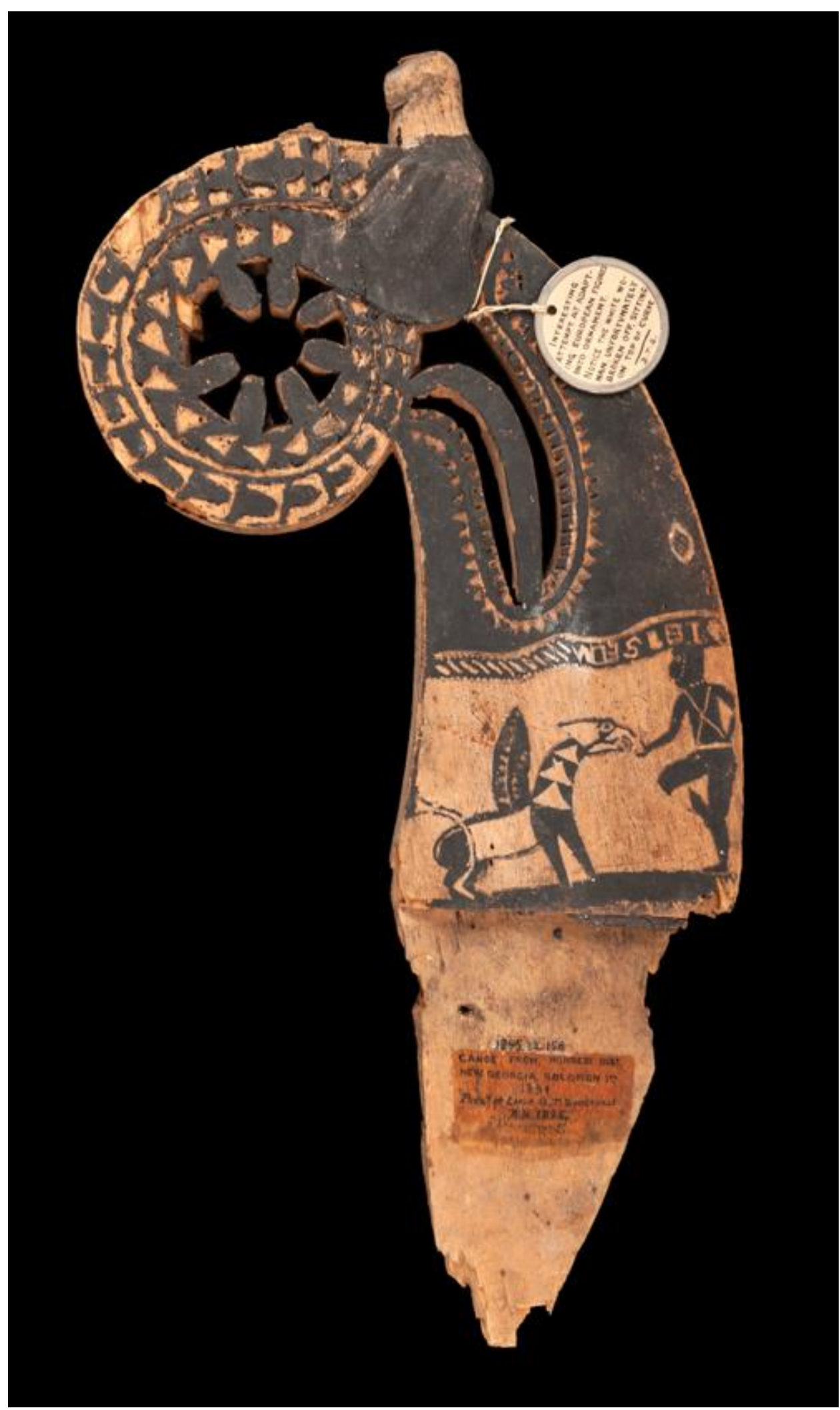

Figure 14. Spiral with griffin on a canoe stern ornament. Marovo, New Georgia. Gr. h. 40.7. cm. Collected by Henry Boyle Townshend Somerville, 1893-4. Photograph by Suzy Prior. Courtesy of the Pitt Rivers Museum, University of Oxford (1895.22.158) 


\section{Waite | Western Solomon Islands Canoe Carvings}

appropriate, given the prominent social significance of both shell rings and the crocodile in nineteenth-century Western Solomon Islands.

The low-relief, decorative designs rendered on both sides of the spiral carving include the barava, rings, and triangular forms with serrated edges that resemble the edges of barava. This serrated treatment of shapes closely corresponds to a similar design process utilized on the skull carvings (Figs. 7-8). Moreover, these three carvings are also united by the presence of a large relief ring; on each of the two profile heads depicted in Figures 7 and 8, the ring that substitutes for an ear terminates in a spiral design.

The social prominence of crocodiles in Western Solomon Islands provides contextual substance for the spiral canoe carving that features the image of this reptile. Hocart noted the existence of one war canoe named Eoro [crocodile] from the Karivara district in Simbo in 1908. The crocodile, he said, "is the sacred animal of Karivara." 60 Large troughs from which men ate during war-related festivals frequently took the form of crocodiles. ${ }^{61}$ One particularly outstanding example was procured from Roviana by Captain Edward Davis on a British government punitive expedition held in 1893 and is now in the British Museum. ${ }^{62}$ Within the historical period in which headhunting prevailed on New Georgia and adjacent islands in the western group, crocodiles constituted major emblems of power.

The other Pitt Rivers spiral canoe carving (Fig. 14) is a stern ornament portraying a totally different animal in a manner that draws upon European sources of imagery. At the bottom of the carving is a painted scene of a man standing on one leg and extending one hand toward a winged animal that resembles a griffin-like creature. Crossed torso bands on the man's chest are comparable to crossed bands visible on several of the Kesoko images. Above this painting and on both sides, the main body of the stern ornament is painted black and carved to look like the profile head of the griffin-like creature in the painting. The head is pointed vertically, with its open mouth and tongue abutting the circular coil of a spiral. The spiral terminus of this carving comprises roughly engraved concentric rows of serrated barava-shaped designs, making it resemble an open-work variant of a kapkap. ${ }^{63}$

This canoe carving apparently intrigued Somerville who described it as "an interesting attempt at adapting European figures into ornament." He remarked, "Notice the white woman, unfortunately broken off, sitting on top of the curve," but did not attempt any analysis of the scene of man and winged animal. ${ }^{64}$ In his "Ethnographical Notes in New Georgia, Solomon Islands," Somerville devoted a short section to "Drawing, Sculpture and Ornamentation" in which he noted that "European drawings are a great source of pleasure

to them [the islanders]; they seem to quite understand them." ${ }^{65} \mathrm{He}$ reproduced local drawings of frigate birds, a Kesoko carving, and a scene of men fishing for sharks that were inspired by European art. 


\section{Waite | Western Solomon Islands Canoe Carvings}

Double Spiral

The last canoe carving in the group is from the Basel Kulturen Museum and comprises a double spiral. ${ }^{66}$ Eugene Paravicini acquired this piece in 1924, but unfortunately accompanying recorded data is minimal. A bird with outspread wings (possibly a kio-kio or beach kingfisher) is rendered immediately above the spirals. ${ }^{67}$ Five rings are carved in low relief on the surfaces of the spirals. The terminating volute of each spiral encompasses a ring, thus representing still another fusion of the two design elements.

\section{Operative Significance of the Canoe Carvings: Connections to Other Artifacts}

The principal artifactual references comprising the operative framework of art from the Western Solomon Islands region are actual ornamented skulls, eating troughs that take the form of a crocodile, triangular clamshell barava ornaments, and the serembule or vovoso sticks to which barava and shell rings were once attached. Perhaps one could add the skull or mortuary shrines to which the sticks once belonged. The shell barava ornament that is represented two-dimensionally on the carvings has its parallel on the prow of the war canoe, and is lashed to the serembule or vovoso. In addition, these sticks were placed in canoes during voyages but kept in mortuary shrines when not at sea. These ornamental assemblages probably simultaneously represented deceased ancestors, who had owned and worn the barava shell ornaments, and their descendants. ${ }^{68}$ It is not impossible that their replicated presence on canoe carvings suggested an ancestral association for all of them, augmenting the probable association of canoe and its ornaments with canoe owner and canoe occupants. Serembule sticks and the skulls of deceased individuals of note were kept in mortuary shrines with which this group of canoe carvings display a particular link. Mortuary shrines, thus, deserve a final category for consideration.

On New Georgia Island, particularly in the Marovo and Roviana districts, and on Simbo Island, skulls obtained in war and, in particular, skulls of deceased chiefs were kept and displayed in mortuary shrines. Such shrines sometimes consisted of a cave or other isolated spot, such as Mbili, Marovo Lagoon, and islets including "Skull Island" in Vonavona Lagoon, Roviana. ${ }^{69}$ Miniature skull houses or boxes (oru) located at these shrines displayed carved and painted designs that echoed those on the canoe carvings. ${ }^{70}$ In one example reproduced in pencil by Somerville, at Mbili village, Marovo, the triangular facade is adorned with a single row of triangular barava ornaments. To the left and right, facing downwards, are images of two crocodiles. ${ }^{71}$ The same theme is repeated on other wooden skull shrines and monuments from Roviana, most notably a monument erected in honor of the famous chief Ingava, first 


\section{Waite Western Solomon Islands Canoe Carvings}

photographed by Count Rudolph Festetics de Tolna in $1895 .{ }^{72} \mathrm{~A}$ mortuary hut on Simbo Island features the oft-repeated image of a man standing in a canoe, beneath which are two images of diverging crocodiles. ${ }^{73}$

Besides imagery, two more factors further link the group of canoe carvings in this paper with skull house ornamentation-more specifically than is true for other canoe carvings from Western Solomon Islands. These are the two-dimensionality or low relief character of the carving and the colors used on pieces within this group (specifically red, blue, and white versus the usual all-black or dark brown treatment of so many other canoe carvings).

Although it is well-nigh impossible to explain the use of color among these specific carvings and their obvious association with colors utilized on mortuary-hut facades, in the absence of interviews with relevant artists (an impossibility at this point), the "relational quality of color" cannot be ignored. ${ }^{74}$

\section{Concluding Remarks}

This paper has presented detailed visual and oral data in order to support the initial thesis: that the canoe carvings under consideration are indeed a group defined by their common stylistic treatment, whether they represent heads, figures, scrolls, or crocodiles. These themes isolate the art, even though, like so many other canoe carvings from Western Solomon Islands, they guaranteed the success of war canoes through their presence, a presence defined by their particular mode of visual treatment. The canoe carvings display image types, such as Kesoko and anthropomorphic heads, as well as representations of ornaments that recur on multiple artifacts once prevalent in Western Solomon Islands. These include eating troughs, serembule sticks, and mortuary shrines. Through the repeated presence of this imagery on this group of canoe ornaments, the effectiveness of the canoes would be assured.

All of these features would seem to testify to the importance of the carvings-not just to the canoes to which they were lashed, but also to the canoe occupants and, most particularly, the canoe owners. This connectivity would have prevailed not only during a war expedition, but before and after. That is when the carvings were taken off canoes and, quite probably, stored in the houses of the canoe owners or in mortuary shrines along with serembule/vovoso sticks. In other words, there exists a spatial-social cyclicity. This symbolic interconnectivity is the particular significance of the nuclear assemblage of canoe carvings that constitute the focus of this article. They are connected to so many aspects of Western Solomon Islands culture, yet display a visual character that defines them as a group. 


\section{Waite | Western Solomon Islands Canoe Carvings}

Deborah Waite earned her PhD from Columbia University and was the curator of ethnology at the Newark Museum in New Jersey from 1968 to 1970. She served as a professor of Pacific art history at the University of Hawai 'i at Mānoa from 1970 until her recent retirement. Her research has focused on Melanesian art, particularly that of the Solomon Islands.

\section{Notes}

${ }^{1}$ Oxford University, England (Figs. 1-5, 7, 9-10, 13-14); Vancouver (Fig. 8); Auckland (Fig. 6). I could not obtain photographs of two images from the Kulturen Museum, Basel. These include: canoe prow figure of Kesoko, Marovo Lagoon, New Georgia Island, h. $69 \mathrm{~cm}$, Paravicini 1924, Vb7620, and double spiral canoe carving with flying bird, Marovo Lagoon, New Georgia Island, Gr.h. 76.5 cm, Paravicini 1924, Vb7619. One Kesoko carving now in the Kulturen Museum Basel, Vb7620 is illustrated in Adrienne L. Kaeppler, Christian Kaufmann, and Douglas Newton, Oceanic Art (New York: Harry N. Abrams, 1993), 563, fig. 824.

The analyses of these carvings in this paper could indicate that the same artist's hand was at work or those of artists working closely together. We obviously cannot know what the artist or artists' comments would be, but it is worth noting that their opinions, now absent, would be of incredible value.

${ }^{2}$ However, a brown patina of age has replaced much of color on the University of British Columbia example.

${ }^{3}$ See Barava tridacna clam shell ornaments-neck ornament. British Museum MM.1904.64. $9.3 \mathrm{~cm}$; b. canoe ornament, British Museum Oc1915,-30, gr.w. $16.4 \mathrm{~cm}$.

${ }^{4}$ See Kapkap (dalo - Solomon Islands term), British Museum 1944, Oc2.1341, Dia. 13.2 cm.

${ }^{5}$ The Pitt Rivers Museum examples were collected by either H. B. T. Somerville or Neil Gordon Monro. The Basel Museum pieces were collected by Paravicini in 1928. Eugene Paravicini, Reisen in den Britischen Salomonen (Leipzig: Huber, 1931). Frank Burnett obtained the Vancouver example from a village in Ramada in 1909, thus putting it well within the group orbit.

${ }^{6}$ In his article "The Art of Canoe Building," Graham Officer writes about a canoe from Roviana and describes carvings attached to the canoe as follows: "The high peaks of both ends of the canoe are terminated by carved wooden figures of human form. The low end has two grotesque prognathous-faced little images placed back-to-back, one looking ahead the other astern. The stern peak has a single two-faced head, like a Janus, looking outwards on each side. . .on the bow, just above the water line is fixed a remarkable prognathous-faced head with hands clasped in front and supporting the chin [the nguzunguzu]. . . . Their significance seems to be in their being regarded as exercising guardian functions. . The totoishu [nguzunguzu] guards against dangers in the waters, whether rocks or spirits, immediately in front. The two figures on the top of the bow peak will look out for more distant dangers ahead and astern, while the two-faced head on the stern peak keeps guard on either side." Rhys Richards, Head Hunters Black and White: Three Collectors in the Western Solomon Islands 1893 to 1914, and the Diary of Graham Officer, Collector of Museum Objects in the Solomon Islands in 1901 for Museum Victoria in Melbourne (Wellington: Paremata Press 2012), 213-14. 


\section{Waite Western Solomon Islands Canoe Carvings}

7 Daniel Miller, Material Culture and Mass Consumption (Oxford: Basil Blackwood Ltd., 1987). See also Christopher Tilley, "Objectification," in Handbook of Material Culture, ed. Chris Tilley, Webb Keane, Susanne Küchler, Mike Rowlands, and Patricia Spyer (London: Sage Publications, 2006), 60-73.

${ }^{8}$ An example can be found in the Australian Museum: \# E.57312.

${ }^{9} \mathrm{~A}$ number of the carvings discussed in this paper have been previously published in articles of mine. Although some of the carvings are the same, ideas about them and "interpretations" differ. The inclusion of carvings such as the spiral with crocodile (Pitt Rivers 1895.22.165) and the initial focus on the two skull carvings before consideration of the Kesoko images has done much to re-focus my previous arguments. See Deborah Waite, "Mon Canoes of the Western Solomon Islands," Art and Identity in Oceania, ed. Allen Hanson and Louise Hanson (Honolulu: University of Hawai'i Press, 1990), 44-66.

${ }^{10}$ Tim Thomas, "Sensory Efficacy in the Art of New Georgia," in Melanesia: Art and Encounter, ed. Lissant Bolton, Nicholas Thomas, Elizabeth Bonshek, Julie Adams, and Ben Burt (London: The British Museum, 2013), 199-208.

${ }^{11}$ T. Thomas, "Sensory Efficacy in the Art of New Georgia," 199-208.

${ }^{12}$ See example referenced in endnote 4.

${ }^{13}$ Interestingly, David Howes notes that in a very different part of the world among the Suya of the Mata Grosso region of Brazil "the ear is the primary organ through which the world is cognized. It is also the organ through which the human subject is socialized." David Howes, "Scent, Sound and Synesthesia: Intersensoriality and Material Culture Theory," in Handbook of Material Culture, ed. Chris Tilley, Webb Keane, Susanne Küchler, Mike Rowlands, and Patricia Spyer (London: Sage Publications, 2006), 161-72.

${ }^{14}$ T. Thomas, "Sensory Efficacy in the Art of New Georgia."

${ }^{15}$ At least two other canoe prow figures feature a similar frontal image with extended hands touching and calling attention to large ear ornaments. One of these figures was collected by Somerville from Marovo (Pitt Rivers 1895.22.205) and illustrated as Fig. 12 in Deborah Waite, "The H.B.T. Somerville Collection of Artefacts from the Solomon Islands in the Pitt Rivers Museum," in The General's Gift: A Celebration of the Pitt Rivers Museum Centenary 1884-1984, ed. B.A.L. Cranstone and Steven Seidenberg (Oxford: Journal of the Anthropology Society of Oxford, 1984), 47. The Reverend Tom Dent, a Methodist missionary at Marovo from 1922 to 1934, obtained the other example in the British Museum (Oc 1959, 06.23) in New Georgia. Very likely, Marovo is also the provenance for this figure.

${ }^{16}$ Arthur Maurice Hocart, "Medicine and Witchcraft in Eddystone," Journal of the Royal Anthropological Institute of Great Britain and Ireland, vol. 55 (1925): 236.

${ }^{17}$ Hocart, "Medicine and Witchcraft," 236.

${ }^{18}$ Hocart, "Warfare in Eddystone of the Solomon Islands," Journal of the Royal Anthropological Institute of Great Britain and Ireland 61 (1931): 315.

${ }^{19}$ Hocart, "The Cult of the Dead in Eddystone of the Solomons," Journal of the Royal Anthropological Institute of Great Britain and Ireland 52 (1922): 269.

${ }^{20}$ Hocart, "Medicine and Witchcraft," 249-50.

${ }^{21}$ Hocart, "The Canoe and Bonito in Eddystone Island," Journal of the Royal Anthropological Institute of Great Britain and Ireland 65 (1935): 101-7. 


\section{Waite | Western Solomon Islands Canoe Carvings}

${ }^{22}$ Hocart, "The Cult of the Dead," 80-95. See also Richard Walter, Tim Thomas, and Peter J. Sheppard, "Cult Assemblages and Ritual Practice in Roviana Lagoon Solomon Islands," World Archaeology 36 (2004): 150.

${ }^{23}$ Hocart, "The Cult of the Dead," 80-95.

${ }^{24}$ Two skulls to which shell rings have been lashed over the eyes and head "were taken with ten others from a shrine in Vella La Vella Island" in 1909. One skull, 276646, is illustrated in Roland W. Force and Maryanne Force, The Fuller Collection of Pacific Artifacts (New York and Washington: Praeger Publishers, 1971): 230. For an historical account of the situation, see David Russell Lawrence, The Naturalist and his "Beautiful Islands": Charles Morris Woodford in the Western Pacific (Canberra: Australia National University Press, 2014), Chapter 8, doi.org/10.22459/NBI.10.2014

${ }^{25}$ See item referenced in endnote 3.

${ }^{26}$ Deborah Waite, "Serembule/Vovoso and Other Sticks with Shell Valuables: Part of a Dialectic with Barava Openwork Plaques," Pacific Arts, New Series 11, no. 2 (2011): 27-8.

${ }^{27}$ One seated image now in the Rijksmuseum voor Volkenkunde, Leiden (1134, Nr.87), is rendered in the seated position, has an extended jaw characteristic of nguzunguzu, and appears to have only one leg (or is that interpretation simply because the image lacks any sort of background or other details of carving that would clearly define it as a profile image?).

${ }^{28}$ Graham Officer, Wed., June 26 1901, quoted in Richards, Head Hunters Black and White, 83.

${ }^{29}$ Hocart, "The Cult of the Dead," 82-3.

${ }^{30}$ Edvard Hviding, "War Canoes of the Western Solomons" in The Things We Value: Culture and History in Solomon Islands, ed. Ben Burt and Lissant Bolton (Canon Pyon: Sean Kingston Publishing, 2005), 146.

${ }^{31}$ Unfortunately, recorded documentation that would make these two possibilities more open for interpretation is lacking.

32 Walter, Thomas, and Sheppard, "Cult Assemblages," 149.

33 Hocart, "The Cult of the Dead," 80-95.

34 Waite, "Serembule/Vovoso and Other Sticks," 9-35.

35 Ingova's Head-hunters, painting by Norman H. Hardy, British Museum EOC88089 ncq OcG.N, 2133, Museum no. Oc2006 drg.135. Hardy apparently based his painting on a photograph published by A.\& C. Black (British Museum, Oc.G.N. 2133), but there is no information about his choice of subject matter, the change of published titles, or whether the fleet of canoes depicted in the painting really had any actual association with Ingova, a prominent chief of Roviana. Therefore, the value of the painting is simply to show the carving in position, attached to the foremost canoe visible in the painting. It is quite small in comparison with the size of the war canoe, yet still visible. The size of other types of canoe carvings including, for example, the nguzunguzu prow figurehead, is also small in comparison with the overall proportions of a canoe. The size of the canoe carving obviously did not necessarily correspond to its symbolic empowerment. The painting was first published in Ernest Elkington, Savage South Seas (London: A \& C Black, 1907); then in John Henry Macartney Abbott and Norman H. Hardy, The South Seas (Melanesia) (1918): plate opposite p. 80; and much later in Crispin Howarth, Varilaku: Pacific Arts from the Solomon Islands (Canberra: National Gallery of Australia, 2011): 23. In Elkington's and Howarth's publications, the painting is entitled Ingova's head-hunters, while in Abbot's book it is labelled Head-hunters setting out on a Raid. 


\section{Waite | Western Solomon Islands Canoe Carvings}

${ }^{36}$ One example of a Kesoko canoe prow image that lacks the framework and is more threedimensional is Melbourne X.607. Howarth, Varilaku, 105.

${ }^{37}$ Evelyn Tetehu, "Some Family Treasures of Santa Isabel," in The Things We Value: Culture and History in Solomon Islands, ed. Ben Burt and Lissant Bolton (Canon Pyon: Sean Kingston Publishing, 2014), 85.

${ }^{38}$ Hocart, "Warfare in Eddystone," 308.

${ }^{39}$ For example, a figurehead from Vella Lavella (Melbourne, X.7487) illustrated in Howarth, Varilaku, 101.

40 This section may appear to be a sudden departure from the topic of the paper, i.e., the original group of canoe carvings under consideration. Oral traditions may not always seem to conform directly to the canoe carving imagery. Some of the oral traditions do and some do not, but it is impossible to judge what may appear to be exceptions or inconsistent data. It is best to include all recorded traditions, as they may or may not once have been applicable to certain viewers of the relevant period.

41 Deborah Waite, "Lt. Boyle Somerville and the Solomon Islands," Journal of the Anthropological Society of Oxford XXXI, no. 3, (2000): 291.

${ }^{42}$ Boyle Somerville, "Ethnographical Notes in New Georgia, Solomon Islands," Journal of the Royal Anthropological Institute of Great Britain and Ireland 26 (1897): 357-412.

43 Waite, "Lt. Boyle," 291.

44 Somerville, "Ethnographical Notes," 294.

45 Somerville, "Ethnographical Notes," 294.

${ }^{46}$ Arthur Maurice Hocart, "Unpublished Diaries," 1908, 1583. "Hocart, Arthur Maurice, 18831939: Papers,” MS-Papers-0060, Alexander Turnbull Library, Wellington, New Zealand, https://natlib.govt.nz/records/23025566.

${ }^{47}$ Arthur Maurice Hocart, "Fishing in Eddystone Island," Journal of the Royal Anthropological Institute of Great Britain and Ireland, 67 (1937): 39.

${ }^{48}$ Hocart, "Fishing in Eddystone Island," 39.

${ }^{49}$ Hocart, "Unpublished Diaries," 38. "Hocart, Arthur Maurice, 1883-1939: Papers,"

MS-Papers-0060, Alexander Turnbull Library, Wellington, New Zealand,

https://natlib.govt.nz/records/23025566.

${ }^{50}$ Geoffrey O. Beti, “Kesoko Pature," Journal of the Cultural Association of the Solomon Islands 5 (1977): 40-46.

${ }^{51}$ Beti, “Kesoko Pature," 40-46.

52 Edvard Hviding, Guardians of Marovo Lagoon: Practice, Place and Politics in Maritime Melanesia (Honolulu: University of Hawai'i Press, 1996): 235.

53 Hviding, "Guardians of Marovo Lagoon," 404.

54 Hviding, "Guardians of Marovo Lagoon," 111.

55 Quoted in Edvard Hviding, Reef and Rainforest: An Environmental Encyclopedia of Marovo Lagoon, Solomon Islands [Kiladi oro vivineidi via tinqitonga pa idere ovo pa goana pa Marovo] (Paris: UNESCO, 2015).

${ }^{56}$ See double spiral canoe carving with flying bird, Marovo Lagoon, Paravicini 1924, Gr.h. 76.5 cm. Kulturen Museum Vb7619, Basel.

57 See Art in Oceania: A New History, ed. Peter Brunt and Nicholas Thomas (New Haven: Yale University Press, 2012): 175. 


\section{Waite $\mid$ Western Solomon Islands Canoe Carvings}

58 Wikipedia, S.v. "Frigatebird," last modified September 9, 2021, 21:20, http://en.wikipedia.org/wikik/Frigatebird.

59 This identification of the bird is only tentative. Bird images depicted on canoe ornaments from this region include, for example, the "wagtail" and a beach kingfisher known as kio-kio on Ranongga Island (Richards, Head Hunters, 114-117, Melbourne X7577). Paired birds may be rendered atop a spiral on a canoe carving as in one example from Simbo Island (Richards, Head Hunters, 116, Melbourne X7529).

60 Hocart "The Cult of the Dead," 108.

61 Deborah Waite, "An Artefact/Image Text of Head-Hunting Motifs," in "Essays on Headhunting in the Western Solomon Islands," special issue, Journal of the Polynesian Society 109, no. 1 (March 2000): 119-22; Nicholas Thomas, "The Kalikonga Feast Trough," in Art in Oceania: A New History, ed. Peter Brunt and Nicholas Thomas (New Haven: Yale University Press, 2012), Fig. 158, 207.

${ }^{62}$ Nicholas Thomas "The Kalikong," 230-1; Deborah Waite and Ben Burt, "The Davis Collection from Roviana, Melanesia," in Melanesia: Art and Encounter, ed. Lissant Bolton, Nicholas Thomas, Elizabeth Bonshek, Julie Adams, and Ben Burt (London: The British Museum, 2013): 209-14, Fig. 160.

63 See item referenced in endnote 4. See Kapkap (dalo-Solomon Islands term), British Museum 1944, Oc2.1341, Dia. $13.2 \mathrm{~cm}$.

${ }^{64}$ Museum label attached to the carving.

${ }^{65}$ Somerville, "Ethnographical Notes," 3787-9.

${ }^{66}$ See item referenced in endnote 57.

67 The canoe carving is illustrated in Richards, Head Hunters, 117.

${ }^{68}$ Waite, "An Artefact/Image."

${ }^{69}$ Paravicini, Reisen, 84.

${ }^{70}$ An example is a burial shrine on Roviana, photographed by the Rev. George Brown in 1899 and illustrated in Howarth, Varilaku, 18.

${ }^{71}$ Pitt Rivers Museum manuscript collection no. 19.f.7 and Waite, “Lt. Boyle,” 290.

${ }^{72}$ Rudolph Festetics de Tolna, Chez les cannibales (Paris, 1903), cited in Magali Melandri, "Autel à la gloire du chef Ingova," in L'éclat des ombres: L'art en noir et blanc des îles Salomon, ed. Magali Melandri and Sandra Revelon (Paris: Musée d'Orsay, 2014), 190-3.

73 The photograph is in the Edge-Partington Collection, British Museum. Richards, Head Hunters Black and White, 205.

74 Diana Young, "The Colours of Things," in Handbook of Material Culture, ed. Chris Tilley, Webb Keane, Susanne Küchler, Mike Rowlands, and Patricia Spyer (London, Sage Publications, 2006), 180. 


\title{
Ymamentears \\ Journal of the Pacific Arts Association
}

\section{SUSAN COCHRANE ARTventures: Art and Life in the Contemporary Pacific}

\begin{abstract}
The unpublished work ARTventures: Art and Life in the Contemporary Pacific is a literary memoir recounting Susan Cochrane's unorthodox life as a roaming curator of contemporary Pacific art. The narrative intertwines vignettes of the author's personal life with her experiences as a "poken" (slang for English-speaking foreigner) in New Caledonia; on fieldwork trips collecting art in remote areas of Papua New Guinea, the Solomon Islands, and Vanuatu; and encountering Māori and Pasifika artists in Aotearoa New Zealand, and Aboriginal Taiwanese in Taiwan. The text is subtly layered with insights into the attitudes and operations of the art world and strategies to establish Indigenous art in its own right.
\end{abstract}

Keywords: Memoir, art history, contemporary art, Pacific, Oceania, Pacific art

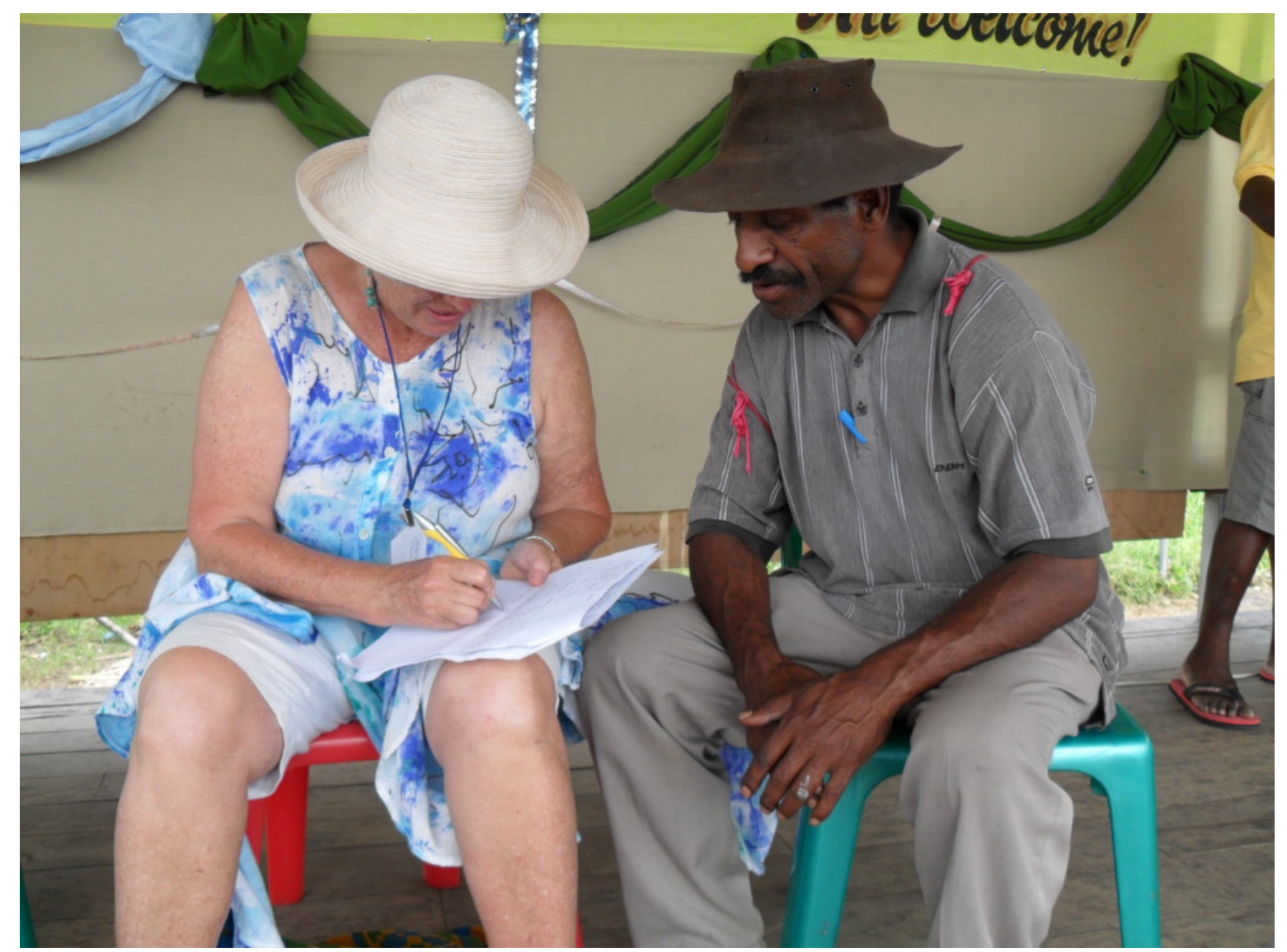

Figure 1. Susan Cochrane field recording with a consultant of the Asaro Goroka Mudmen, at the 2008 National Mask Festival, Kokopo, East New Britain Province, Papua New Guinea. Courtesy of Michel Bonnefis 


\section{Cochrane | ARTventures}

ARTventures: Art and Life in the Contemporary Pacific (a work in progress) is an art professional's view of art and life in Pacific societies-a literary memoir recounting my unorthodox life as a roaming curator of contemporary Pacific art. The narrative aptly intertwines vignettes from my personal life with eye-opening experiences as a "poken" (slang for Englishspeaking foreigner) in New Caledonia; on fieldwork trips collecting art in remote areas of Papua New Guinea, the Solomon Islands, and Vanuatu; and encountering Māori and Pasifika artists in Aotearoa New Zealand, and Aboriginal Taiwanese in Taiwan. As I am a specialist art curator and established writer in the field of contemporary Indigenous art, the text is subtly layered with insights into the attitudes and operations of the art world and strategies to use to overcome stereotypes and help establish Indigenous art and thought in its own right. The story moves between village, urban, and global zones of art creation and display.

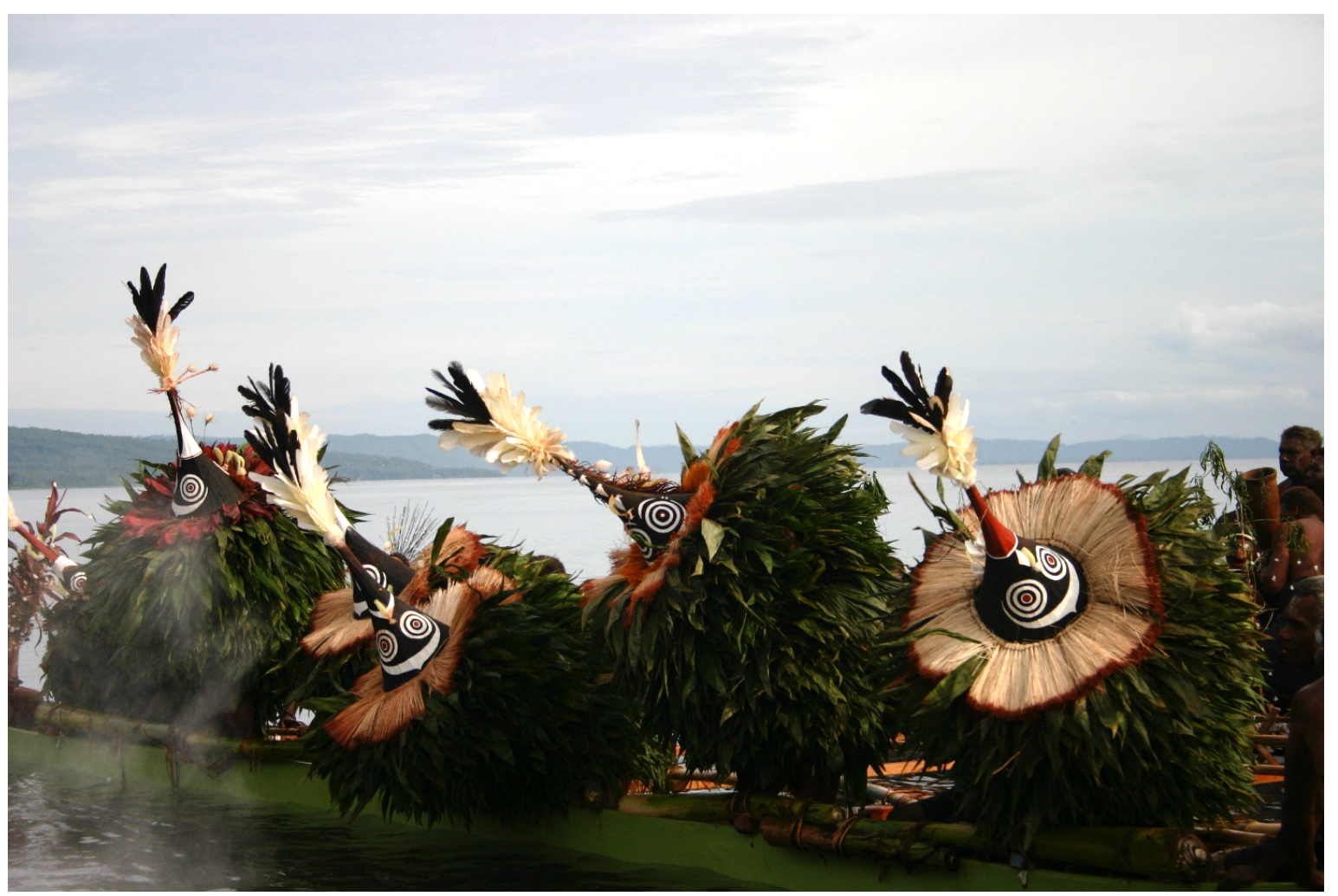

Figure 2. Arrival of Dukduks for the Warawgira ceremony at the 2008 National Mask Festival, Kokopo, East New Britain Province, Papua New Guinea. Courtesy of Susan Cochrane

The narrative opens with my arrival in New Caledonia in 1995. I had been recruited as a specialist in contemporary Pacific art by the Agency for the Development of Kanak Culture (Agence de développement de la culture kanak, or ADCK), which had been charged with the 
monumental task of creating the Tjibaou Cultural Centre in time for its inauguration in May 1998. The Centre was the French government's gift of reconciliation following New Caledonia's near-civil-war from 1984 to 1988. As the only "poken" among the ADCK's ensemble of Kanak and French specialists, I had to prove my capabilities in a heady cultural mix with the moral support of my team and my future husband, Michel Bonnefis.

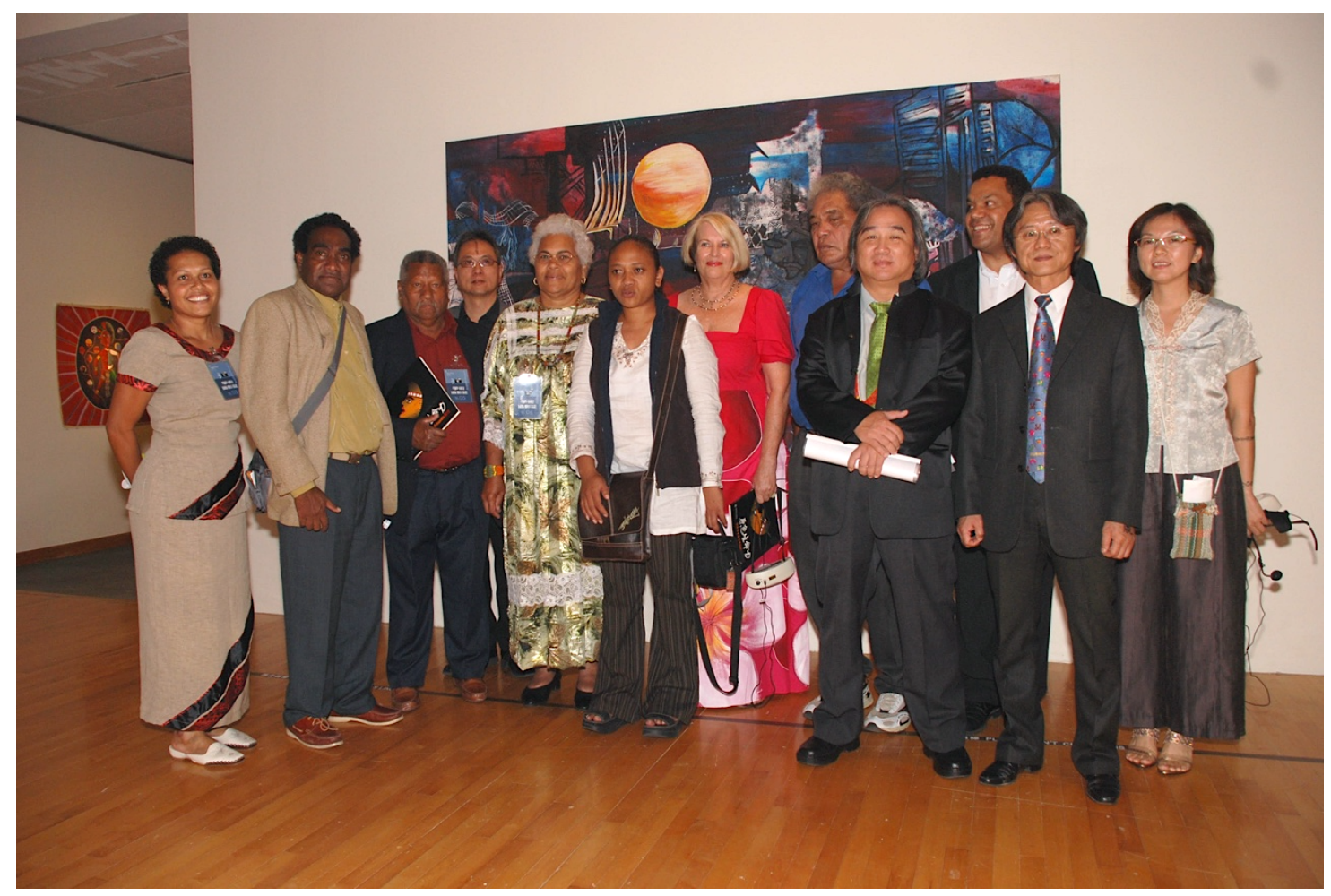

Figure 3. Directors of Pacific Islands museums and Aboriginal Taiwanese cultural leaders at the opening of the exhibition Across Oceans and Time, Kaohsiung Museum of Fine Arts (KMFA), Taiwan, October 2007. The Director of KMFA, Jiunshyan Lee, fourth from left; Madame Marie-Claude Tjibaou next to him; Emmanuel Kasarherou, Director of the Tjibaou Cultural Centre, third from right; and Susan Cochrane in the centre. Courtesy of Kaohsiung Museum of Fine Arts

In the book's first chapters, the Tjibaou Cultural Centre takes shape. My role was to establish a network of connections within New Caledonia and neighbouring Pacific nations. I share memorable adventures of traveling with the Kanak assistant curators to commission and collect contemporary artworks, and on some occasions with my husband for his initiation into neighbouring cultures. The objective was to form a major collection of contemporary Pacific art for the Tjibaou Cultural Centre and to train the curatorial team to take over following its inauguration. 


\section{Cochrane | ARTventures}

The collection development being undertaken gained attention in Australia and New Zealand, and in 1996 and 1999 I was invited to be on the curatorial team charged with transforming the world's view of contemporary Pacific art through the Queensland Art Gallery's Asia Pacific Triennial. In 2000, I was invited to be the guest Pacific curator for the Sydney Olympics Art Festival. In 2005, a new research project and exhibition, ARTventure, emerged as a joint project between Taiwan and New Caledonia with the goal of connecting Aboriginal Taiwanese and Pacific artists who shared Austronesian heritage. As the guest curator for the Kaohsiung Museum of Fine Arts in Taiwan, once again I found myself in a vastly different cultural milieu.

As prolific writer, I always aim to raise the profile of contemporary Pacific art across a range of genres, from scholarly to general readership materials-theses, monographs, catalogue essays, journal articles, and reviews-as well as through academic and public presentations. My memoir, ARTventures, is an exploratory volume telling my story as a roaming curator of contemporary Pacific art from the 1980s to the 2010s: a kaleidoscope of art and artists in diverse cultural settings. My life is a continuing ARTventure.

ARTventures: Art and Life in the Contemporary Pacific

ARTventures: Aventures artistiques dans le Pacifique contemporain (Unpublished manuscript. Original text in English with French translation by the author)

Susan Cochrane has achieved recognition as a specialist on the Indigenous art of the Pacific region. Her formative years in Papua New Guinea influenced her career path as an art historian, curator, and writer. Frequent fieldwork in Pacific countries has contributed to her long-term professional relationships with Indigenous artists and communities. Her innovative curatorial approach has led to roles as guest curator of or consultant on major exhibitions and art events in Australia. Internationally, she has been a consultant to the Tjibaou Cultural Centre in New Caledonia and Kaohsiung Museum of Fine Arts in Taiwan on several occasions. She has published extensively on contemporary Pacific art and regards writing for diverse publications as an indispensable component to making Pacific art accessible to a wide audience. 


\section{Cochrane | ARTventures}

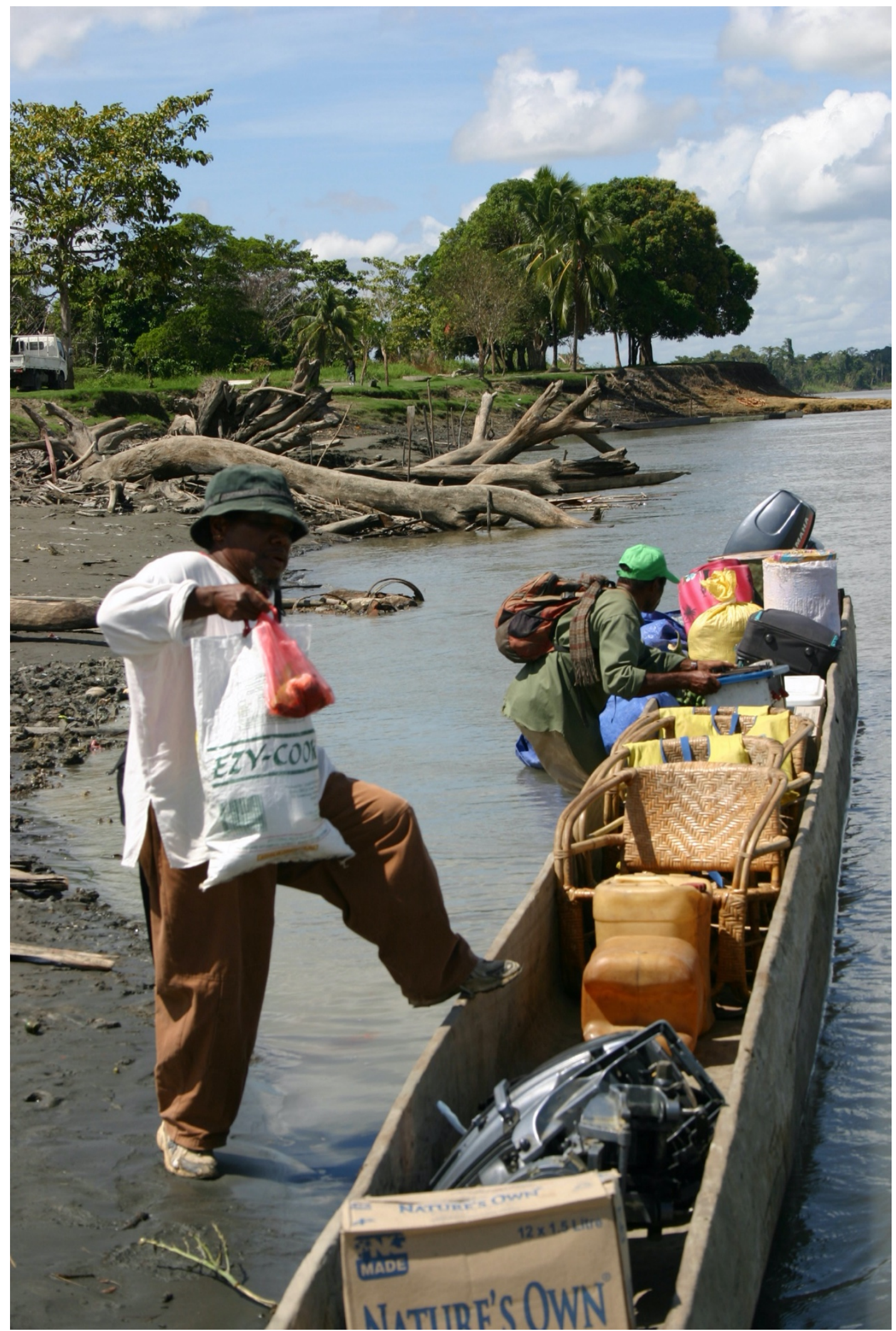

Figure 4. Loading a canoe for the Sepik River Project (interpreter Materina Wai in foreground), Campbelltown Arts Centre, 2010. Courtesy of Susan Cochrane 


\section{ANNOUNCEMENTS}

\section{Pacific Arts - Call for Submissions}

Pacific Arts, the journal of the Pacific Arts Association, has an ONGOING OPEN CALL for submissions on the arts of Oceania and its diasporas focusing on visual arts, material cultures, and heritage arts. The scope is temporally broad, highlighting both historical and current topics while engaging with a wide range of creative mediums, forms, and subject matter.

Pacific Arts encourages interdisciplinary approaches to examining the political, social, economic, cultural, aesthetic, and environmental stakes in the production and study of Indigenous visual and material cultures in Oceania, past and present.

Please send full-length submissions and an abstract to pacificarts@ucsc.edu. Submissions should follow the Pacific Arts style guide. Pacific Arts is a peer reviewed, open access, online journal published by the University of California/eScholarship and encourages broad participation and circulation.

Pacific Arts is also accepting reviews of books, media, and exhibitions that relate to visual and material cultures of Oceania. Authors, artists, museums, and publishers interested in having their work reviewed and anyone interested in writing a review should contact the book reviews editor Joslyn Chu at jxchu@ucsc.edu.

\section{Pacific Arts - Forthcoming Issue}

The forthcoming issue of Pacific Arts is a special issue focused on "Pacific Island Worlds: Oceanic Dis/Positions" (vol. 22, 2022). The collection of essays and creative work explores how past and present visual art forms and practices shape place-making and identities in Oceania. Colonial interactions have produced a range of mobilities, yielding fraught processes of displacement, place-making, establishing new homes, and forming social, cultural, and political positions in the face of various dis-positionings. Articles and creative work lend insight into understanding human experiences in Oceania that generate future imaginings and contribute not only to a "mode of survival," but to "an art of living" across the region. Contributors include: Christina Ayson Plank, Jesi Luhan Bennett, Jewel Block, Kaili Chun, James Clifford, Stacy L. Kamehiro, Yuki Kihara, Claudia Ledderucci, Diana Looser, Katharine Losi Atafu-Mayo, Margo Machida, Carl Pao, Giles Peterson, Meleia Simon-Reynolds, Mārata Tamaira, Katerina Teaiwa, Axelle Toussaint, and Michelle Williams. 


\section{Pacific Arts | Announcements}

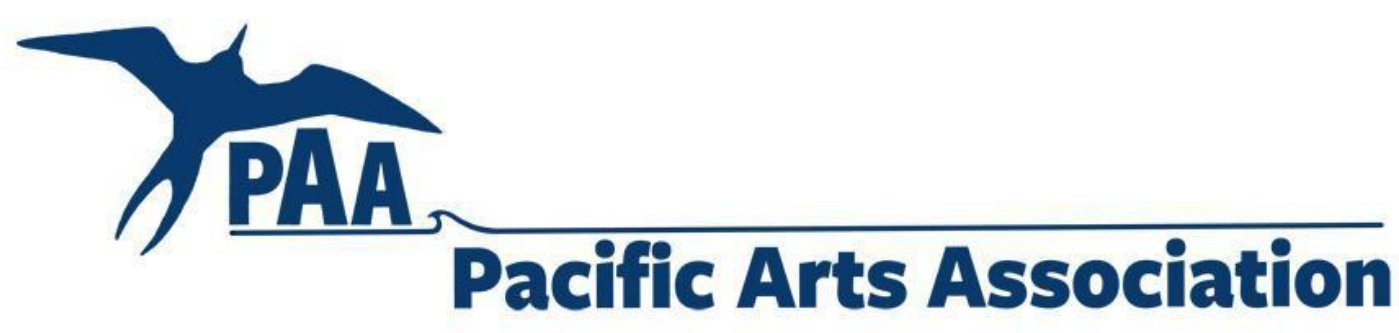

The Pacific Arts Association is an international organization devoted to the study of the arts of Oceania. The Pacific Arts Association (PAA), founded in 1974 and established as an association in 1978, is an international organization devoted to the study of all the arts of Oceania. PAA provides a forum for dialogue and awareness about Pacific art and culture. By connecting individuals and institutions around the world, PAA encourages greater cooperation among those who are involved with the creation, study, and exhibition of Pacific art.

The peer-reviewed Pacific Arts journal features current research and reviews. The PAA Newsletter provides timely information about important events to members. PAA's triennial International Symposium takes place in alternating venues across the globe and includes special tours, performances, exhibitions, and presentations of academic and artistic research on the arts of Oceania. Members have the opportunity to meet and participate in a PAA-sponsored session at the College Art Association annual meeting. PAA-Europe holds a meeting in Europe annually.

PAA's goals are to:

- Make members more aware of the state of all the arts in all parts of Oceania.

- Encourage international understanding among the nations involved in the arts of Oceania.

- Promote high standards of research, interpretation, and reporting on the arts of Oceania.

- Stimulate more interest in the teaching of courses on Oceanic art especially but not only at the tertiary educational level.

- Facilitate greater cooperation among the institutions and individuals who are associated with the arts of Oceania.

- Support high standards of conservation and preservation of the material culture in and of Oceanic arts.

Membership: US\$50 for professional individuals and institutions, US\$35 for visual and performing artists, students, and retired persons. Individuals and institutions wishing to become members of PAA can visit the membership page of the PAA website: www.pacificarts.org/membership. 


\section{Pacific Arts | Announcements}

\section{POSITION ANNOUNCEMENT}

\section{Assistant Professor of Indigenous Media, Cultural Sovereignty, and Decolonization University of California-Santa Cruz}

(initial review date: Dec. 1, 2021)

The Department of Film and Digital Media at the University of California, Santa Cruz (UCSC) invites applications for an Assistant Professor of Indigenous Media, Cultural Sovereignty, and Decolonization (Job \# JPF01147).

We seek to hire a colleague whose creative work and/or scholarship embodies or addresses emerging and/or historical Indigenous/Native media practices. Candidates might be a mediamaker and/or a theorist-practitioner. Mediamakers will be working with audiovisual systems of meaning that are centered in Indigenous/Native communities and expression. Theorist-practitioners might emphasize ethical, social and cultural considerations of Indigenous knowledge, sovereignty and decolonization theories, methods and practices. Ideal candidates will demonstrate a commitment to community involvement and an Indigenous lived experience including working with Native American, First Nations, Inuit, or Métis communities and organizations in Turtle Island; or more broadly the Americas, the Pacific Rim, Borderlands, or Circumpolar Indigenous Nations. We are interested in located knowledges and practices but also collaborative or comparative approaches across geographically diverse areas.

We welcome Indigenous/Native pedagogical and practical approaches to media production and theory as an opportunity to strengthen the breadth of both critical research and production methods and perspectives taught and supported in the department at the undergraduate, graduate and faculty levels. Such a position would be supported by our departmental commitment to an ongoing process of developing structures and practices for centering social justice in teaching and research, and would enrich ongoing collaborations with other programs such as: the new MFA in Environmental Art and Social Practice in the Art Department, the Digital Arts and New Media MFA Program, Critical Race and Ethnic Studies, Feminist Studies, History of Art and Visual Culture, Latin American and Latino Studies, Literature, Sociology, History of Consciousness, the Science and Justice Research Center, the Center for the Middle East and North Africa, Center for Creative Ecologies, Center for Documentary Arts and Research, and/or the Center for South Asian Studies.

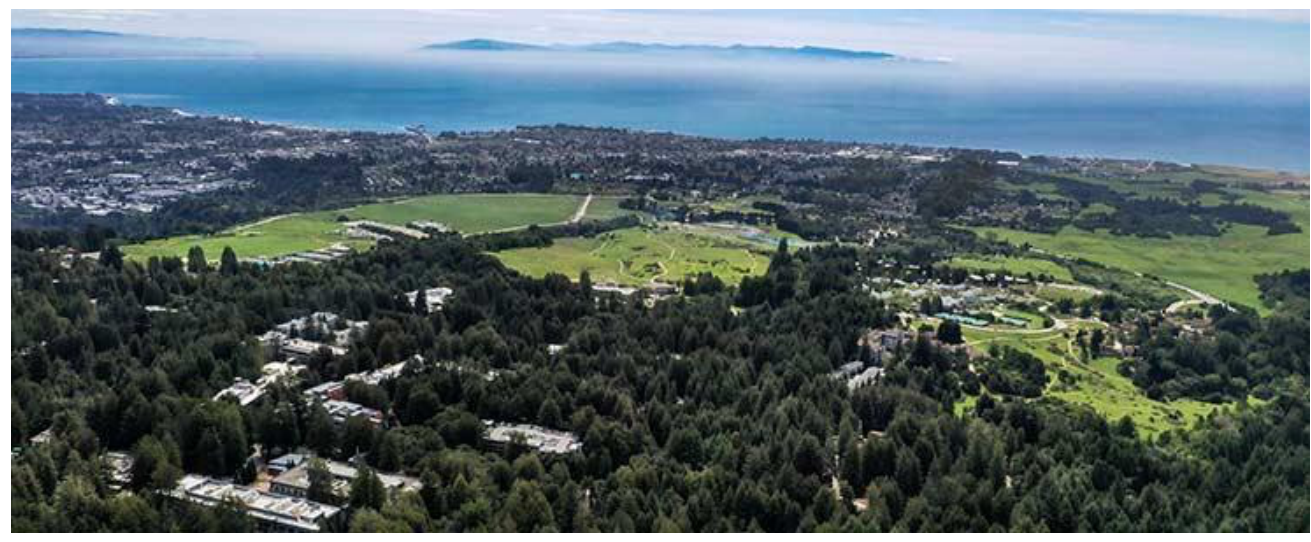

For the complete position overview, description, qualifications, and application requirements, please visit: https://recruit.ucsc.edu/JPF01147 


\section{Pacific Arts | Announcements}

\section{POSITION ANNOUNCEMENT \\ Assistant Professor of Environmental and Social Equity and Justice Mount Holyoke College}

Mount Holyoke College invites applications for a tenure-track position in environmental and social equity and justice to begin Fall 2022. The search is open to candidates working in any discipline or area of environmental and social equity and justice. We are particularly interested in candidates with an emphasis on humanistic perspectives. Areas of specialty are open but could include: environmental art, history, or literature; ecocriticism; ethics; religion and ecology; queer ecologies and ecofeminism; post-colonial environmentalism and indigenous studies; climate or health justice; just sustainabilities or futures; or other areas. The successful candidate will have: a strong interest in cross-disciplinary teaching and research; a demonstrated commitment to promoting diversity, equity, and inclusion and experience mentoring students who are broadly diverse with regard to race, ethnicity, socioeconomic status, gender, nationality, sexual orientation, and religion; and a commitment to undergraduate, liberal-arts education. The hired applicant will be expected to employ interdisciplinary perspectives and approaches in teaching and in an active research program that ideally involves undergraduates. Teaching responsibilities will include participation in teaching introductory and capstone courses as well as development and teaching of intermediate and advanced courses in the field. A Ph.D. is required (we will consider A.B.D. candidates also), and post-doctoral research, teaching, or mentoring experience is helpful. Teaching load is $2 / 2$; salary is competitive.

Although the position will initially be housed in the Department of Environmental Studies, it will soon be in a new Department of Earth, Environment, and Sustainability (EES), and is supported in part by generous funding from The Andrew W. Mellon Foundation. The EES curriculum will offer students a foundation for understanding Earth's natural systems and their interactions with political, economic, social, cultural, and historical factors from global to local scales. The new EES Department will result from a planned merger of the Department of Environmental Studies with the Department of Geology and Geography. The successful candidate will participate in building this new interdisciplinary major and curriculum.

Please submit a letter of application, a C.V., and statements covering (1) research interests, (2) teaching philosophy, (3) the mentoring of a diverse student body. The successful candidate should be able to demonstrate excellence in teaching and mentoring students who are broadly diverse with regard to gender, race, ethnicity, nationality, sexual orientation, and religion. Review of applications will begin on Friday October 1, 2021 and continue until the position is filled.

For the full position description: https://careers.pageuppeople.com/1024/cw/enus/job/492743/assistant-professor-of-social-and-environmental-equity-and-justice

Inquiries: Tim Farnham, Chair, Dept. Of Environmental Studies, tfarnham@mtholyoke.edu 
Pacific Arts | Announcements

POSITION ANNOUNCEMENT

\section{UNIVERSITY OF HAWAI'I AT MĀNOA}

\section{Center for Pacific Islands Studies}

The UH Mānoa Center for Pacific Islands Studies is currently accepting applications for a Junior- or Assistant-level Outreach Director. This is a full-time, non-tenure track position supported by UH and federal grant funds.

The selected candidate will lead our outreach activities including organizing Pacific Islands-related seminars, faculty workshops, and conferences, as well as oversee our social media initiatives and our partnerships with local communities, across the US, and within the Pacific Islands region.

The full description and qualifications of the Outreach Director position can be seen here: https://www.governmentjobs.com/careers/hawaiiedu/jobs/3265362/outreach-program-director.

Application deadline is 11/2/20211:59 PM HST.

To Apply: Go to the NeoGov page above and click on "Apply" at the top right corner of the screen and attach the required documents. Applicant must submit (1) cover letter indicating how you satisfy the minimum and desirable qualifications, (2) curriculum vitae, (3) names and contact information of three (3) professional references, and (4) copies of transcripts. Copies of transcripts are acceptable, but official transcripts will be required at the time of hire.

Note: If you have not applied for a position using NEOGOV, you will need to create an account.

Inquiries: Professor Alexander Mawyer, Director, Center for Pacific Islands Studies; mawyer@hawaii.edu 


\title{
Pacific Arts | Announcements
}

\section{CALL FOR PARTICIPATION}

\author{
Island of Shattered Dreams, 15 Years On: \\ Reframing Francophone Oceanian Studies \\ https://www.fabula.org/actualites/appel-a-contribution-acla--pour-la-session-suivante-island 104113.php
}

Call for papers for next ACLA [American Comparative Literature Association] Annual Meeting, to take place online and at the National Taiwan Normal University June 15-18, 2022.

2022 marks the 15th anniversary of the publication of Jean Anderson's English translation of Chantal Spitz's "L'île des rêves écrasés," a turning point in the reception and production of contemporary Oceanian literary production in French. While Francophone Oceanian studies have been gaining traction over recent years, the Oceanic region remains a severely under-studied part of the Francophone world, despite its booming literary, artistic, and cultural productions.

This seminar seeks to reposition Oceanian studies within the global Francophone studies academic discourse by establishing an état présent of research into the literary, artistic and cultural productions in French in the region. Selected papers from this seminar will be included in a book proposal submission to Liverpool University Press's 'Francophone Postcolonial Studies' series to be submitted in February 2022. By publishing this volume with Liverpool University Press, one of the only Anglophone academic publisher to have previously published a monograph on Francophone Oceanian literature (Ramsay 2014), we aim to give increased visibility to recent and contemporary literature, visual arts, film, and performing arts from Oceania while creating island-to-island bridges. We seek to interrogate Oceanian studies' relative exclusion from the postcolonial Francophone discourse, and a lack of focus on Francophone writers and artists in Anglophone Pacific studies.

In this perspective, we seek contributions from established and early-career scholars, as well as graduate students, dealing with Francophone literature, including poetry, in the Francophone South Pacific context (Tahiti, New Caledonia, Vanuatu, or the Francophone diaspora in Australia and New Zealand or Hawai'i). We are also particularly interested in contributions engaging with visual arts, film, theatre and performance in French-speaking Oceania. Contributions that explore cross-artistic dialogues, island-to-island cultural exchanges or examine the place of Oceanian studies in Francophone studies are also welcome. The preferred language of proposals is English, since that will be the language of our volume, but proposals in French may also be considered.

Possible topics include:

- local/regional and global reception and exhibition of contemporary Francophone artists based in Oceania

- Case-study on specific writer, filmmaker, artist/artwork/exhibition, film and cultural festivals or comparative analyses across time, region, language, artistic expression

- How today's writers, directors and artists navigate between traditional knowledge and contemporary concerns (climate, political and social issues)

- Position of Francophone Oceanian artists within contemporary Pacific art

- Reappropriation of colonial gaze on Oceania by contemporary Oceania-based writers, filmmakers, artists

To submit a proposal for this seminar before October 31st, please follow the instructions on ACLA's website: https://www.acla.org/node/add/paper

For any questions, please contact the organizers:

Nathalie Segeral: nathalie.segeral@sydney.edu.au

Léa Vuong: lea.vuong@sydney.edu.au 


\section{Pacific Arts | Announcements}

SPEAKER SERIES

(details on following page)

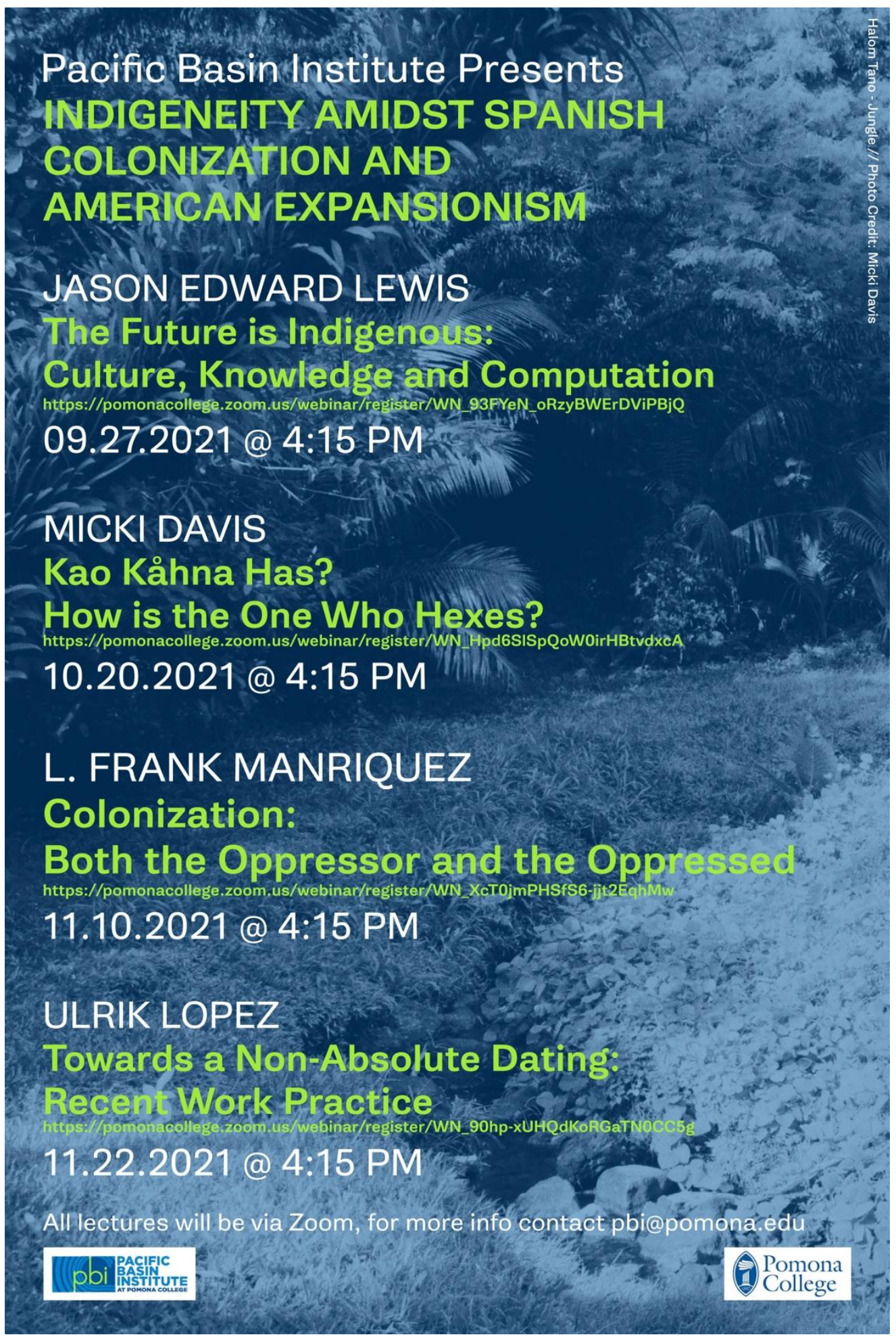

Note: Dates and times are in Pacific Time (California). 


\section{Pacific Arts | Announcements}

\section{Pacific Basin Institute Fall 2021 Lecture Series Indigeneity amidst Spanish Colonization and American Expansionism}

For the Fall 2021, Pacific Basin Institute speakers series will consider the relationship between Spanish colonization and American expansionism in the late 19th century across the Pacific as well as the Atlantic. Through considering the different practices of these writers and artists, we navigate the histories of islands such as Guahan (Guam), Samoa, and Puerto Rico, while also interrogating the Spanish influence on the continent in places such as California and Mexico. We invite you to join us in our centering of indigenous perspectives in this series and explore this different discourse of the Pacific.

Jason Edward Lewis is a digital media theorist, poet, and software designer who is deeply committed to developing intriguing new forms of expression by working on conceptual, critical, creative, and technical levels simultaneously. He is the University Research Chair in Computational Media and the Indigenous Future Imaginary and Professor of Computation Arts at Concordia University. In addition to being lead author on the award-winning "Making Kin with the Machines" essay and editor of the groundbreaking Indigenous Protocol and Artificial Intelligence Position Paper, he has contributed to chapters in collected editions covering Indigenous futures, mobile media, video game design, machinima, and experimental pedagogy with Indigenous communities. Born and raised in northern California, Lewis is Hawaiian and Sāmoan.

Mariquita "Micki" Davis is a CHamoru artist and educator based in Los Angeles. She completed her MFA at the University of California San Diego in 2011. Her work explores notions of artistic collaboration in the contexts of personal, familial, and communal memory. She is a participating artist for the MALI'E performance research project, a 13-moon series of creative development workshops that unites a cohort of culturally rooted Matao/CHamoru artists in the homeland and in the diaspora to produce a traveling exhibit between Guåhan, Los Angeles and Seattle. She is the co-curator of Pasifika Transmissions, a monthly learning series that invites indigenous artists to visit the archive of the Pacific Island Ethnic Art Museum of Long Beach and develop a video "transmission" of this exchange. She is currently a programmer for the Los Angeles Asian Pacific Film Festival and mentor for Armed with a Camera Fellowship program at Visual Communications. Her work has been exhibited nationally and internationally, including at the Honolulu Biennial, Vancouver Art Gallery, and UNSW Galleries, Museum of Contemporary Native Arts, as well as Yamagata International Documentary Film Festival (YIDFF) and Guam International Film Festival.

L. Frank Manriquez (Tongva/Ajachmem), an award-winning Native California Indian artist working in many media and a tribal scholar, community activist, and language advocate, has exhibited her artwork in museums and galleries nationally and internationally. She has served or serves on a number of boards, including that of the California Indian Basketweavers Association (for 15 years) and the Cultural Conservancy, and is a founding board member of the Advocates for Indigenous California Languages.

Ulrik Lopez was born in Mexico City (1989) and lives and works between Mexico City and San Juan, Puerto Rico. He acquired a BFA in Sculpture with a minor degree in Industrial Design in 2013 from the Escuela de Artes Plásticas de Puerto Rico. He participated in the independent program, La Práctica in Beta-Local, Puerto Rico, from 2013 to 2014. He has participated in residencies such as Artist Village, Warp- Contemporary Art Platform (Genk, Belgium), ClockTower+Mana (Miami, USA), and Flora ars+natura (Bogota, Colombia), and will be part of Delfina Foundation's Collecting as Practice residency in Fall 2021. López has exhibited in several galleries, museums, and alternative spaces in Puerto Rico, Mexico, Spain, Colombia, United Kingdom and USA. His recent shows include Enterrar la Montaña at El Lobi, Puerto Rico; Siembra at Kurimanzutto, Mexico City; and Never Spoken Again at the Jepson Center, USA. He is currently in the MFA program at Bard College. 
Pacific Arts | Announcements

NEW PUBLICATION

\section{TATTOOED HISTORY: THE STORY OF MOKOMOKAI by Robert K. Paterson}

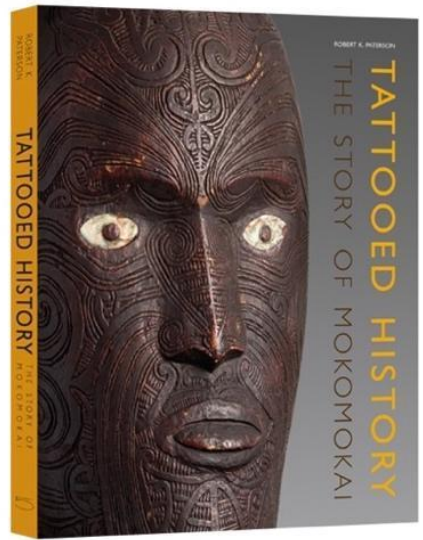

This book is the first comprehensive historical account of the unique Māori ancestors-mokomokai or toi moko. It explores the earliest written accounts to explain how outsiders first understood the practices surrounding their preparation and use, sometimes in connection with peacemaking between iwi. The intense trafficking between Māori and visitors to New Zealand is then explored, along with how mokomokai were first displayed for profit in England by unscrupulous entrepreneurs.

After extensive British settlement in New Zealand began after 1840 heads were rarely preserved and within a short time there were very few left in the country itself. Mokomokai were sold at auction in England and elsewhere and entered into the collections of physicians and scientists, along with collectors of artifacts from remote parts of the world. This book examines early attempts by Mãori to secure the return of heads and how court proceedings were sometimes resorted to as part of these initiatives. Early efforts were also made by non-Māori, such as Major General Robley and Kenneth Webster, but these rarely succeeded.

Comprehensive repatriation efforts by New Zealand have now succeeded in securing the return of large numbers of mokomokai which are housed at the Museum of New Zealand Te Papa Tongawera in Wellington. This book seeks to explore the broad historical context from which this process emerged and the characters who featured in it.

Robert K. Paterson is a professor emeritus of law at the University of British Columbia in Vancouver, Canada. He obtained his law degree in New Zealand and then completed a JSM at Stanford Law School in California. He has written extensively in the area of cultural property and art law, including co-authoring Cultural Law: International, Comparative, and Indigenous (Cambridge, 2010). He was rapporteur of the Cultural Heritage Law Committee of the International Law Association. He is also a member of the editorial board of the International Journal of Cultural Property and the director's advisory council of the University of British Columbia Museum of Anthropology.

Milan: 5 Continents Editions, July 2021

https://www.fivecontinentseditions.com/en/p/tattooed-history/ 


\section{Pacific Arts | Announcements}

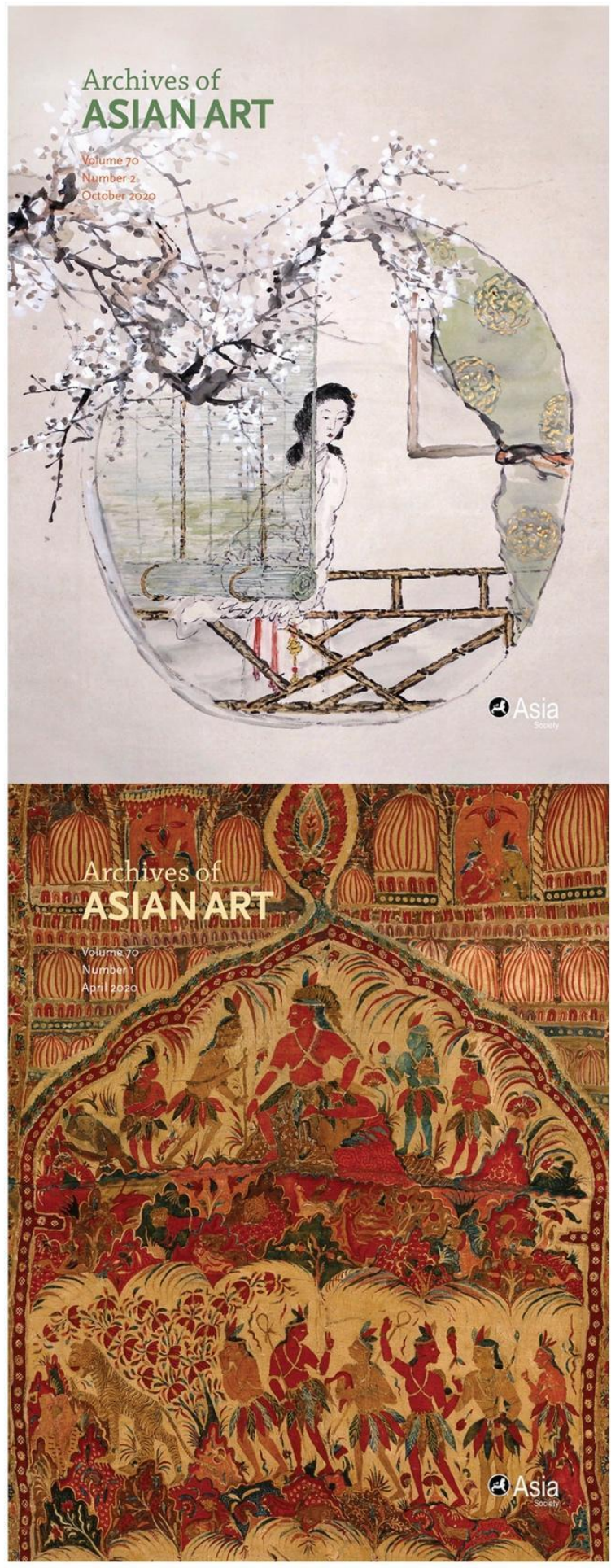

\section{Archives of ASIAN ART}

Patricia Berger, editor

Since its establishment in 1945, Archives of Asian Art has been devoted to publishing new scholarship on the art and architecture of South, Southeast, Central, and East Asia. Articles discuss premodern and contemporary visual arts, archaeology, architecture, and the history of collecting. Every issue is fully illustrated (with color plates in the online version), and each fall issue includes an illustrated compendium of recent acquisitions of Asian art by leading museums and collections.

Archives of Asian Art is a publication of Asia Society.

Sign up for new issue alerts at dukeu.press/alerts.

Subscribe today.

Two issues annually

$\$ 60$ Print and digital

\$35 Student print and digital

dukeupress.edu/archives-of-asian-art

Asia

D U K E 


\section{Pacific Arts | Announcements}
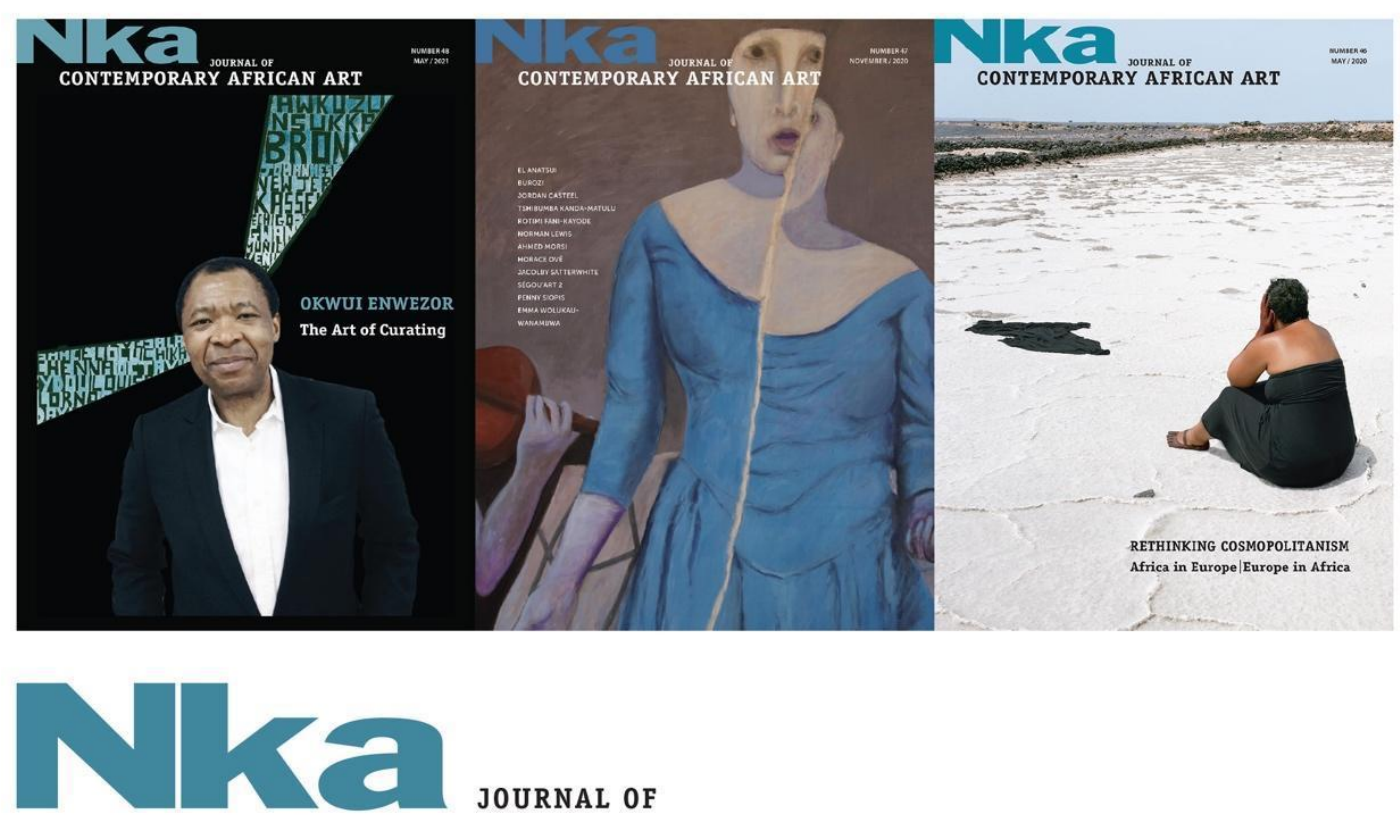

\section{CONTEMPORARY AFRICAN ART}

Salah M. Hassan and

Chika Okeke-Agulu, editors $k a$ contributes to the intellectual dialogue on world art by publishing critical work in the developing field of contemporary African and African Diaspora art. The journal features scholarly articles, reviews of exhibitions, book and film reviews, and roundtables.

SUBSCRIBE TODAY. Two issues annually

Individuals: $\$ 50$ Students: $\$ 35$ Single issues: $\$ 27$

dukeupress.edu/nka

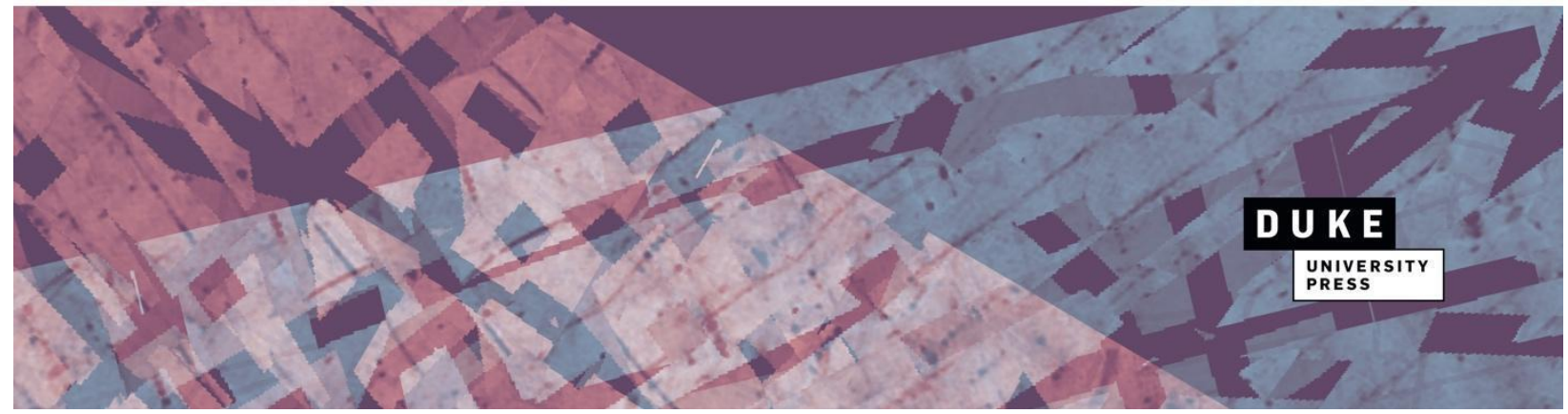




\section{British Museum Research Publication 235}

\section{Objects as Insights: \\ R.H. Codrington's Ethnographic Collections from Melanesia by Nick Stanley}

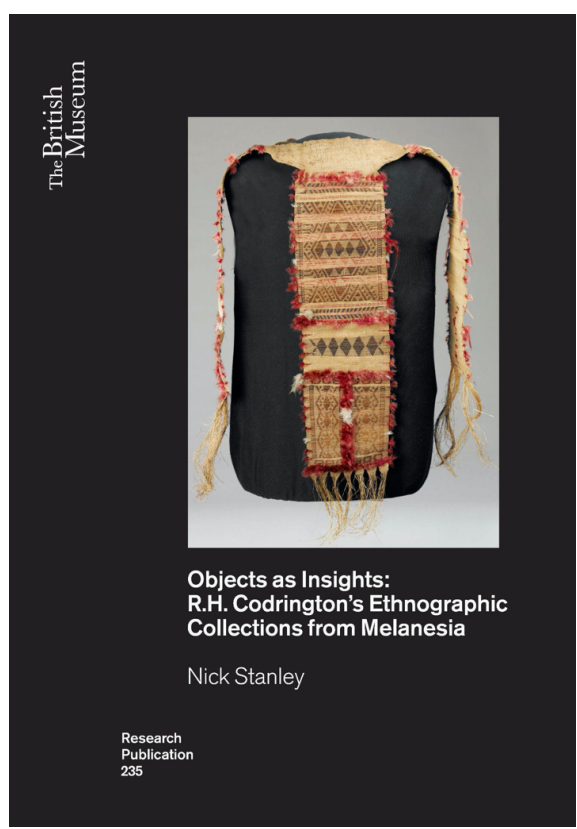

R.H. Codrington (1830-1922) graduated from Oxford University in 1856 and was ordained in 1857. He volunteered to work in Nelson, New Zealand, from 1860-1864 and was appointed as headmaster of the Melanesian Mission training school on Norfolk Island in 1867. He spent the next twenty years in this post and for eight of these years he was the head of the Mission travelling through the Melanesian region. Throughout his time in the region, he attempted to gain an ethnographic understanding of the people whom he was serving. To this end he studied local languages and translated scriptures into Mota, the lingua franca of the Mission. However, for Codrington material artefacts were fundamental to his understanding of Melanesian life. He therefore took a lively interest in material culture as a collector and donated objects to a number of museums, including the British Museum and the Pitt Rivers Museum. His specialist knowledge made him a valued informant for scholars of Melanesia who regularly consulted him. He is regarded today as one of the founding scholars of Pacific anthropology.

This book intends to provide a more comprehensive understanding of how Codrington formed his collection, through the study of his written anthropological works, correspondence with other collectors and scholars and particularly through the private correspondence with his brother and his five journals written between 1867 and 1882. The book also highlights his equally important contribution to the development of material culture studies in the region and how his work has influenced Melanesian studies to the present day.

Nick Stanley is an Honorary Research Fellow with the Department of Africa, Oceania and the Americas at the British Museum. He was previously Director of Research and Chair of Postgraduate Studies at Birmingham Institute of Art and Design, Birmingham City University. He is a specialist in Asmat art of West Papua, New Guinea.

Released August 2021, British Museum

https://www.britishmuseumshoponline.org/objects-as-insights.html 


\section{British Museum Press Publication \\ Ancestors, artefacts, empire: \\ Indigenous Australia in British and Irish museums \\ Edited by Gaye Sculthorpe, Maria Nugent and Howard Morphy}

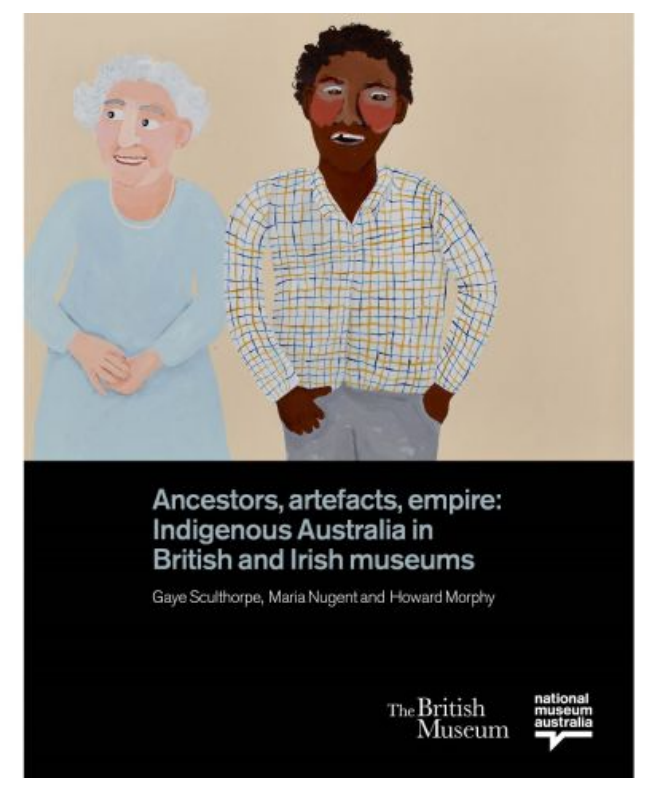

New British Museum Press publication Ancestors, artefacts, empire: Indigenous Australia in British and Irish museums, brings together an important collection of extraordinary Indigenous Australian art and artefacts preserved in museums across Great Britain and Ireland. This landmark publication presents a global history that entwines ancestral pasts with epochs of empire and colony leading to the contemporary moment.

Paired alongside authoritative, eloquent and accessible text written by twenty-two Indigenous, Australian and international experts, the reader is invited to explore nearly 160 artefacts, selected from over 30 public museums, both large metropolitan and small regional, to present a multistranded narrative that opens up vistas on Britain's Australian history as much as Australia's British history.

Released Sept. 2021, British Museum

Copies can be purchased via the British Museum online shop: https://www.britishmuseumshoponline.org/ancestors-artefacts-empire-indigenous-australia-in-british-and-irish-muse$\underline{\text { ums.html }}$ 


\section{Pacific Arts | Announcements}

\section{ARCHIVE OPENING}

\section{SUSAN COCHRANE PACIFIC ARCHIVE}

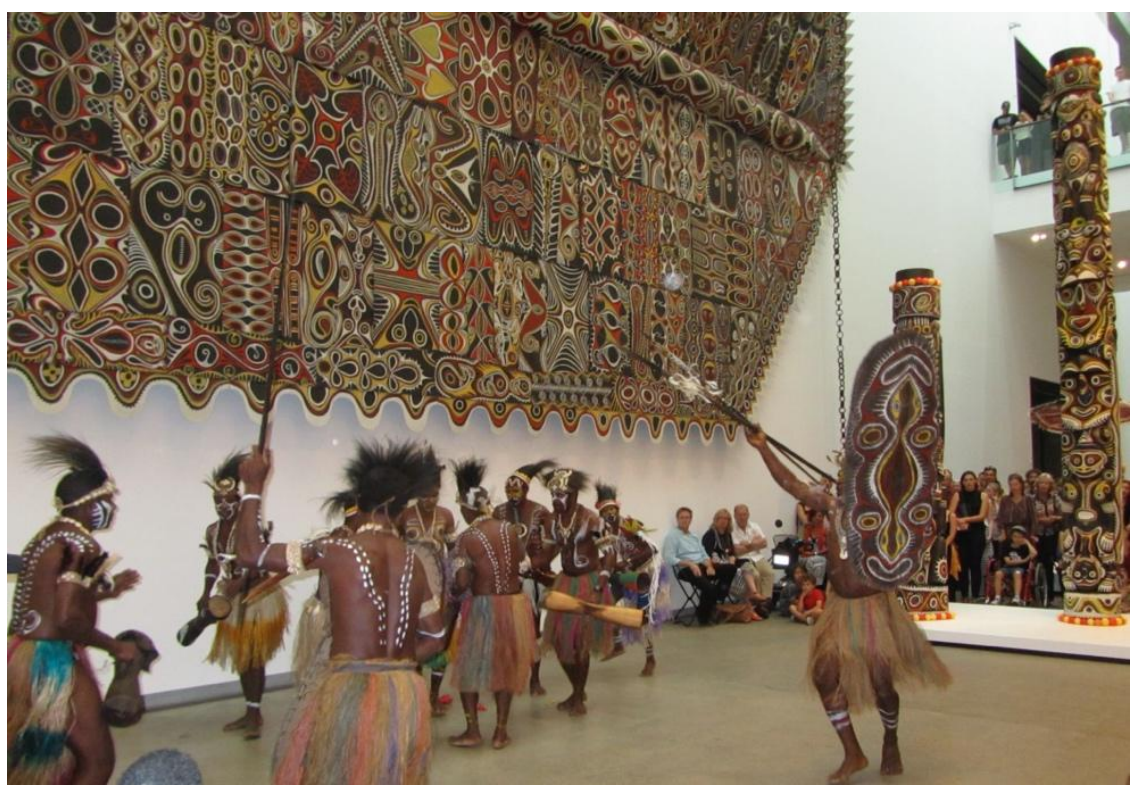

The E H McCormick Research Library at Auckland Art Gallery Toi o Tāmaki is pleased to announce that the Susan Cochrane Pacific Archive is now available for researchers.

Dr Cochrane is an Australian/French researcher, curator, and author whose research interest is contemporary Pacific art. She was head of the Department of Kanak and Pacific Contemporary Art at the Tjibaou Cultural Centre, New Caledonia (1995-1998), a consultant to the Asia Pacific Triennial (Australia, 1996 and 1999) and for the Austronesian Contemporary Art project at the Kaohsiung Museum of Fine Arts (Taiwan, 2007-9). Her publications include Contemporary Art from Papua New Guinea (1997); Bérétara: New Pacific Art (2001); and Art and Life in Melanesia (2001).

In 2019, Dr Cochrane donated her personal papers to the Research Library, choosing Auckland Art Gallery as her preferred repository on the recommendation of Anna-Marie White, Te Âtiawa (curator and, at that time, a doctoral candidate in art history at Victoria University). In the papers there are documents (including field notes and artist correspondence), interviews with artists, exhibition catalogues (including some rare examples), manuscripts, academic papers, essays and journal articles, photograph prints, diaries, field notebooks, audio-visual resources, and field recordings.

The subject of the Archive is contemporary Pacific art. It includes archival documents pertaining to Papua New Guinea (PNG) artist Mathias Kauage (1944-2003) and many other leading PNG artists, projects at or about the Solomon Islands Pacific Festival of the Arts, the Stevenson Collection, the Tjibaou Cultural Centre, the Kaohsiung Museum of Fine Arts, the Singapore Art Prize, the Melanesian Arts and Culture Festival, and art centres in remote Aboriginal communities.

Details of the Susan Cochrane Pacific Archive can be found here: https://www.aucklandartgallery.com/explore-artand-ideas/archives/31385

Contact the E H McCormick Research Library for more information: library@aucklandartgallery.com

Explore art by artists of Pacific and Melanesian heritage in the collection of Auckland Art Gallery Toi o Tāmaki: https://www.aucklandartgallery.com/art-ideas/explore-art-and-ideas

Photograph credit: Susan Cochrane, Kwoma Performance at the $7^{\text {th }}$ Asia Pacific Triennial of Contemporary Art, 2013. Susan Cochrane Pacific Archive, E H McCormick Research Library, Auckland Art Gallery Toi o Tāmaki, gift of Susan Cochrane, 2019. 


\title{
Pacific Arts | Announcements
}

\author{
CALL FOR PARTICIPATION \\ Berkshire Conference of Women, Genders and Sexualities, 2023 \\ Celebrating the 50th Anniversary of the Big Berks! \\ 28 June-2 July 2023, Santa Clara University, California \\ https://berksconference.org/big-berks/2023-berkshire-conference-cfp/
}

\section{Oceans, Islands, and Continents: \\ Reconceptualizing the Spatialization of Women's, Gender, and Sexuality Histories}

What does it mean to gather on the Ohlone peoples' ancestral homeland, situated next to the San Francisco Bay, a gateway to the Pacific Ocean and Pacific Islands? What does it mean to convene, craft, share, and celebrate feminist histories in the ongoing contexts of climate change-fueled hurricanes and storm surges, sea level rise and coastal flooding, fires, and marine life extinction? What does it mean to celebrate fifty years of promoting and exploring histories of women, genders, and sexualities when immigrants, refugees, Indigenous and Black people, queer and trans communities are marginalized and subject to violence; political and individual freedoms are eroded; and growing autocratic and totalitarian regimes embolden racial nationalism?

We invite you - national and international scholars of all persuasions, and especially graduate students and early career colleagues - to collaborate with us in framing histories within broadly expansive configurations across time, space, and place. We seek to develop conversations across our interconnected yet disparate social, political, economic, and cultural worlds and to consider the transitions, transformations, and spatializations that keep them in constant flux. We solicit panels, papers, and workshops that help us consider what histories emerge when relations are formed and linkages are drawn that transcend traditional national borders and reference instead, for example, oceans, islands, or continents? What innovative or timeless feminist methodologies help us conceptualize and engage in conversations at new depths, attentive to the vastness of the oceans, lands, and islands we traverse and inhabit, as well as the importance of the care we give to a loved one, a garden, or a forest? What are the affective geographies and histories of spaces of refuge, resistance, and renewal? What are the gendered histories of water, rain, and rivers that move us into new understandings of the relationships among plants, animals, and humans? What are the specific histories of organizing against nuclear testing, deep sea drilling, rainforest destruction, political prisoners, femicide, human and sex trafficking, forced labor, state-based, anti-gay, lesbian, and trans legislation, and religious persecution that center women's leadership as activists as well as mothers, daughters, sisters, partners, and friends? How do we illuminate the depths of connective organizing across Asia, North and South America, the Pacific and Caribbean Islands, Africa, Europe, and the Middle East? What are the ways these efforts transcend temporal and spatial boundaries?

As the Big Berks contemplates its fiftieth year of triennial conferences and plans for the future, we invite you to explore these questions through gendered analyses in addition to more spatially and temporally focused approaches.

We encourage submissions to engage activism and resistance, the local, global, and transnational, the biopolitical and necropolitical, as well as geographies that transcend the continental and the human. We also welcome submissions that explore interdisciplinary methodological, pedagogical, and digital humanities approaches that engage up to three of the themes listed below. Please begin by selecting the format of your proposal. You can choose to submit a single paper, traditional panel, roundtables, interactive workshop, lightning session, curriculum discussion/workshop, or other formats. Once you begin your submission you will be required to select 1-3 of the following themes in order of relevance.

$$
\text { (continued, next page) }
$$




\section{Pacific Arts | Announcements}

CONFERENGE SUBTHEMES:

Activism, Resistance, and Feminisms

Affective Geographies of the Sacred, Religious, and the Secular

Bodies, Health, and (Dis)ability

Childhood, Family, and Reproduction

Decolonizing the Environment and the Post-Human

Disaster Capitalism, Social Death, and Femicide

Economies, Work, and Labor

Imperialism, Militarism, and Pacifism

Indigeneity, Colonialism, and Revitalization

Migrations, Diasporas, Refugees, and Borderlands

Queering and Querying Intimacies, Desire, and the Erotic

Racial Justice, Abolition, and Decolonization

The 2023 Berkshires conference will have a small theater setting for the ongoing screening of films submitted for viewing at the conference. To submit a film to be included as part of the screening, we offer a separate form on the submission site to provide required information for the film along with information for the format required to be included in the screening. Note that this venue does not allow for post-screening discussion nor responses and is distinct from submitting a panel or roundtable about a film.

Submissions for the 2023 conference opened on 1 September and end on 31 December 2021.

\section{Submit your proposal here: \\ https://berks.confex.com/berks/berks23/cfp.cgi}

For more information, please contact Sandra Trudgen Dawson, execadmin@berksconference.org

The Berks is committed to encouraging new scholarship, especially by graduate students. If your session includes at least three presentations by graduate students and you would like your session flagged, please check "emergent scholars" on your session submission.

The Program Committee actively promotes the full and equitable inclusion of racial and ethnic minorities, religious minorities, differently-abled people, and LGBTQ+ people. To that end, the Program Committee encourages session proposals that include diverse participants as well as participants in various career paths and of various ranks (i.e., senior and junior scholars, public historians, graduate students, independent historians, and historically-grounded scholars in any discipline).

The Program Committee encourages the submission of complete sessions. When this is not possible, the program committee will accept single papers that will then be added to the program where appropriate.

We are planning for an in-person meeting. We also are monitoring the public health situation and will make adjustments accordingly. 